\title{
A DETERMINAÇÃO DE SULFATO EM ÁGUAS NATURAIS E DIGERIDOS DE VEGETAIS POR TURBIDIMETRIA EMPREGANDO SISTEMA DL 'NJEÇĀO EM FLUXO
}

FRANCISCO JOSÉ KRUG

Orientador: Prof. Dr. HENRIQUE BERGAMIN FILHO

Tese apresentada à Escola Superior de Agricultura "Luiz de Queiroz", da Universidade de São Paulo, para obtenção do título de Doutor em Agronomia. AREA DE CONCENTRAÇÃO: Solos $e$ Nutrição de Plantas.

PIRACICABA

Estado de São Paulo - Brasil

Setembro, 1984 
$\cdot i$.

Aos meus pais, irmãos,

esposa e filhos, com muito amor

OFEREÇO

Aos amigos e irmãos da Seção de

Radioquímica e Ruímica Analitica do CENA

DEDICO 
Ao Centro de Energia Nuclear na Agricultura, ao Conselho Nacional de Desenvolvimento Cientifico e Tecnolögico, à Financiadora de Estudos e Projetos, à Comissão Nacional de Energia Nuclear e à Agência Internacional de Energia Atômica.

A todos vocês meus amigos:

Este não foi um trabalho comum, porque a ajuda que recebi de vo cês, em momento algum foi comum.

Em dado instante, uma solução de muitos amigos, bluindo com alta intensidade de boas idéias, e com muito amor, substituia meus momentos de turbidez, por momentos de maior estabilidade.

Consequentemente, um sistema de amor pôde ser construído, cujo valor espiritual tem um signifi cado muito especial para mim.

Obrigado, Deus Pai, por todos estes amigos $e$ por mais este momento de felicidade. 
.ii.

I $N$ D $D$ I

Pägina

RESUMO

viii

SUMMARY

1. INTRODUÇAO . . . . . . . . . . . . . . . . . 1

2. Revisáo Bibliografica. . . . . . . . . . . . . . . 4

2.l. Análises por injeção em fluxo . . . . . . . . 44

2.1.1. 0 conceito FIA. . . . . . . . . . 4

2.1.2. Constituição dos sistemas FIA. . . 7

2.1.3. Principais sistemas FIA. . . . . . 10

2.2. Métodos automatizados para a determinação de sulfato. . . . . . . . . . . . 15

3. MAterial. . . . . . . . . . . . . . . . . . . . . 22

3.1. Instrumentação. . . . . . . . . . . . 22

3.2. Reagentes e soluções. . . . . . . . . . 23

3.3. Amostras.............. . . . 24

3.3.1. Material vegetal....... . . 24

3.3.2. Aguas............ 26

4. MÉTODO. . . . . . . . . . . . . . . . . . . . . . 27

4.1. Considerações sobre a metodologia . . . . 27

4.2. Fundamentos para o projeto do sistema. . . 29

4.2.1. Escolha da configuração. . . . . . 29

4.2.2. Determinação das vazões, do volume de amostra injetado e das dimensões do reator tubular. . . . . . . . 30

4.3. Protótipo do sistema. . . . . . . . . 39 
Pägina

4.4. Estudo das principais variàveis. ......

4.4.1. Efeito da acidez e de diferentes áci dos. . . . . . . . . . .

4.4.2. Efeito da concentração de bário...

4.4.3. Efeito do teor de sulfato......

4.4.4. Efeito da adição de sulfato. . . .

4.4.5. Efeito da temperatura. . . . . . : 44

4.5. Análises de rotina utilizando o protótipo..

4.6. O sistema proposto. . . . . . . . . 46 46

4.6.1. Considerações preliminares . . . .

4.6.2. Operação do sistema com fluxos alter nativos. . . . . . . . . . . 46

4.6.3. Efeito do fluxo intermitente de EOTA

4.6.4. Efeito da acidez das amostras...

4.6.5. Efeito de íons interferentes. . .

4.6.6. Análises de águas e de digeridos de vegetais. . . . . . . . . . .

5. Resultados e discussao . . . . . . . . . . .

5.1. Dimensionamento do protótipo. . . . . . . 54

5.2. Efeito da acidez e de diferentes ácidos. .

5.3. Efeito das concentrações de íons bário e sulfato. . . . . . . . . . . .

5.4. Efeito da adição de sulfato. . . . . . 67 67

5.5. 0 sistema proposto. . . . . . . . . . 72

5.5.1. Lavagem do sistema... . . . . . 73

5.5.2. Efeito da acidez das amostras. . . 74

5.5.3. Características analiticas . . . . 77

6. COnclusoles. . . . . . . . . . . . . . . . 83

7. BIBLIOGRAFIA . . . . . . . . . . . . . 85 
.$v$.

\section{LISTA DAS TABELAS}

Tabela

Pägina

1 - Efeito da acidez de digeridos de vegetais.. 76

2 - Interferências químicas na determinação de sulfato. . . . . . . . . . . . .

3 - Comparação de procedimentos para a determinação de sulfato em digeridos de vegetais e àguas naturais. . . . . . . . . . 
.vi.

\section{LISTA DAS FIGURAS}

Figura

Păgina

1 - Diagrama de blocos de um sistema de injeção em fluxo. . . . . . . . . . . .

2 - Diagramas de fluxo dos principais sistemas FIA. . . . . . . , . . . . .

3 - Diagrama de um sistema FIA em confluência com o injetor I na posição de amostra gem (a) e sua respectiva imagem simplificada (b). . . . . . . . . . . .

4 - Sistema de fluxos alternativos amostra/car regador da amostra. , . . . . . .

5 - Curvas registradas para uma solução padrão em regime de volume infinito (a) e vo lume $V^{1} / 2$ (b). . . . . . . . . .

6 - Avaliação de reações empregando sistemas FIA. . . . . . . . . . . . . . .

7 - Diagrama de fluxos do protótipo . . . .

8 - Diagrama de sistemas de injeção em fluxo com zonas coalescentes em confluência (a) e zonas sequenciais (b). . . . , . .

9 - Sistema FIA com fluxos alternativos proposto para determinação de sulfato em águas e digeridos de vegetais. . . . . . 
10 - Efeito do ácido perclórico. . . . . 56

11 - Efeito do ácido clorídrico. . . . . 57

12 - Efeito do ácido nítrico......... 58

13 - Efeito da concentração de bário em meio de ácidos clorídrico e nítrico 0,01 M. . 62

14 - Efeito da concentração de bário em meio de ácidos clorídrico e nítrico $0.25 \mathrm{M}$. .

15 - Efeito da concentração de sulfato e bário na cinética de nucleação. . . . . .

16 - Efeito da adição de sulfato nas curvas de padronização. . . . . . . . . . . .

17 - Efeito da adição de sulfato na estabilida de da linha básica e no limite de detecção.

18 - Análise de rotina de digeridos de vegetais empregando o protótipo da Figura 7 .

19 - Efeito da intensidade de fluxo da solução de EDTA alcalino. . . . . . . . .

20 - Análise de rotina de amostras de äguas utilizando-se o sistema de injeção em fluxo proposto (Figura 9). . . . . . . . 
viii.

\section{A DETERMINAÇAOO DE SULFATO EM AGUAS NATURAIS E DIGERIDOS DE VEGETAIS POR TURBIDIMETRIA EMPREGANDO SISTEMA DE INJEÇAOO EM FLUXO}

\section{Francisco Josē Krug}

Prof. Dr. Henrique Bergamin Filho

- Orientador -

\section{RESUMO}

Um sistema de injeção em fluxo com alternāncia de reagentes foi projetado para a determinação turbidimétrica de sulfato em águas naturais e em digeridos de vegetais. As concentrações dos reagentes foram definidas após um estudo detalhado enfatisando aspectos de cinética de nu cleação.

A amostra é injetada em um fluido carregador não segmentado e quimicamente inerte, originando uma zona de amostra bem definida e reprodutivel. Posteriormente,uma solução de bário-álcool polivinílico é adicionada. A suspensão de sulfato de bário formada em meio ácido é quantitativamente avaliada quando a zona de amostra processada atraves sa a célula de fluxo de um espectrofotómetro. o sinal tran siente medido,proporcional ao teor de sulfato na amostra, é registrado.

A faixa de concentrações do método pode ser estendida para menores valores se sulfato for adicionado continuamente ao fluido carregador da amostra. Após a medida, o percurso analítico é lavado, empregando-se uma solução alcalina de EDTA bombeada sob alta vazão. Durante o p $\underline{\underline{e}}$ 
ríodo de limpeza, a solução de cloreto de bário-álcool polivinflico é dirigida ao seu recipiente de origem. 0 sistema, simples e versátil, é operado manualmente e não requer funcionamento intermitente da bomba peristáltica.

Os processos propostos permitem uma velocida de analitica de 120 determinações por hora. Após análise con tínua de aproximadamente 1000 amostras, mudanças na linha bá sica não são observáveis. Os desvios padrão relativos de su cessivas medidas referentes à mesma amostra são, em geral, me nores do que $1 \%$ para faixas de concentrações de sulfato entre 1 e $25 \mathrm{mg}^{-1} \mathrm{l}^{-1}$ (águas) ou entre 5 e $100 \mathrm{mg} \cdot \mathrm{l}^{-1}$ (digeridos de plantas). Concentrações maiores de sulfato são facilmente determinadas após redução do volume injetado de amostra. Os resultados das análises de amostras de águas e de digeridos de vegetais são comparáveis àqueles obtidos por procedimentos manuais recomendados. 


\title{
SULPHATE DETERMINATION IN NATURAL WATERS AND PLANT DIGESTS BY FLOW INJECTION TURBIDIMETRY
}

\author{
Francisco Jose Krug
}

\author{
Prof. Dr. Henrique Bergamin Filho
}

- Adviser -

\section{SUMMARY}

After a detailed study involving nucleation kinetics, an improved flow injection system with alternating streams of reagents was designed for the turbidimetric determination of sulphate in natural waters and plant digests. The sample is injected into a chemically inert non segmented carrier stream originating a well defined and reproducible sample zone which is further mixed with a barium chloride - polivinyl alcohol solution. The barium sulphate suspension formed in acidic medium is quantitatively evaluated when the processed sample zone flows through a spectrophotometric sensor, the transient signal, proportional to the sulphate concentration in the sample, being recorded.

The range of the method can be extended to low concentrations by continuously adding sulphate to the sample carrier stream. After measurement, the analytical path is washed by means of an alkaline EDTA solution pumped at high flow rate. During the wash period, the barium chloride-polivinyl alcohol solution is directed towards its recovery vessel. Stoppage of the peristaltic pump is not required. 
The flow injection system is very simple and can be manually operated. After routine analysis of about 1000 samples, baseline drift is not observed.

The proposed procedures are suitable for 120 ; samples per hour, yielding precise results, the relative standard deviations between sucessive measurements being often less than $1 \%$ for sulphate concentrations in the ranges $1,0-25 \mathrm{mg} \cdot \mathrm{l}^{-1}$ (waters) and $5,0-500 \mathrm{mg} \cdot \mathrm{l}^{-1}$ (plant digests). Higher sulphate concentrations can be easily determined after diminishing the sample injected volume. The results compare well with those obtained bv standard manual procedures. 
1. INTRODUÇAO

Qualquer tentativa para solucionar o. proble $m a$ de sistemas dispersos $\bar{e}$ desalentadora, $f \bar{a}$ ce à extrema dificuldade para se entender $\bar{a}$ complexidade do benomeno. Diafanômetros, ne felômetros, turbidimetros, tyndallimetros, dispersimetros, opacimetros têm sido desenvolvidos e colocados no mercado, porem nenhum deles tem sido aceito como instrumento padrão de um laboratörio... Aparentemente, as medidas de turbidez não têm aprovado satis fa toriamente, mas mesmo assim os prospectos dos babricantes são mais otimistas do que aquilo que realmente ocorre. Quando as limitações destes métodos oticos forem compreendidas, as possibilidades reais dos mesmos poderäo at $\vec{e}$ ser apreciadas, mas ficaremos sem saber onde elas serão üteis.

WELLS

A crescente demanda por análises químicas em diferentes matrizes, tais como águas naturais, tecidos animais e vegetais, solos, efluentes industriais, tem exigido constantes investigações visando ao desenvolvimento e aprimo ramento de métodos analiticos. Infelizmente, boa parte das técnicas propostas na literatura e disponiveis comercialmente não atende aos países menos industrializados, face ao eleva- 
do custo operacional dos sistemas analíticos utilizados. Este fato pode ser ilustrado, quando se considera o sistema au toanalisador desenvolvido a partir do conceito proposto por SKEGGS (1957) e produzido comercialmente pela Technicon Instruments Co.

Em 1975, RUZICKA e HANSEN e, independentemente STEWART et alii em 1976, propuseram um novo conceito em automa ção analítica o qual deu origem aos sistemas de análise por injeção em fluxo, FIA*. O desenvolvimento demonstrou que méto dos baseados neste conceito apresentam características analí ticas iguais ou superiores aos métodos até então en: uso,ainda com vantagens adicionais. Os sistemas FIA são em geral, sim ples e de fácil construção. Além do baixo custo operacional e alta versatilidade, frequentemente apresentam velocidade analitica superior a 120 amostras por hora e requerem volumes de amostras e de reagentes da ordem de microlitros por determinação. Por outro lado, métodos fIA apresentam boa precisão (desvio padrão relativo das medidas em geral inferior a $2 \%$ ), sua exatidão e sensibilidade sendo comparáveis às dos métodos convencionais. Detalhes do potencial analítico dos sistemas FIA podem ser obtidos em artigos de revisão (BETTERIDGE, 1978; RUZICKA e HANSEN, 1980; STEWART, 1981; RANGER, 1981; ZHAOLUN, 1981) e em monografia (RUZICKA e HANSEN, 1981).

Deve-se salientar também que, em um período de apenas uma década, houve uma evolução signifiuativa nas idéias ligadas ao conceito FIA, o que resultou na publicação de cerca de trezentos trabalhos cientificos, cifra esta que tem crescido exponencialmente em função do tempo. Os resul

*FIA, do inglès Flow Injection Analysis. 
tados das pesquisas FIA têm revelado ser esta uma das ferra mentas mais versáteis visando ao desenvolvimento da química analitica.

Especialmente nas äreas de agricultura e ciên cias do ambiente, vários métodos FIA já foram estabelecidos, muitos dos quais sendo utilizados em análises de rotina para determinação de espécies químicas em águas naturais, digeri dos* de vegetais e extratos de solos na Seção de Radioquímica e Química Analitica do Centro de Energia Nuclear na Agri cultura, da Universidade de são Paulo (ZAGATTo et alii, 1981; RIIZICKA e HANSEN, 1983) e em vários laboratórios do exterior (RUZICKA E HANSEN, 1981).

O objetivo principal do presente trabalho é apresentar, de maneira tão simples como os sistemas FIA, o projeto e desenvolvimento de um método automatizado para determinação turbidimétrica de sulfato em águas naturais e em digeridos de vegetais, com características analiticas superio res àquelas descritas na literatura. A escolha desta es pécie química é justificada pela essencialidade do enxofre às plantas e pela importanncia da determinação de sulfato em estudos hidrológicos, aliadas à dificuldade em se determinar sulfato pelos métodos convencionais de análise usualmente re comendados, baseados em gravimetria e turbidimetria,os quais, além de extremamente morosos (cerca de dez determinações por hora com dois operadores), exigem cuidados especiais durante o procedimento analítico.

\footnotetext{
* Nesta tese, o termo digerido é sempre utilizado no sentido do termo inglès digest.
} 


\section{REVISAO BIBLIOGRAFICA}

A marcha da ciência $\bar{e}$ orientada mais pelos autores de livros textos do que pelo trabalho daqueles que ganharam o prêmio Nobel.

EINSTEIN

2.1. Anālises por injeção em fluxo

2.1.1. 0 conceito FIA

Análise por injeção em fluxo, FIA, foi recentemente definida como um processo analítico automatico ou se miautomätico tendo como jundamento a inserção sequencial de volumes de soluçöes de amostras em um fluido não segmentado dirigido continuamente para um sensor, onde o analito de interesse $\bar{e}$ detectado (STEWART, 1981).

0 conceito FIA originalmente introduzido por RUZICKA e HANSEN (1975) e por STEWART et alii (1976) referia-se ao termo injeção e restringia esta injeção em um fluxo contínuo de reagentes. Apesar de atualmente não serem mais utilizadas seringas e agulhas para injeção de amostras, 
substituídas por válvulas rotativas, injetores proporcionais, injetores comutadores e comutadores temporizados,o termo injeção permanece por motivos históricos,mesmo considerando-se o curto período de tempo transcorrido desde a proposição do conceito FIA.

BERGAMIN et alii (1978a) expandiram o conceito FIA, propondo a utilização de um fluido carregador de amostras, o qual poderia ser tanto um reagente como uma solu ção quimicamente inerte. Apesar de esta proposição ter passado desapercebida em diversas revisões posteriores (BETTERIDGE, 1978; RUZICKA e HANSEN, 1980; RANGER, 1981), a mesma apresentava uma contribuição significativa para o desenvolvimento de sistemas FIA com configuração em confluência. Enquanto o conceito fIA original limitava o volume de amostra a ser injetado, o novo conceito deixava de apresentar esta rígida condição de contorno, ou seja, o volume de amos tra empregado poderia até mesmo tender ao “infinito. Nesta condição, o fluido carregador apresentaria características de acidez, coloração, Indice de refração, polaridade e visco sidade similar às das amostras, e os reagentes requeridos se riam adicionados por confluência de fluido.

Neste mesmo ano, o conceito FIA foi novamente ampliado, quando BERGAMIN et alii (1978c), e, independentemente, MINDEGAARD (1979) propuseram sistemas com: zonas coalescentes*, os quais utilizam inserções simultāneas de volumes de amostras e reagentes - eventualmente soluções padrão ou soluções de.íons interferentes (ZAGATTO et alii, 1981; HANSEN et alii, 1983; GINE et alii, 1983) - em fluidos carregadores. As zonas de amostra e de reagentes estabelecidas interagem parcial ou totalmente, sendo que o produto desta interação é

*Do inglês merging zones. 
posteriormente quantificado na unidade de detecção. É interessante notar que, quando se consideram sistemas FIA com zonas coalescentes, a definição de STEWART (1981) precisa ser revisada, a fim de prever não só a injeção de amostras como também de outras soluções.

Nos anos seguintes, novos avanços na tecnolo gia FIA levaram à necessidade de expansão no conceito original. Desta forma, a idéia de um fluido carregador escoando continuamente deve ser reavaliada para incluir os. sistemas FIA que empregam escoamentos intermitentes (RUZICKA e HANSEN, 1980; ZAGATTO et alie, 1980) ou aprisionamento da zona de amostra*, KRUG et alii, 1983). Nestes últimos sistemas, a porção central da zona da amostra é selecionada,removida do fluido carregador, mantida sem escoamento durante certo intervalo de tempo sob condições definidas e, posteriormente, reintroduzida na mesma solução carregadora que a transporta até o sensor.

Igualmente, a conotação uma zona de amostra bem definida e reprodutivel que $\vec{e}$ transportada at $\vec{e}$ um detector, onde $\vec{e}$ medida, precisa ser revista, jä que em 1981, REIS et alii demonstraram que é possivel selecionar apenas uma fração da zona dispersa de amostra lou de quaisquer outras soluções) e introduzíla em um outro fluido carregador dirigido ao sensor que, evidentemente, poderá quantificar ape nas parte da zona da amostra. O desenvolvimento posterior confirmou as potencialidades deste processo de reamostragem da zona dispersa**(JACINTHO et alie, 1981a; ZAGATTO et alii, 1981; GINE et alii, 1983).

* Do inglés zone trapping.

**Do inglès zone sampling. 
Paralelamente a estas novas propostas, foram descritos diversos métodos FIA envolvendo diferentes proces sos de separação ou concentração (diálise, extração líquido-líquido, troca iónica, destilação), de detecção (espectro fotometria, potenciometria, espectrometria de absorção/emis são atômica, fluorimetria, polarografia, etc.l bem como determinações simultàneas, adições padrão, cinética, quimiolu minescência, etc. (RUZICKA e HANSEN, 1981).

Em função destes avanços, observa-se que o conceito FIA é muito amplo,não podendo ser considerado de ma neira simplista e restrite como inicialmente formulado em 1975 e reenfatizado em 1979 e 1981 por RUZICKA e HANSEN, nem defi nido, como por STEWART (1981). Entretanto, o funcionamento, operação e principais variáveis envolvidas em um sistema fIA precisam ser bem compreendidos, em que pese o fato de a teo ria FIA estar longe de exata e completa.

\subsubsection{Constituição dos sistemas FIA}

Os sistemas FIA são constituídos por uma unidade propulsora de fluidos, uma unidade de comutação e reação e uma unidade de medida, as quais podem,opcionalmente,ser comandadas por uma unidade de controle e aquisição de dados (Figura l).

De um mora geral, a unidade propulsora é uma bomba peristáltica operando com intensidade de fluxo na fai$x a$ de 0,1 a $10 \mathrm{ml} \mathrm{min}^{-1}$ (RUZICKA e HANSEN, 1981). O emprego de gás comprimido como propulsor de fluidos foi recentemente proposto (RUZICKA et alii, 1982).

A unidade de comutação e reação, de fabricação 
.8.

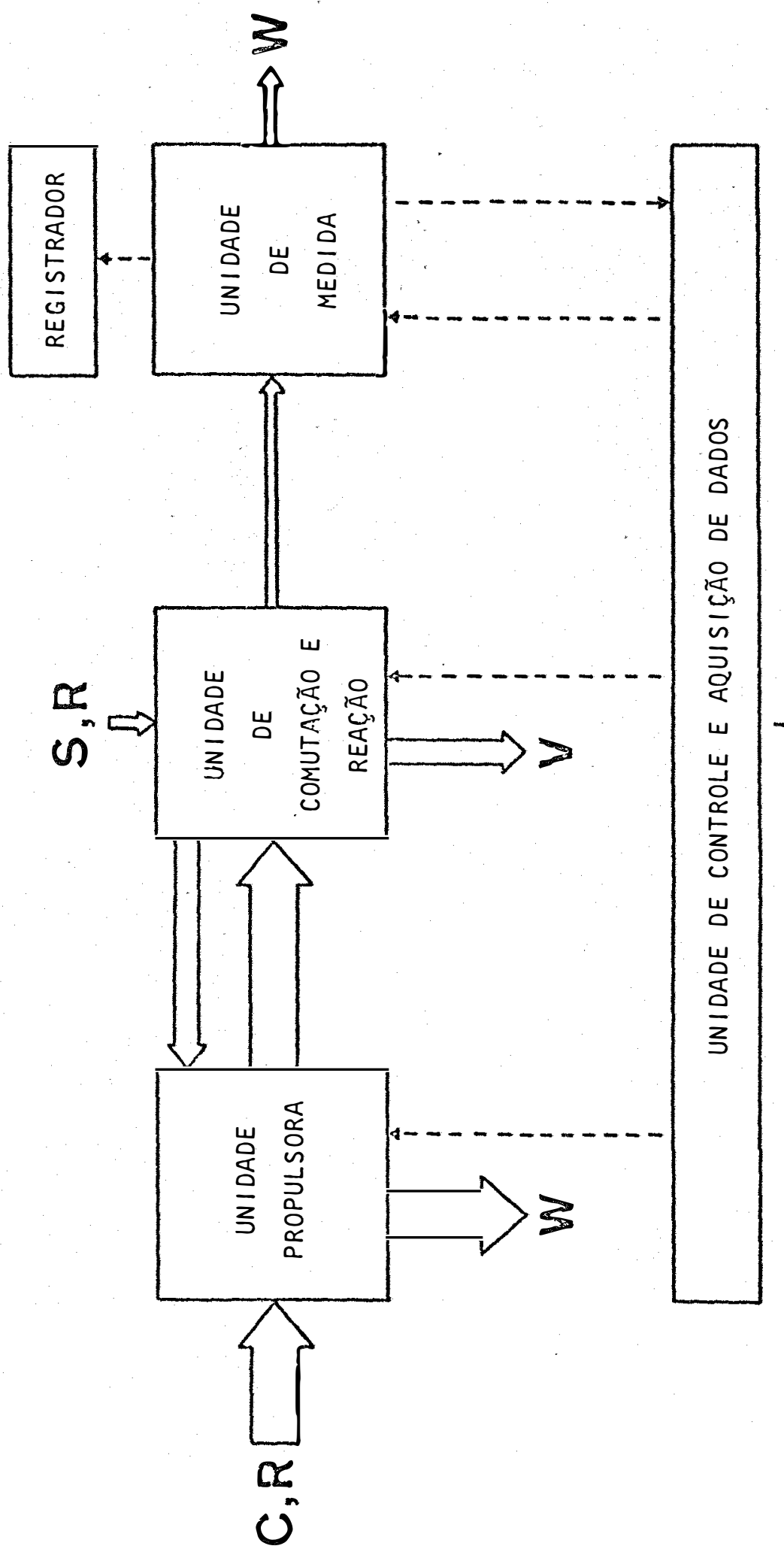

$\begin{array}{lll}0 & 1 & 1 \\ -4 & c & 0\end{array}$

o 00

$E$ o o o

ס 0

$\begin{array}{lll}\text { J } & 0 & 0 \\ \text { O } & \text { L } & \text { L }\end{array}$

ס

ह

כ

II

11.

( 0 क

E

$\dot{E}$
$\times$
$\times$

$\supset \propto$

$\frac{1}{4} 0$

E $\ddot{0}: 0$

Q 00

$+0$

ㄷㄷ 4

ir 00

un on

(ब) 0

C 4 a

-r 4

e 0 II

o 0

ह

E 4

$0+1$
$+\infty$

ज 04

- $E$ E

ज 0

E ه

ब 011

$\begin{array}{ll}0 & 0 \\ 0 & 0 \\ 4 & 0\end{array}$

ง 0

음

- on 4

$\therefore$ 누

อ 4 is

40

О 0 ठ

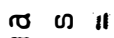

E 01

or.

ठั

ه न ज

.

I

-

$\frac{\pi}{2}$ 
muito simples, inclui um injetor ou comutador, bobinas de homogeneização e/ou desenvolvimento de reações químicas e, eventualmente, conectores para a adição de fluidos confluen tes. Esta unidade pode incluir, ainda, câmaras de separa ção de fases para extração com solventes (BERGAMIN et alii, 1978b; KARLBERG e THELANDER, 1978), resinas de troca iónica (BERGAMIN et alii, 1980; KONDO et alii, 1982; 0LSEN et alii, 1983), câmaras de destilação(ZAGATTo et alii, 1979), membra nas de diálise (HANSEN e RUZICKA, 1976), etc. A unidade de comutação e reação pode ainda promover modificações no módu lo de análise** durante a inserção da amostra (GINE et alii, 1980), intermiténcia de fluxos sem parada da unidade propul sora (ZAGATTO et alie, 1980), aprisionamento de zonas (KRUG et alii, 1983), amostragem na zona dispersa(REIS et alii,1981), etc. Todos os componentes desta unidade são de dimensões bastante reduzidas, especialmente aqueles situados no percur so analítico, uma vez que os volumes injetados de amostra va riam, na maioria dos casos, de 5 a $500 \mu \ell$ (RUZICKA e HANSEN, 1981). Assim, os tubos condutores mais empregados para as transmissões e para confecção das bobinas (teflon, polietile no, polipropilenol apresentam em geral diâmetro interno de 0,5 a $1,0 \mathrm{~mm}$; volumes mortos*** no percurso analítico devem ser minimizados, de forma que a unidade de comutação e rea ção apresente um volume interno total em geral não exceden do $2 \mathrm{ml}$.

* O termo bobina é aqui empregado no sentido de reator tu bular helicoidal. Recentemente, foi proposta a substi tuição de reatores tubulares por reatores empacotados, do inglès packed reactors (VAN DEN BERG et alii, 1980). ** Do inglés manifold. *** Do inglès dead volumes. 
Com relação à unidade de medida, têm sido e pregados colorímetros, espectrofotômetros, espectrômetros de absorção/emissão atómica, potenciómetros, fluorímetros, etc.

\subsubsection{Principais sistemas FIA}

Os diversos sistemas FIA propostos na litera tura são mostrados esquematicamente na. Figura 2.

(a)

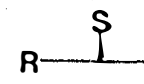

Lesoree<smiles>[W]c1ccccc1</smiles>

(e)

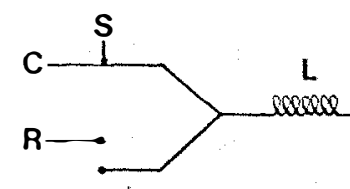<smiles>N#Cc1ccccc1</smiles>

(b)<smiles>[R]CC([AlH2])CC(C)S</smiles>

(c)<smiles>CC(S)C(C)S</smiles>
$\stackrel{L}{\text { ccasede }}$<smiles>[W]c1ccccc1</smiles>

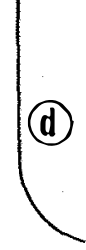<smiles>[R]C(C)CC(CC)CC(C)S</smiles><smiles>N#Cc1ccccc1</smiles>

(9)

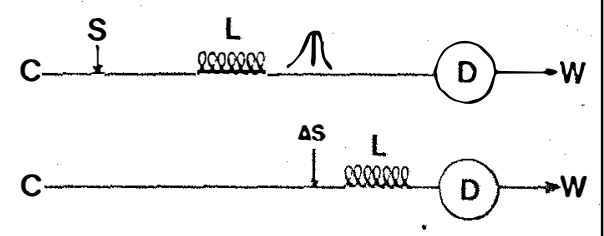

(f)

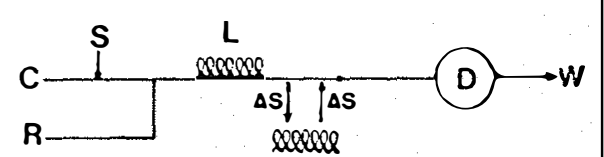

(b)
L

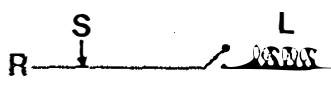

Figura 2 - Diagramas de fluxo dos principais sistemas FIA. a) Iinha única; b) em confluência; c) com zonas coalescentes em linha única;

d) com zonas coalescentes em confluéncia;

e) com fluxos intermitentes em confluéncia;

f) com aprisionamento da zona da amostra;

g) com reamostragem na zona dispersa; $h$ ) com fluxos intermitentes (stopped flow). 
No sistema elementar básico, ou em linha única, conforme proposto por RUZICKA e HANSEN em 1975, a amostra (S) é injetada em um fluxo carregador reagente (R), originando uma zona de amostra muito bem definida e reprodutivel, a qual sofre um processo contínuo de dispersão à medida em que é empurrada pelo carregador através do reator ( $L$ ) em direção ao detector (D), com posterior descarte (W). o processo de dispersão da zona da amostra possibilita a intera ção entre a amostra e o reagente. Nestes sistemas, especia mente sob condições de dispersão média ou limitada (RUZICKA e HANSEN, 1978), o aproveitamento do reagente é deficiente, considerando-se a diluição causada pela zona da amostra e o tempo requerido para o reagente atingir a porção central da amostra (BERGAMIN et alii, 1978a). Tais sistemas são mais difíceis de serem projetados por ser imprescindível o conhe cimento exato de como a zona de amostra se dispersa no reagente. Em qualquer situação,o estabelecimenţo de gradientes de concentração ao longo da zona da amostra é inevitável, gradientes estes que, apesar de explorados beneficamente em algumas aplicações (BETTERIDGE e FIELDS, 1978; BABAN et alii, 1980; REIS et alii, 1981), são em geral indesejáveis (BERGAMIN et alii, 1978a). Atualmente,os sistemas em linha única são empregados em métodos FIA com dispersão alta (RUZICKA e HANSEN, 1978) nos quais a sensibilidade analítica não é o fa tor limitante, sendo então negligíveis os efeitos transientes indesejáveis causados pela injeção de pequenos volumes de amostra. Sistemas em linha única têm sido ainda utilizados em métodos que não requerem dispersão de amostra e adição de reagentes (JACINTHO et alii, 198Ib; ATTIYAT e CHRISTIAN,1984). Nestes, a amostra é introduzida em um fluido carregador quimicamente inerte, de composição matricial similar à mesma, o qual promove o transporte das amostras até o sensor e a lava 
gem do percurso analítico, minimizando problemas de interpenetração de amostras*. Diversos autores têm apresentado modelos matemáticos cada vez mais detalhados para o sistema em Iinha única (REIJN e.t alii, 1980, 1981a, 1981b; PAINTON e MOTTOLA, 1983) visando relacionar as diversas variáveis envolvidas no processo de dispersão da amostra e as implicações desta nas características analiticas.

No sistema elementar em confluência (Figura 2b) originalmente proposto por BERGAMIN et alie (1978a), a amostra é introduzida em um fluido carregador quimicamente inerto, sendo os reagentes adicionados através de pontos de confluência. Desta forma, a mesma quantidade de reagente é adicionada a cada porção da zona da amostra, evitando-se gra dientes de concentração indesejáveis bem como permitindo um melhor aproveitamento do reagente, relativamente aos sistemas FIA em linha ünica. Considerando-se ainda que, neste sistema, quaisquer volumes de amostra podem ser injetados, torna-se possivel o estabelecimento de métodos com maior sensibilida de analitica e melhor relação sinal-ruído.

No sistema em confluência com zonas coalescen tes proposto por BERGAMIN et alii (1978c), a amostra e o rea gente são simultaneamente introduzidos nos correspondentes fluidos carregadores inertes, cuja confluéncia promove a interação entre as zonas estabelecidas. Este sistema apresen ta, entre outras vantagens, menor consumo de reagentes (BERGAMIN et alii, 1978c; ZAGATTO et alii, 1979), maior estabili dade da linha básica com consequente aumento na precisão (RE Is et alii, 1979; ZAGATTO et alii, 1979), permitindo, ainda,determinações simultâneas utilizando um ünico módulo de análise e um único sensor (REIS et alii, 1980; GINE et alii, 1980)

\footnotetext{
*Do inglés carryover.
} 
ou sensores diferentes (ZAGATto et alie, 1980), síntese de reagentes instáveis fora do percurso analítico (JACINTHO et alii, 198la), automação do método das adições padrão (ZAGATTo et alii, 1983; GINE et alii, 1983), determinação de altas concentrações de espécies químicas sem pré-diluição manual' (MINDEGAARD, 1979), etc. Recentementé, para avaliação de sé letividades, foi proposto sistema FIA utilizando injeções simultáneas da espécie química a ser determinada e da solução contendo interferente\{s\} no mesmo fluido carregador, a coalescéncia entre as zonas formadas ocorrendo em consequên cia do processo de dispersão (HANSEN et alii, 1983). Tal sís tema apresenta as vantagens e limitações intrínsecas dos sís temas FIA em linha única.

Métodos FIA nos quais a sensibilidade é críti ca utilizam grandes volumes injetados de amostra, de forma a apresentarem fatores de dispersão (ZAGATTO et alii, 1979b) maiores do que 0,7 (GINE et alii, 1979; KRUG et alii, 1981; MORTATTI et alii, 1982). o tempo médio de residência da amostra no percurso analitico,que em geral determina o tempo médio disponível para as reações químicas envolvidas, pode ser aumentado empregando-se taxas de escoamento menores para os fluidos carregadores (RUZICKA e HANSEN, 1978). Assim, são fre quentes os sistemas FIA que usam grandes volumes injetados de amostra e baixas vazões,os quais, se projetados empregan do um dos sistemas elementares acima, ou combinações destes, apresentam invariavelmente um compromisso entre sensibilida de e velocidade analiticas,esta última intimamente relacionada com o consumo de reagentes (KRUG et alii, 1981). Visando minimizar este efeito,foram propostos sistemas FIA com flu xos intermitentes (RUZICKA e HANSEN, 1980) e com aprisionamento da zona da amostra (KRUG et alii, 1983). 
No sistema FIA elementar em linha ünica com fluxo intermitente (stopped-flow) proposto por RUz।CKA e HANSEN em 1980, a amostra é injetada em um fluido carregador que, apōs transportá-la até a unidade de detecção, tem sua taxa de escoamento reduzida a zero. Assim, permite-se um. acréscimo no tempo médio de residência de amostra no sistema sem afetar significativamente o grau de dispersão da zona formada e o tempo de limpeza*. Posteriormente, a vazão original é restaurada de forma a descartar a zona de amostra e permitir o processamento da amostra seguinte. No sistema FIA elementar em confluéncia com fluxos intermitentes (ZAGATTO et alie, 1980), a amostra é inserida em seuflui do carregador que escoa lentamente, após a passagem da porção de interesse da zona de amostra pelo detector, o tempo de limpeza, que em geral limita a velocidade analitica, é diminuído pela ação do fluxo intermitente (Figura 2), - qual permanece fluindo até o início do proçessamento da amostra seguinte. 0 sistema FIA elementar em confluência com fluxos intermitentes tem sido também empregado para promover coalescência de zonas (RUZICKA e HANSEN, 1981). Originalmente, tais sistemas utilizavam duas bombas peristálticas,uma das quais operando intermitentemente (RUZICKA e HANSEN,1980, 1981). Em 1980, ZAGATTO et alie demonstraram que apenas uma bomba peristáltica, operando em regime contínuo, poderia ser utilizada para este fim, a intermitência do fluxo $R$ sendo conseguida com emprego de injetor-comutador operado manualmente.

O sistema com aprisionamento da zona da amostra (KRUG et alii, 1983) não envolve intermitência de fluxos. Neste sistema, a porção central da zona da amostra, que jä sofreu adição de reagentes, é selecionada, removida,

*Do inglès wash time. 
deixada em repouso sob condições definidas por um perído de tempo pré-estabelecido e reintroduzida no fluido carregador para posterior deteç̧ão. Um temporizador acoplado à unidade de comutação e reação garante o alto grau de precisão nas análises efetuadas. No caso de reações lentas,a sen sibilidade analitica é melhorada aumentando-se o tempo de aprisionamento, sendo a velocidade analitica dependente deste tempo e não mais do tempo de limpeza.

A Figura 2 apresenta, ainda, o sistema FIA com reamostragem na zona dispersa, proposto por REIS et alii em 1981. Neste sistema, a amostra ou eventualmente uma solução padrão é injetada em um fluido carregador e, após determina do intervalo de tempo, uma fração ( $\Delta S$ ) da zona da amostra é reamostrada e introduzida em um segundo fluido carregador pa ra ser posteriormente processada e quantificada. A fração re manescente pode também ser processada, visando determinações simultāneas (ZAGATTO et alii, 1981), ou simplesmente descarta da. Empregando-se diferentes intervalos de tempo, podem ser selecionadas alíquotas com graus de dispersão diferentes, mas perfeitamente reprodutíveis. A reamostragem na zona dispersa é particularmente útil quando se deseja a obtenção de uma curva de padronização usando apenas uma solução padrão (GINE et alii, 1983).

\subsection{Métodos automatizados para a determinação de sulfato}

A determinação de sulfato, principalmente em baixas concentrações, tem sido um dos problemas difíceis com que se defrontam os químicos analistas.

0 método turbidimétrico manual, apesar de recomendado para análise de águas naturais (APHA, 1975), falha 
pela morosidade e pela má qualidade dos resultados analficos. As causas da inexatidão e imprecisão são atribuluas ì necessidade de rígido controle das condições que governam a formação da suspensão de sulfato de bário durante as operações que precedem às medidas de turbidãncia.

Da mesma forma, o método gravimétrico, em es pecial recomendado para a determinação de sulfato em digeri dos de vegetais (AOAC, 1980), é criticado por sua morosidade, além de ser considerado relativamente inexato e impreciso,em função principalmente das contaminações do precipitado, das variações na temperatura de ignição e das dificuldades de pe sagem do precipitado (KOLTHOFF e SANDELL, 1962; BATAGLIA,1976).

De qualquer maneira, dentre os métodos manuais recomendados, aquele baseado na medida da turbidez de suspensões de sulfato de bário é reconhecido como um método padrão para a determinação de sulfato em águas naturais (APHA, 1975), além de ser extensivamente usado na maioria dos laboratórios, em procedimentos manuais ou automatizados, para a determinaçăo do teor de enxofre total em plantas e sulfato extraível em solos (BEATON et alii, 1968).

E interessante observar que, em 1970, BESWICK e JOHNSON, comparando os métodos colorimétrico via cloroanilato de bário, volumétrico via perclorato de bário e turbidi métrico via sulfato de bário conclúr ram que os dois primeiros não eram adequados para análises em larga escala. Por o tro lado, afirmaram que o método turbidimétrico poderia ser recomendado desde que precisão não fosse fator limitante. De ve ser salientado aqui que técnicas amplamente utilizadas pa ra dèterminação de outras espéc: ss químicas tais como espectrometria de absorção ou emissão atómica, potenciometria direta, colorimetria, fluorescéncia de raios-x, etç., têm se 
mostrado inviáveis quando aplicadas à determinação de sulfáto ou enxofre em águas e tecidos vegetais. Por outro lado, técnicas sofisticadas, caras ou raras, tais como espectrome tria de massa, cromatografia iōnica, nefelometria, métodos radioanaliticos, etc., não são em geral disponívels para anä lises em larga escala na maioria dos laboratórios.

Com o advento dos autoanalisadores empregando fluxo segmentado por bolhas de ar, segundo conceito de SKEGGS (1957), dos métodos manuais até então preconizados, o turbidimétrico ocupou lugar de destaque na literatura para a determinação de sulfato em digeridos de vegetais. Neste sentido, BASSON e BÖHMER propuseram em 1972 um sistema caracterizado por precisão superior à dos métodos manuais em uso, fato este explicado por serem mantidos constantes para todas as amostras as condições de mistura* o intervalo de tempo entre a introdução da amostra e a leitura do sinal. No trabalho, ènfase foi dada ao processo de lavagem entre amostras, sendo utilizada solução alcalina de EDTA para evitar a adsor ção e acúmulo de sulffato de bário nas paredes internas da cé lula de fluxo** do colorímetro. Modificações no amostrador foram posteriormente sugeridas por SANSUM e ROBINSON (1974) e por TEIXEIRA et alii (1976).

Em 1980, LEA e WELLS sugeriram um sistema mais estável e versátil,no qual a solução de EDTA era omitida e uma solução de cloreto de bário preparada em presença do agente protetor de colóides polivinil pirrolidona era utiliza da. Apesar de a velocidade analitica ser mantida entre 20 e 30 determinações por hora, o método proposto apresentava me lhor limite de detecção (em torno de $1 \mathrm{mg} \mathrm{SO}_{4}^{2-} \cdot 1^{-1}$ ).

* Do inglès mixing conditions.

**Do inglès flow cell. 
KRUG et alii, em 1977, demonstraram que era possivel automatizar o método turbidimétrico de uma maneira mais simples, rápida e económica, empregando tecnologia FIA. O segredo da boa precisão alcançada estava no emprego de álcool polivinílico como agente protetor to colóides e nas características favoráveis dos sistemas fiA. 0 método. que se constituiu na primeira aplicação de sistemas FIA a determinações turbidimétricas, era caracterizado por uma velocidade analítica de até 180 determinaçóes por hora, desvio padrão relativo das medidas inferiores a $3 \%$ e boa exatidão. Na época, era uma boa alternativa para a determinação desta espécie química em águas naturais e em digeridos de vegetais, sendo utilizado em larga escala nos laboratórios do CENA. Em 1978a, BERGAMIN et alii, empregando um sistema FIA em confluéncia,verificaram que não era possivel melhorar significativamente o limite de detecção do método, ao redor de $10 \mathrm{mg} \mathrm{SO}{ }_{4}^{2-} \cdot 1^{-1}$.

Em 1980, BABAN et alii, confirmando observações realizadas quando do uso extensivo do método proposto por KRUG et alii (1977), reportaram que, às vezes, o método apresentava problemas inerentes à adsorção de sulfato de bário nas paredes internas da célula de fluxo. Esta adsorção causava uma instabilidade na linha básica que comprometia,em situações extremas, a precisão e exatidão analitica. Para contornar este problema, sugeriram um sistema FIA em linha única no qual amostras ácidas,apresentando pH em torno de 1,5, eram injetadas em uma solução alcalina de cloreto de bário e EDTA. Embora a exṕloração dos gradientes de $\mathrm{pH}$ originados minimizassem efeitos de adsorção, o procedimento proposto re queria preliminarmente um ajuste manual de pH das amostras, dificultando sua aplicação para análises de rotina. Além dis to, o método apresentava uma velocidade analítica de apenas 30 determinações por hora, após o ajuste manual de pH, e um 
limite de deteç̧ão de $30 \mathrm{mg} \mathrm{SO} 4^{2-} \cdot 1^{-1}$.

Estudos realizados por KRUG em 1980 permitiram concluir que a adsorção e acúmulo de sulfato de bário nas paredes internas da cubeta de fluxo eram dependentes do pro cesso de injeção de amostras empregado, sendo mais acentuados quando injetor-comutador (ZAGATTO et alii, 1979) era utí lizado. Este injetor, além de conferir uma melhor precisão aos volumes de amostra injetados, apresenta a vantagem de não alterar a dinãmica do sistema durante a inserção da amostra, comparativamente ao injetor usado por KRUG et alii (1977). Em contrapartida, o injetor antigo apresentava a vantagem de acelerar a passagem da zona da amostra pelo detector durante a injeção da amostra seguinte. A brusca injeção a uma vazão muito alta promovia uma limpeza mais eficiente do percurso analítico em virtude do efeito de transporte de massa.

Em 1966, LAZRUS et alii propuseram um método para a determinação dé sulfato em águas, na faixa de 10 a $30 \mathrm{mg} \cdot \mathrm{l}^{-1}$ de sulfato, com base na colorimetria do complexo bário-azul de metiltimol, empregando sistema de fluxo segmen tado por ar. Posteriormente, o método foi adotado pela TECHNICON (1972) e apresentado em versão industrial com velo cidade analítica de 30 determinações por hora.

Dois anos mais tarde, MCSWAIN e WATROUS, através de um aprimoramento do sistema,verificaram que era possí vel a determinação do sulfato na faixa de 0,02 a $1,00 \mathrm{mg} \cdot \mathrm{l}^{-1}$ de sulfato. Nestes sistemas, a incorporação de uma coluna com resina de troca iónica se fez necessäria para remoção de íns interferentes tais como cálcio, magnésio, alumínio e ferro, porém a eficiéncia da resina não é comentada para a tas concentrações dos interferentes. 
Em 1981, o método do azul de metiltimol foi automatizado por MADSEN e MURPHY em sistema FIA. 0 método foi desenvolvido para determinação de sulfato em águas de chuva, na faixa de 0,1 a $6,0 \mathrm{mg} \cdot \mathrm{l}^{-1}$ de sulfato, a uma veloci dade analítica de 20 determinações por hora. Teores de cálcio até l mg.1-1 não afetavam a exatidão do método, já que uma microcoluna com resina de troca ionnica era acoplada ao injetor.

Uma outra alternativa para determinação colo-

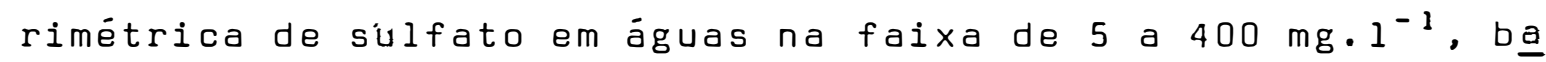
seada na reação com cloroanilato de bário em sistema automatizado com fluidos segmentados, foi proposta por GALES et alii em 1968. O método apresentava velocidade analítica de 15 determinações por hora e envolvia o uso de coluna com resina de troca iónica para remoção de interferentes, agitador eletromagnético para geração da suspensão de cloroanilato de bário e um dispositivo para filtração antes da célula de flü xo para remoção dos cristais de sulfato de bário e de cloroanilato de bário.

Recentemente, REIJNDERS et alii (1979) demons traram a viabilidade da determinação de sulfato em águas naturais a partir da reação com o complexo colorido bário-di metilsulfonazo,em sistema com fluxos segmentados por ar. Apresentando velocidade analitica de 40 determinações por hora, o método permitia determinações na faixa de 0,1 a 6,0 mg $\mathrm{SO}_{4}^{2-} \cdot 1^{-1}$.

Em 1982, a mesma reação foi explorada por KONDO et alii em sistema FIA. O método se aplicava a deter minações de sulfato em águas naiurais na faixa de 0,0 a 30,0 mg. $1^{-1}$, apresentando limite de detecção aproximado de 0,5 $\mathrm{mg} \cdot \mathrm{l}^{-1}$, desvio padrão relativo das medidas em torno de $1 \%$ e 
exatidão adequada. Anteriormente à injeção das amostras.hovia necessidade de separação de íons interferentes en coluna com resina de troca iónica. Após, a velocidade analfica era de 30 determinações por hora.

$$
\text { Por razões que ficam claras pela anáise da }
$$
literatura, optou-se, no presente trabalho, pelo aprimoramen to do método turbidimétrico proposto por KRUG et alie em 1977. 


\section{MATERIAL}

-.. porém os componentes utilizados precisam ser suficientemente simples, de forma que o instrumento inteiro não se torne demasiado complexr ou volumoso.

RUZICKA E HANSEN

\subsection{Instrumentação}

Como unidade propulsora, foi utilizada bomba peristáltica mpl3 GJ4 de fabricação Ismatec, provida de tubos de TYGON de diferentes diàmetros internos.

A unidade de comutação e reação constituiu-se de:

- injetor-comutador construído no Centro de Energia Nuclear na Agricultura segundo REIS et alii (1981) operado manual ou eletronicamente por meio de solenóides de tração (BERGAMIN et alii, 1980);

- bobinas de mistura preparadas enrolando-se tubos de polietileno com diàmetro interno de $0,86 \mathrm{~mm}$ em ci- 
lindros de vidro de diámetro externo igual a $2 \mathrm{~cm}$;

- conectores de acrílico em forma de $Y$;

- tubulação de polietileno igual à utilizada para as bobinas.

Como unidade de deteç̧ão, foi utilizado o espectrofotómetro Varian, modelo $634 \mathrm{~S}$, equipado com célula de fluxo Hellma 178 os lpasso ötico de $10 \mathrm{~mm}$, volume interno de $80 \mu l)$ e conectado a um registrador potenciométrico Radiometer 61 provido de unidade de alta sensibilidade REA ll2, de mesma fabricação.

Para preparo das amostras de vegetais, foram utilizados blocos digestores Sarge para 40 tubos.

\subsection{Reagentes e soluções}

Ds reagentes utilizados foram pró-anälise, à exceçao do álcool polivinílicoppoduto comercial da OU PONT denominado ELVANOL grau 71-30. Todas as soluções empregadas foram preparadas com ägua destilada-deionizada.

- Soluções padrão de sulfato: a solução estoque contendo $1000 \mathrm{mg} \mathrm{SO} 4^{-} .1^{-1}$ foi preparada dissolvendo-se $1,376 \mathrm{~g}$ de $\left(\mathrm{NH}_{4}\right)_{2} \mathrm{SO}_{4}$ em ägua e diluindo-se a $1000 \mathrm{ml}$ com água. Soluções padrão na faixa de 0,0 a $100 \mathrm{mg} \mathrm{SO}_{4}^{2-} .1^{-1}$ foram preparadas em água por diluições adequadas da solução estoque. Especificamente para a anālise de digeridos de vegetais, as soluções padrão eram também $0,25 \mathrm{M}$ em $\mathrm{HClO}_{4}$.

- Soluções de cloreto de bārio em álcool polivinilico (PVA) a $0,05 \% \mathrm{~m} / \mathrm{v}$ : estas soluções, na faixa de 5 
a $40 \% \mathrm{~m} / \mathrm{V} \mathrm{BaCl}_{2} .2 \mathrm{H}_{2} \mathrm{O}$, foram preparadas conforme o procedimento descrito por KRUG et alie (1977):

- Suspender 500 mg de PVA em aproximadamente $100 \mathrm{ml}$ de água sob agitação contínua e adi cionar $800 \mathrm{ml}$ de água em ebulição. Quando uma solução clara for obtida,adicionar clo reto de bário dihidratado. Após dissolü ção, deixar esfriar e completar o volume até $1000 \mathrm{ml} \mathrm{com} \mathrm{āgua.} \mathrm{Estas} \mathrm{soluções} \mathrm{são}$ estáveis, requerendo filtração caso haja polimerização visível do álcool polivinílico.

- Soluções padrão de íons potencialmente interferentes: para os elementos Al, Ca, Fe, K, Mg, Mn e P, foram preparadas soluções padrão estoque de concentração 1000mg. $1^{-1}$, empregando-se os compostos $\mathrm{AlCl}_{3} .6 \mathrm{H}_{2} \mathrm{O}, \mathrm{CaCO}_{3}, \mathrm{Fe}_{2} \mathrm{O}_{3}, \mathrm{KCl}, \mathrm{MgO}$, $\mathrm{MnO}_{2}$ e $\mathrm{KH}_{2} \mathrm{PO}_{4}$, respectivamente. Sempre que possível, as soluções estoque e aquelas de trabalho eram também $0, l \% \mathrm{v} / \mathrm{v}$ em $\mathrm{HNO}_{3}$. Para verificação da interferência do bicarbonato/car-

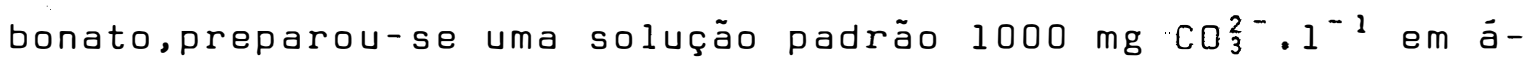
gua, a partir de $\mathrm{NaHCO}_{3}$.

- Outras soluções: - $\mathrm{HCl} \mathrm{HNO}_{3}$ e $\mathrm{HClO}_{4}$ na fai xa de 0,1 a $5,0 \mathrm{M}$;

- EDTA la partir de seu sal dissódico J na faixa de 0,3 a $1,2 \% \mathrm{~m} / \mathrm{v}$, em $\mathrm{NaOH}$ na faixa de 0,07 a $0,8 \mathrm{M}$.

\subsection{Amostras}

\subsubsection{Material vegetal}

As amostras de material vegetal, previamente 
lavadas com água de torneira e água destilada.secas a $60^{\circ} \mathrm{C}$ em estufa de circulação forçada até peso constante. e moídas em moínho tipo Wiley ( 30 a 60 mesh), foram decompostas por via úmida de acordo com procedimento empregado por KRUG et alii (1977):

- Pesar 750 mg de material,transferir para tubo de digestão com marca nos $75 \mathrm{ml}$ e acrescentar $7.5 \mathrm{ml}$ de ácido nltrico concentrado. Misturar bem e deixar à tempe ratura ambiente por 1 - 2 horas lou por uma noite). Após, colocar os tubos no bloco digestor e elevar a temperatura a $160^{\circ} \mathrm{C}$. Observar cuidadosamente, retirando os tubos do bloco se a mistura começar a subir nos mesmos. Quando a maior parte do ácido nítrico tiver evaporado e a solução clarear ( $\cong 15 \mathrm{~min}$ a $160^{\circ} \mathrm{C}$ ), retirar os tubos do bloco e acrescentar $2,0 \mathrm{ml}$ de ácido perclórico concentrado. Aumentar a temperatura para $210^{\circ} \mathrm{C}$. A digestão estará completa quando se obtiver uma solução incolor coincidindo com a evolução de fumos brancos e densos de $\mathrm{HClO}_{4} \cdot \mathrm{H}_{2} \mathrm{O}\left(\cong 15 \mathrm{~min}\right.$ a $\left.210^{\circ} \mathrm{C}\right)$. Uma vez resfriados os tubos, completar o volume com ägua. Os digeridos assim preparados serão aproximadamente $0.25 \mathrm{M}$ em ácido perclórico (REIS et alii, 1979). 


\subsubsection{Aguas}

As amostras de águas naturais foram coletadas em frascos de polietileno de um litro, trazidas ao laboratório, filtradas através de filtros de membrana de acetato de celulose $(0,45 \mu \mathrm{m})$ e armazenadas em frascos de polietileno, conforme recomendação da APHA (1975). As análises foram rea lizadas dentro de, no máximo, três dias após a coleta. 
4. METODO

... ao quimico analista deveriam ser ensina dos princípios, não métodos.

SANDELL E ELVING

4.1. Considerações sobre a metodologia

De um modo geral, para que as determinações turbidimétricas procedam, os seguintes fatores devem ser levados em consideração (KOLTHOFF e SANDELL, 1962; HOCHGESANG, 1966):

a) as concentrações das espécies químicas iónicas que se combinam para produzir o precipitado e o pH do meio;

b) a razão entre as concentrações das espécies químicas reagentes;

c) a forma, ordem e velocidade com que se mis turam as espécies reagentes;

d) o tempo necessário para produzir o máximo 
espalhamento de luz ou máxima turbidezs

e) a estabilidade da suspensão,

f) a temperatura;

g) a presença de outros eletrólitos:

h) a presença de não eletrólitosı

i) a presença de protetores de colóides.

De acordo com MARCZENKO (1976), quando a concentração de sulfato em solução é suficientemente baixa, o sulfato de bärio formado apös a adição de íns Ba ${ }^{+}$não coagula para formar um precipitado,permanecendo como uma fina suspensão,cuja turbidez pode ser avaliada fotometricamente. A suspensão de sulfato de bário é formada em meio levemente ácido, e a turbidez obtida varia em função do tempo, tornando-se quase estável após 10-15 minutos.

A acidez do meio é recomendada para prevenir uma possível precipitação de outros sais de bário, tais como carbonato e fosfato, insolúveis em soluções neutras ou alcalinas. Além disso, a coprecipitação de hidróxido de bário também é evitada (KOLTHOFF e SANDELL, 1962).

Por outro lado, desde que os cristais de sulfato de bário podem crescer durante o período que precede à leitura da tưrbidez, recomenda-se que o tempo de reação seja o mesmo para amostras e padrões (MARCZENKo, 1976). Neste ponto, convém salientar que esta condição de contorno é rigo rosamente obedecida nos sistemas FIA.

Assim, de acordo com as recomendações citadas, os itens $a, b, d, f$ e foram estudados em detalhe, conforme metodologia descrita em 4.4 e 4.6 . D fator c foi manti- 
do constante em todos os experimentos, com o mesmo dimensionamento básico dos sistemas FIA apresentados em 4.3 e 4.6. A estabilidade da suspensão (ítem e). apesar de não ser relevante face à utilização do sistema fIA, pode ser avaliada em função dos resultados obtidos nos estudos de cinética de nucleação, realizados conforme 4.4 .

Quanto à presença de não eletrólitos, alguns autores recomendam a utilização de etanol (KEILY e ROGERS, 1955) ou de etanol em presença de glicerol (ZAHN, 1937; TOENNIES e BAKAY, 1953). De um modo geral, o etanol tem a função de diminuir a solubilidade das partículas de sulfato de bário, permitindo a determinação de menores concentrações de sulfato, ao passo que o glicerol atua como um estabilizador de co lóides. Neste sentido,a presença de protetores de colóides é recomendada a fim de que a turbidez obtida para soluções apresentando o mesmo teor de sulfato seja reproduzida quanti tativamente (HOCHGESANG, 1966; KRUG et alii, 1977). No presente trabalho, foi utilizado álcool polivinilico, face aos bons resultados obtidos por KRUG et alii (1977).

\subsection{Fundamentos para o projeto do sistema}

\subsubsection{Escolha da configuração}

Dois procedimentos têm sido recomendados para se projetar um sistema de injeção em fluxo com leitura colorimétrica. Um deles,preconizado por RUZICKA e HANSEN(1981), baseia-se na injeção ou inserção da amostra diretamente sobre um reagente ou mistura de reagentes,podendo ainda outros reagentes serem adicionados, via pontos de confluência. Assim a amostra injetada forma uma zona bem definida que interage com os reagentes através de um processo contínuo de disper- 
são, enquanto é transportada em direção ao sensor. Neste caso, a formação de gradientes de concentração ao longo da zona da amostra é inevitável. Projetos baseados neste princí pio requerem o conhecimento prévio de como a amostra injeta-, da se dispersa no reagente. Embora os aspectos teóricos da dispersão em reatores tubulares tenham sido levantados(RUZICKA e HANSEN, 1978; REIJN et alii, 1980; VAN DER BERG et alii,. 1980 ; VANDERSLICE et alii, 1981), a maioria dos sistemas apre sentados na literatura tem sido estabelecida empiricamente. De um modo geral, o analista seleciona o volume de amostra a ser injetado, as intensidades dos fluxos, as concantrações de reagentes e as dimensões dos reatores, de forma a obter sinais reprodutílveis no menor tempo possivel e com o menor consumo de reagertes (ROCKS e RYLEY, 1982).

C outro procedimento baseia-se nu sistema elementar em confluência (Figura 3 ) proposto por BERGAMIN et alii (1978a). Como foi comentado anteriormente (item 2.1.2), a amostra é introduzida em um fluido quimicamente inerte, e os reagentes são adicionados por confluência (ponto $x$ - Figura 3). Após passagem pelo reator tubular,o produto da interação amustra/reagentes é medido e posteriormente descartado.

No presente trabalho, o sistema com confluéricia foi adotado face às vantagens sobre o modelo preconizado por RUZICKA e HANSEN (1981).

4.2.2. Determinação das vazões, do volume de amostra injetado e das dimensões do reator tubular

As intensidades de fluxo de $C_{S}$ e $R$, o volume (V) e o comprimento do reator tubular foram escolnidos visan 

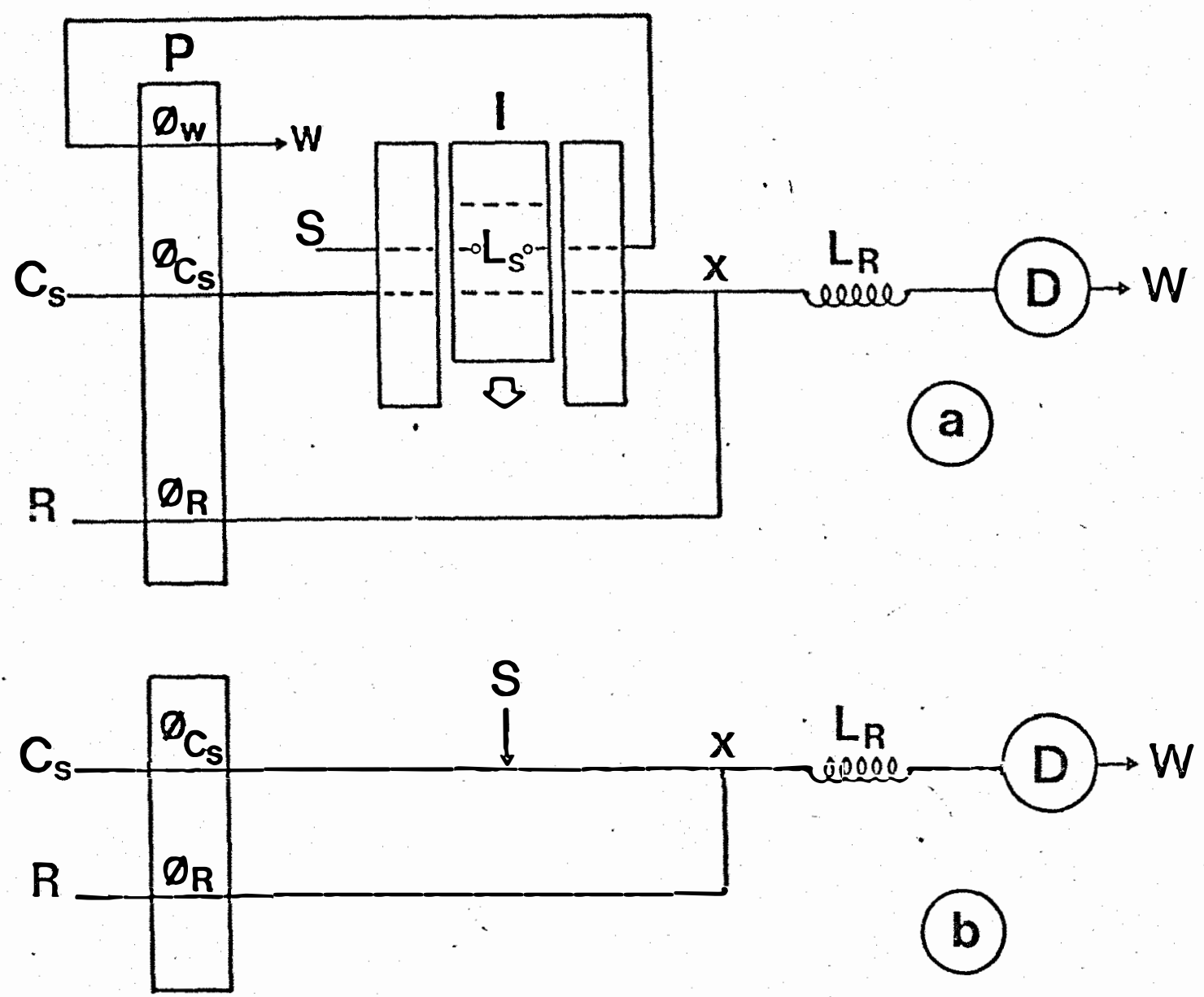

Figura 3 - Diagrama de um sistema FIA em confluēncia com 0 injetor I na posição de amostragem (a) e sua res pectiva imagem simplificada (b).

$C_{S}=$ solução carregadora de amostras impulsionada cóm intensidade de fluxo $\emptyset_{c} ; R=u m$ ou mais reagentes impulsionado (s) comsintensidade(s) de fluxo $\emptyset_{R} ; S=$ amostra (aspirada com intensidade de fluxo $\emptyset_{S}$ em (a)); Ls = reator tubular, cujas dimensões defi nêm o volume de amostra a ser introduzido em Cs. $x=u m$ ou mais pontos de confluéncia; $L_{R}=$ reator tu bular heliocoidal de mistura e/ou de reação; $D=u \bar{i}$ dade de detecção; $W=$ descarte. 
do a um bom limite de deteção, com base nas seguintes consi derações :

a) em todos os sistemas testados, a solução carregadora das amostras deveria ter aci dez média das amostras, de forma a serem evitados problemas relacionados a mudanças no índice de refração (BERGAMIN et alii, 1978a) e à formação de gradientes de $\mathrm{pH}$ na zona da amostra (BETTERIDGE e FIELDS, 1978);

b) a razão entre as intensidades de fluxo $\emptyset_{C_{S}}$ e $\emptyset_{R}$ deveria ser a maior possível, de forma a evitar uma diluição acentuada da zona da amostra no pento de confluência. A intensidade do fluxo confluente apresenta um limite mínimo que depende da solubilidade do reagente, da quantidade deste requerida pela reação química e das condições de mistura;

c) Uma vez que $\emptyset_{R}$ é fator de menor relevāncia, $\nabla_{C_{S}}$ deveria ser escolhido de forma a permitir um tempo médio de residência da zona da amostra e uma velocidade analitica adequada, que não comprometessem o limi te de detecção e a versatilidade do método;

d) o volume de amostra,definido pelo volume in terno de $L_{S}$, deveria ser suficientemente grande para minimizar a dispersão da amos tra no percurso analitico, sem, entretanto, comprometer a velocidade analitica do método; 
e) o reator tubular deveria ser o menor poss vel, mas com dimensões suficientes para garantir uma boa mistura entre a zona da amostra e o reagente,além de permitir um tem po adequado ṕara o desenvolvimento das rea ções. Deve-se salientar ainda que, aumen tando-se as dimensões do reator, ocorreria a diminuição da velocidade analitica, o au mento do consumo de reagentes e a diminui ção do sinal analitico, mantidos constantes $L_{S}, \emptyset_{C_{S}}$ e $\emptyset_{R}$.

Com base no sistema FIA mostrado na Figura 3 , uma vez definidos $\emptyset_{C_{S}}$ e $\emptyset_{R}$ pode-se determinar o volume de amostra a ser introduzido na solução carregadora,após a defi-

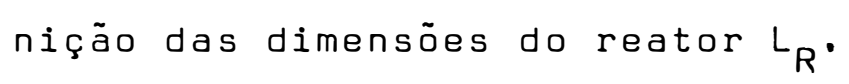

As dimensões de $L_{R}$ dependerão das condições de mistura inerentes ao sistema e do tempo necessärio para que a reação progrida até o nível desejado (Ts). Para reaçöes rápidas, considera-se adequado $T s<10 \mathrm{~s}$, e para reações relativamente lentas, $30 \mathrm{~s}<\mathrm{Ts}<60 \mathrm{~s}$; o termo adequado refere-se, neste caso, à velocidade analitica resultante. Convém lembrar que, quando $T s$ é maior dó que $30 \mathrm{~s}$, existem al ternativas para se aumentar a velocidade analitica, as quais são comentadas na revisão.

Assim, para um sistema FIA no qual a dispersão da zona da amostra é limitada,o comprimento do reator tú bular $\left(X_{L_{R}}\right)$ é função do tempo disponível para desenvolvimento das reações químicas, das intensidades de fluxos envolvi das e do diámetro interno do reator tubular (d), conforme a equação simplificada: 


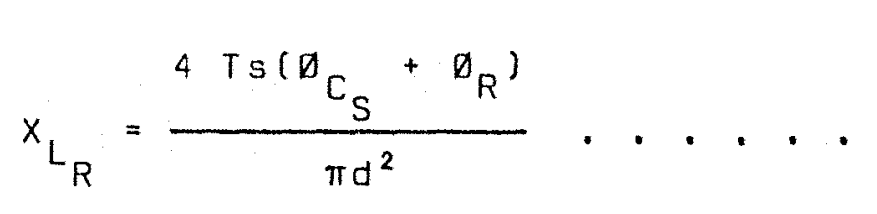

Deve-se enfatizar que o comprimento do reator tubular calculado desta maneira prevé apenas o tempo disponível para o desenvolvimento das reações químicas,mas não diz respeito às condições de mistura. Estas dependem,também, da natureza físico-quínica dos fluidos envolvidos, da razão ${ }^{C_{C_{S}}} / \theta_{R}$, do número de pontos de confluéncia no percurso analítico e de outros fatores secundários tais como temperatura, material da tubulação, geometria dos conectores para adição de fluidos confluentes. De um modo geral,quando as reações envolvidas são rápidas,o comprimento do reator tubular é definido experimentalmente, devendo ser tão pequeno quanto possível,porém suficiente para garantir boas condições de mistura. Estas são avaliadas em função da flutuação do sinal de linha de base do sistema ou da razão sinal/ruido desejada, considerando-se a flutuação do sinal da linha de b́ase e o ruído como sinónimos. Para o caso particular deste trabalho,o com primento do reator tubular foi ajustado experimentalmente de forma a gerar uma flutuação do sinal da linha básica sempre menor do que 0,002 unidades de absorbància*.

Após definição do comprimento do reator tubular,pode-se proceder à determinação do volume de amostra a ser introduzido no sistema, de duas maneiras:

a) injetar volumes crescentes, variando-se a dimensão do loop $L_{S}$, até se atingir a dispersão desejada (RUZICKA e HANSEN, 1981);

b) empregar o sistema FIA na situação de volu

\footnotetext{
*O termo absorbància, nesta tese, é também empregado no sentido de turbidancia.
} 
O sistema FIA na situação de volume infinito de amostra, utilizado no presente trabalho, baseia-se na, substituição da solução carregadora $C_{S}$ por uma solução padrāo da espécie química a ser determinada. Para tanto, pode-se utilizar o sistema de fluxos intermitentes mostrado na Figura 4, o qual possibilita a obtenção de fluxos alternativos entre $C_{S}$ e $S$, as condiçäes hidrodinàmicas sendo mantidas fazendo-se $\emptyset_{C_{S}}=\emptyset_{S}$. Assim, quando o injetor-comutador está na posição especificada na Figura, gera-se o voluma infinito da solução carregadora de amostras (ou da prova ém branco) e. quando na posição alternativa,gera-se um volume infinito da solução padrão desejada, desde que o injetor permaneça na quela posição o tempo suficiente para a obtenção de um sinal estacionário. Uma vez conhecidos o tempo de introdução da amostra no sistema e a intensidade de fluxo desta,calcula-se - volume da amostra necessário para a obtenção do máximo si nal analitico, correspondente a $\mathrm{C}^{0}$.

Considerando-se que este volume pode ser excessivamente grande,prejudicando sensivelmente a velocidade analítica do método e que o sistema.FIA opera sob condi ções transientes, o volume de amostra a ser injetado no sistema deve ser selecionado fazendo-se um compromisso entre a velocidade analitica e a sensibilidade. Quando se requer boa sensibilidade, o volume a ser introduzido no sistema não deve exceder a duas vezes àquele que gera um sinal igual a $50 \% \mathrm{C}^{\circ}$ (RUZICKA E HANSEN, 1981).

A partir da curva de resposta obtida na situa ção de volume infinito (Figura 5), é possivel estimar-se com boa aproximaçio qual volume injetado gerará um sinal corres 


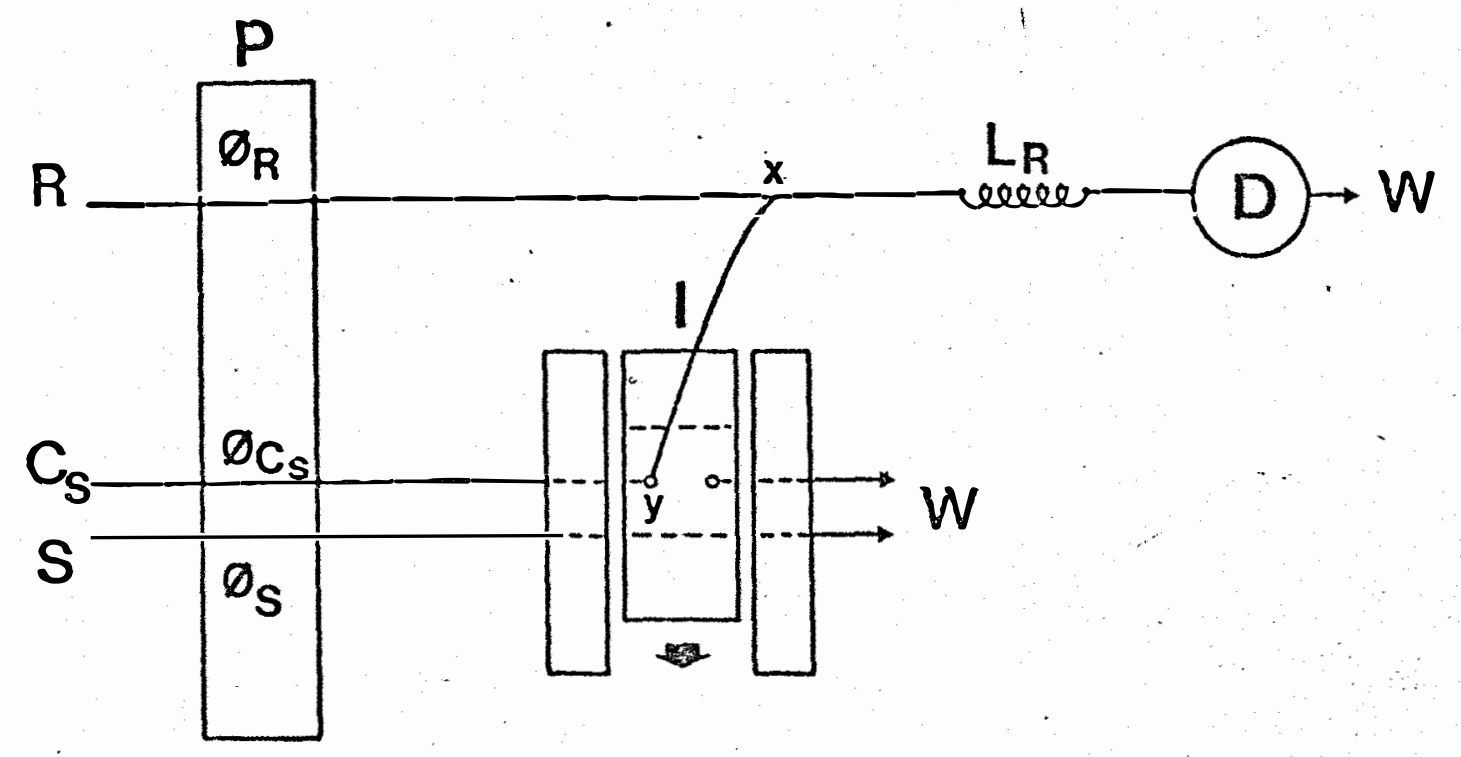

Figura 4 - Sistema de fluxos alternativos amostra/carregador da amostra. Os símbolos são os mesmos que os uti lizados na Figura $3 . \quad \theta_{C_{S}}=\theta_{S} \cdot x y=1 \mathrm{~cm}$ (volume morto $=10 \mu 1$ J. 


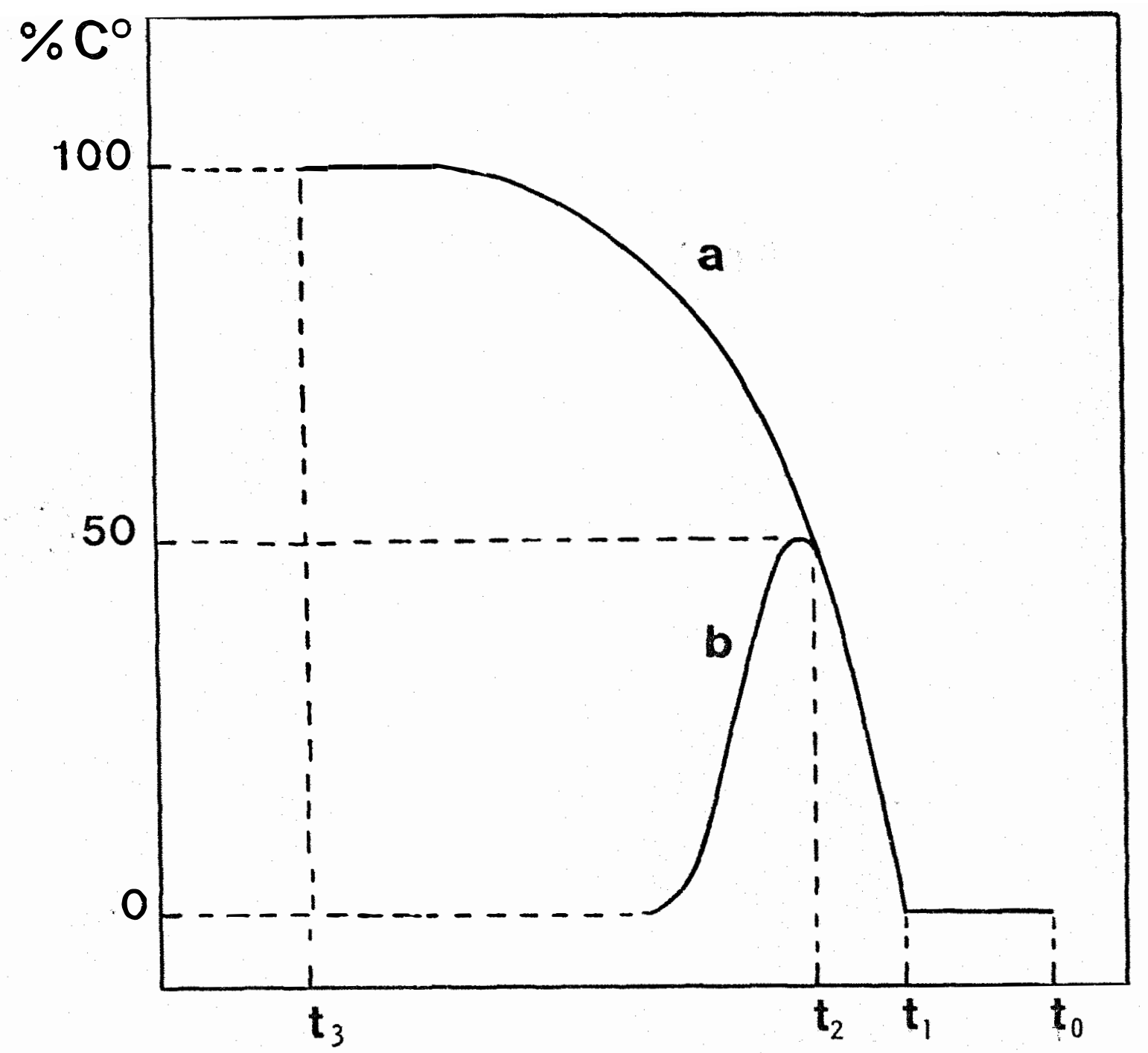

Figura 5 - Curvas registradas para uma solução padrão em regime de volume infinito (a) e volume $V^{1 / 2}(b)$. $t_{0}=$ instante de introdução da amostra no sis tema: $t_{2}=$ instante no qual a frente da zona da amostra inicia seu percurso através do sen sor: $t_{2}=$ instante tomado como referéncia pa $\vec{a}$ ra o cálculo do volume a ser introduzido no sistema de forma a gerar um sinal igual a $50 \% \mathrm{C}^{0}, \mathrm{t}_{3}=$ instante tomado como referència para o cálculo do volume consumido da amostra que gera o máximo sinal analitico $\left(C^{\circ}\right)$. 
pondente a $50 \% \mathrm{C}^{\circ}$.

Assim, o volume de saturação ( $V_{\text {máx }}$ ) correspon dente a $C^{0}$ e o volume $\left(V_{1 / 2}\right)$ referente a $50 \% C^{0}$ poderão ser calculados a partir das seguintes expressões:

$$
\begin{aligned}
& v_{\text {máx }}=\left(\nabla_{S}+\theta_{R}\right)\left(t_{3}-t_{1}\right) \cdot \cdots \cdot \cdot \cdot \cdot \\
& v_{1 / 2}=\left(\theta_{S}+\theta_{R}\right)\left(t_{2}-t_{1}\right) \cdot \cdots \cdot \cdot \cdot \cdot
\end{aligned}
$$

Apesar de o procedimento de volumes injetados crescentes ser extremamente simples e permitir, para cada vo lume injetado, uma avaliação da velocidade analitica, a situação de volume infinito apresenta vantagens:

a) flutuações do sinal em torno de $A^{0}$ \{sinal referente a $C^{0}$ ) fornecem indicação das con dições de mistura do sistema;

b) a partir da obtenção do sinal $A^{0}$ e, determinando-se posteriormente a absorbancia re lativa à amostra injetada $S$,pode-se quanti ficar a dispersão da zona da amostra (RUZICKA $P$ HANSEN, 1981);

c) a partir da obtenção do sinal referente a $C^{0}$, pode-se reavaliar a dimensão do reator tubular em função da tendência das reações químicas envolvidas.

Neste último caso, após a obtenção do sinal estacionário,desliga-se a bomba peristáltica,podendo de um modo geral ocorrer trés fenômenos (ou combinações destes ): aumento gradual de $A^{0}$, manutenção do valor $A^{0}$ e diminuição de 
$A^{0}$ (Figura 6). Se as reações químicas se completaram durante o tempo Ts e um composto estável foi produzido,observa-se a constância de $A^{0}$ após o desligamento da unidade propulsora de fluidos. Se se observa um aumento de $A^{0}$ tendendo assintoticamente a um valor máximo ( $A_{\text {máx }}^{0}$ ), pode-se inferir que Ts não foi suficiente para a completação da reaçãos se ocorre formação de um produto estável,pode-se calcular a por centagem de completação das reações envolvidas (\%R), como:

$$
\% R=\frac{A_{0}}{A_{\text {mäx }}^{0}}, 100, . . . \cdot .
$$

Por outro lado, se ocorre diminuição do sinal após o desligamento da bomba peristáltica, ou seja, $A^{0}$ tende a $A^{0}$ min' a decomposição de um produto instável pode ser inferida. Evidentemente, as considerações anteriores são mais procedentes se perfeita linearidade da curva de resposta do sistema FIA é assumida.

A partir do exposto, torna-se claro o potencial deste procedimento de volume infinito em estudos relati vos à cinética química. Como aspectos cinéticos são relevan tes no estudo da precipitação de íns sulfato por íons bário, tal procedimento foi adotado neste trabalino.

\subsection{Protōtipo do sistema}

De acordo com as considerações apresentadas nos ítens 4.2.1. e 4.2.2.,projetou-se um protótipo cujo diagrama de fluxos é mostrado na figura 7. o volume injetado de amostra $(600 \mu l)$ e o comprimento do reator tubular $(100 \mathrm{~cm})$ foram definidos usando-se: 
.40.

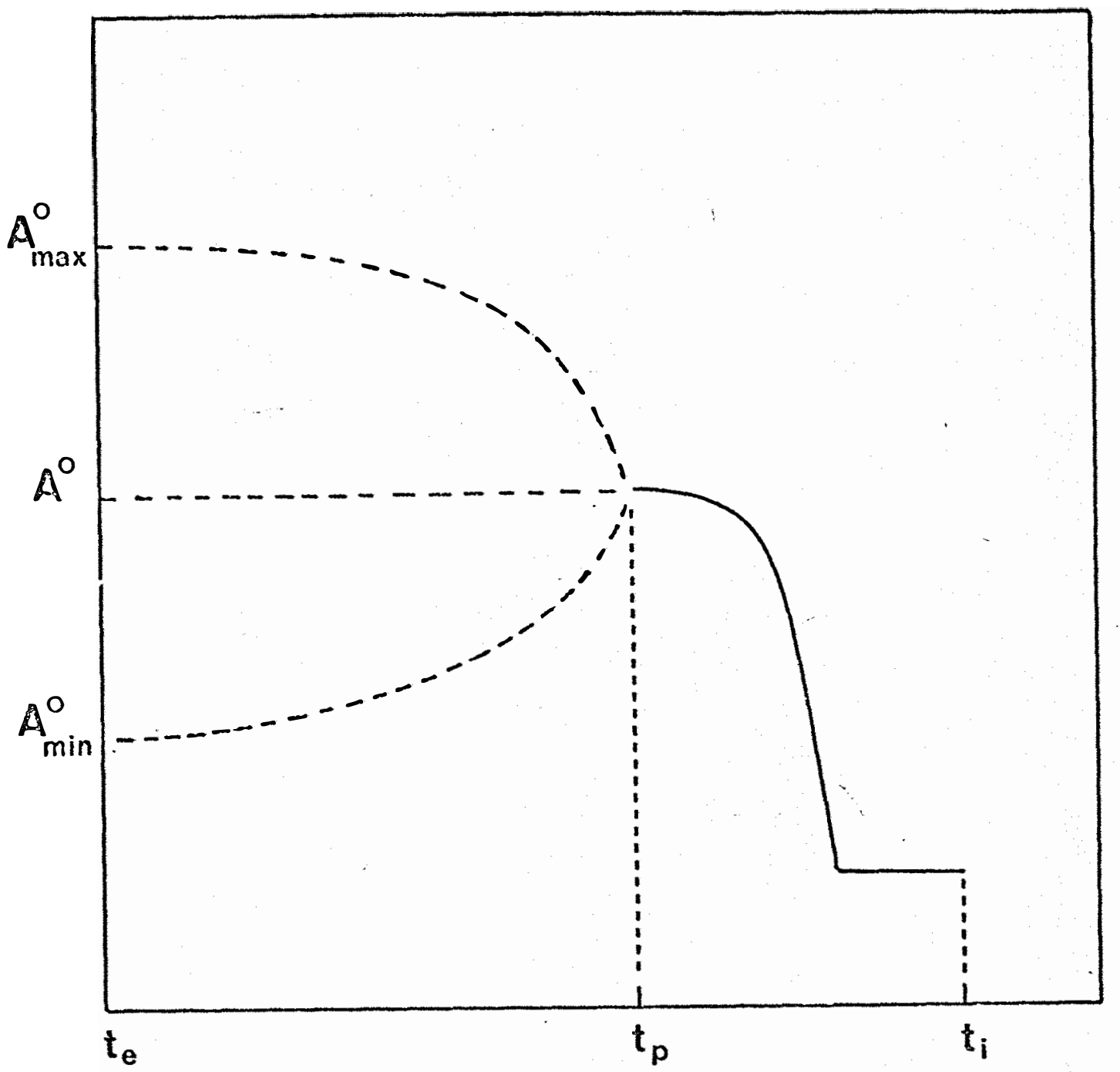

Figura 6 - Avaliação de reações empregando sistemas FIA.

$$
\begin{aligned}
& t_{i}=\text { instante de introdução da amostra; } \\
& t_{p}=\text { instante referente à parada dos fluxos; } \\
& t_{e}=\text { instante no qual é atingido o equilí- } \\
& \text { brio químico. }
\end{aligned}
$$




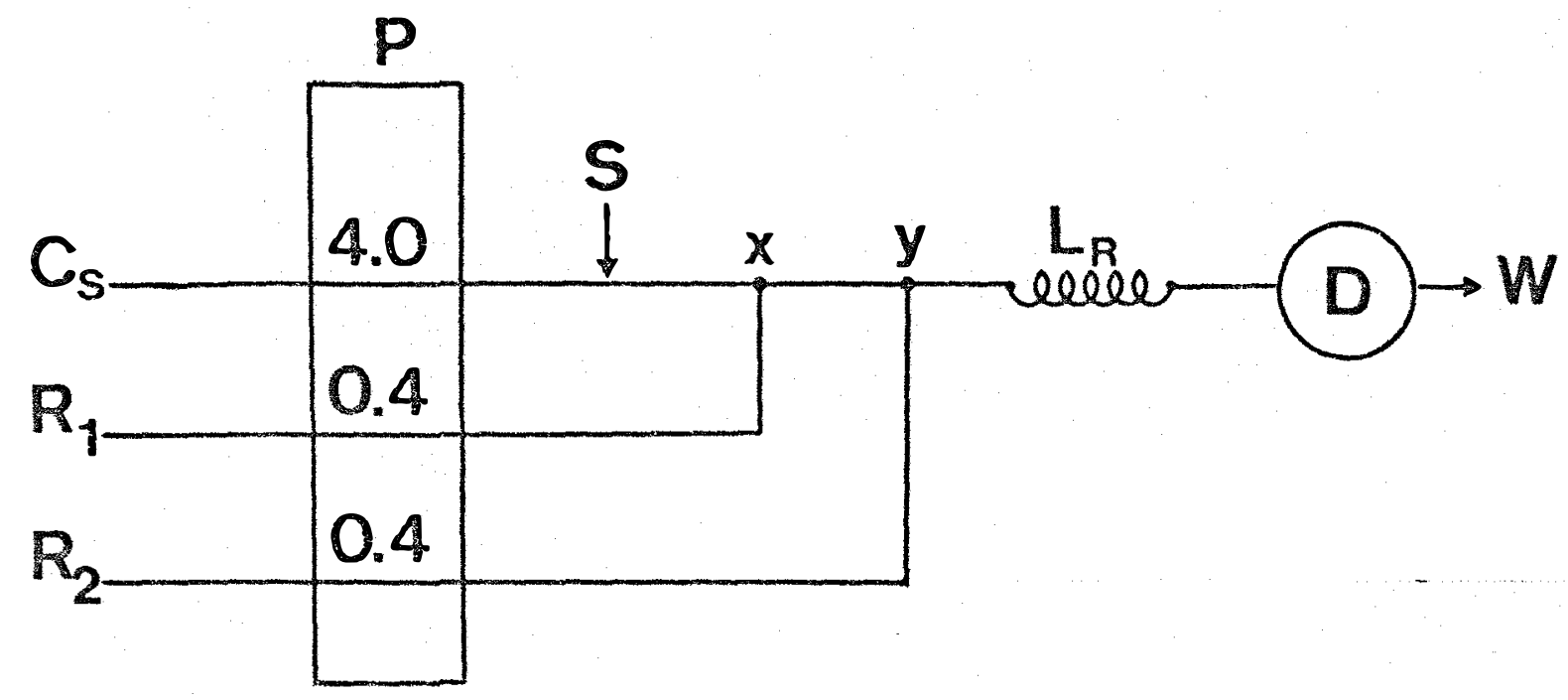

Figura 7 - Diagrama de fluxos do protōtipo.

$P=$ bomba peristáltica indicando as intensidades de fluxo em ml.min ${ }^{-1}$;

$S=$ amostra;

$\mathrm{C}_{\mathrm{S}}=$ solução carregadora de amostras;

$R_{1}=$ solução opcional;

$R_{2}=$ solução de cloreto de bário em álcool polivi nílico;

$L_{R}=$ bobina de homogeneização e reação;

$x$ e $y=$ pontos de confluência;

$D=$ espectrofotómetro a $410 \mathrm{~nm}$;

$W=$ descarte. 
$C_{S}=a ̈ g u a$, com vazão de $4 \mathrm{ml} \cdot \mathrm{min}^{-1}$,

$R_{1}=$ solução $0,1 M$ de àcido clorídrico,escoan-

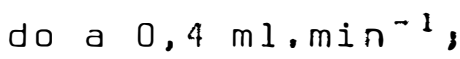

$R_{2}=$ solução de BaCl $2 \cdot 2 \mathrm{H}_{2} \mathrm{O}$ a $5 \% \mathrm{~m} / \mathrm{v}$ em PVA a $0,05 \% \mathrm{~m} / \mathrm{v}$, bombeada a $0,4 \mathrm{ml}^{-\mathrm{min}^{-1}}$.

A composição de $R_{2}$ foi inicialmente escolhida em função dos resultados obtidos por KRUG et alii (1977). Para a definição do volume injetado de amostra e do comprimento da bobina $L_{R}$, foram utilizadas soluções padrão de sulfato na faixa de 0 a $60 \mathrm{mg} \cdot \mathrm{l}^{-1}$. As linhas de transmissão entre o injetor-comutador e $x$ e entre $x$ e $y$ foram de 1 e $10 \mathrm{~cm}$, respectivamente. A linha de transmissão de $l \mathrm{~cm}$ foi escolhi da tãu pequena quanto possivel,para se evitar uma dispersão maior da zona da amostra e a de $10 \mathrm{~cm}$, para garantir uma mistura adequada entre a solução opcional ( $\left.R_{1}\right)$ e a zona da amostra. O comprimento de onda no espectrofotómetro foi fixa do em $410 \mathrm{~nm}$.

\subsection{Estudo das principais variāveis}

Com auxilio do sistema de fluxos mostrado na Figura 7, cujos parámetros são discutidos também em 4.3. fo ram avaliados os efeitos da acidez, da concentração do rea gente $R_{2}$ e do teor de sulfato na amostra. Em todas as situa ções, usou-se ägua como solução carregadora. Foram sempre utilizadas soluções padrão na faixa de 0 a $100 \mathrm{mg} \mathrm{SO} \mathbf{4}^{-} \cdot \mathrm{l}^{-1} \mathrm{pre}$ paradas em água e injetadas em triplicata. Para cada situação,foi feito um estudo da cinética de nucleação,operando-se o sistema em regime de volume infinito e interrompendo-se o fluxo após a obtenção do sinal estacionário. 
4.4.1. Efeito da acidez e de diferentes àcidos

Foram utilizadas em Rl (Figura 7) soluções de ácidos nitrico, clorfdrico e perclórico,na faixa de $0, l$ a 5.0 M, de modo a prover condições de acidez na faixa de 0,0l a $0.5 \mathrm{M}$ no reator $L_{R}$. Neste estudo, foi utilizada uma solu ção de cloreto de bário dihidrato a $5 \% \mathrm{~m} / \mathrm{V}$ em $P V A$ a $0,05 \% \mathrm{~m} / \mathrm{V}$. Em regime de volume infinito,foi utilizada solução padrão de $60 \mathrm{mg} \mathrm{SO} 4^{2-} \cdot 1^{-1}$.

E importante ressaltar que algumas das conżntrações de àcido utilizadas correspondem à acidez das amostras de águas preservadas ( 1 a $4 \mathrm{ml} \mathrm{HNO}_{3}$ ou $\mathrm{HCl}$ concentrados por litro de amostra), assim como àquela dos digeridos de plantas $\left(0,25 \mathrm{M} \mathrm{HClO}_{4}\right.$, conforme 3.3 .1.)$.

4.4.2. Efeito da concentração de bārío

Foram utilizadas em $R_{1}$ soluções de ácidos ní trico, clorídrico e perclórico 0,1 e $2,5 \mathrm{M}$ e, em $R_{2}$, soluções de cloreto de bário dihidrato na faixa de $5 \%$ a $40 \% \mathrm{~m} / \mathrm{V}$ em PVA a $0,05 \% \mathrm{~m} / \mathrm{v}$, de forma a prover concentrações de bärio na fai xa de 0,02 a $0,16 \mathrm{M}$ no reator $L_{R}$. Em regime de volume infinito, foi também empregada solução padrão de $60 \mathrm{mg} \mathrm{SO}_{4}^{2-} \mathbf{I}^{-1}$.

\subsubsection{Efeito do teor de sulfato}

Foram utilizadas em $R_{1}$ soluções de ácido peㅗ clórico 0,1 a $2.5 \mathrm{M}$ e, em $R_{2}$, soluções de cloreto de bário dihidrato a $5 \%$ e $20 \% \mathrm{~m} / \mathrm{V}$ em PVA a $0,05 \% \mathrm{~m} / \mathrm{V}$.' Em regime de vo 
lume infinito, foram utilizadas soluções padrão de sulfato na faixa de 10 a $60 \mathrm{mg} \cdot \mathrm{l}^{-1}$.

\subsubsection{Efeito da adição de sulfato}

Em função dos resultados obtidos nos experimentos anteriores, formulou-se a hipótese de que uma adição de sulfato à zona da amostra implicaria em melhores condições analíticas para menores teores de sulfato. o efeito desta adição foi estudado utilizando-se em $R_{1}$ soluções de sulfato na faixa de 0 a $300 \mathrm{mg}^{-1}$, preparadas em ácido perclórico 0,1 e $2,5 \mathrm{M}$. Uma vez que a razão $\nabla_{R_{1}} / \theta_{C_{S}}$ (Figura 7 ) é igual a l/lo,uma adição de $100 \mathrm{mg} \cdot \mathrm{l}^{-1}$ correspoñderá a uma concentração efetiva na zona da amostra de aproximadamente $10 \mathrm{mg} \cdot \mathrm{l}^{-1}$ acima do teor da amostra injetada, após o ponto $x$. Para cada situação de acidez, foram empregadas em $R_{2}$ soluções de cloreto de bärio dihidrato a $5 \%$ e $20 \% \mathrm{~m} / \mathrm{v}$ em PVA a $0,05 \% \mathrm{~m} / \mathrm{v}$.

\subsubsection{Efeito da temperatura}

Tem sido recomendada temperatura ambiental pa ra a determinação turbidimétrica de sulfato (MARCZENKO, 1976). Nos laboratórios do CENA, a temperatura varia, em geral, entre 22 e $28^{\circ} \mathrm{C}$, e a temperatura das amostras pode variar de 10 a $25^{\circ} \mathrm{C}$. Visando estudar o efeito da variação da temperatü ra, foram conduzidos dois experimentos:

a) a bobina de reação $L_{R}$ foi mergulhada em banho de água, variando-se a temperatura des te de 15 a $35^{\circ} \mathrm{C}$; 
b) o sistema todo foi mantido à temperatura ambiental $\left(24^{\circ} \mathrm{C}\right)$; variando-se a temperatura das soluções injetadas de 7 a $40^{\circ} \mathrm{C}$.

Em ambas as situações, foram utilizadas em $R_{1}$ soluções de ácido perclórico 0,1 e $2,5 \mathrm{M}$ e, em $R_{2}$, soluções de cloreto de bário dihidrato a $5 \%$ e $20 \% \mathrm{~m} / \mathrm{V}$ em PVA $0.05 \% \mathrm{~m} / \mathrm{v}$. As soluções utilizadas cobriram a faixa de concentração de 20 a $100 \mathrm{mg} \mathrm{SO} 4^{--} \cdot \mathrm{I}^{-1}$.

\subsection{Anälises de rotina utilizando o protótipo}

Ém função dos resultados obtidos nos experimentos referentes ao item 4.4. testou-se o sistema da Figura 7 para análises de rotina de águas e digeridos vegetais. o fluido carregador de amostras, $C_{S}$ ' era água (para análises de águas) ou solução de ácido perclórico a 0,25 M (para análise de plantas), a solução $R_{1}$ era $100 \mathrm{mg} \mathrm{SO} 4^{-} \cdot 1^{-1}$ em HCl a $0,5 \mathrm{M}$

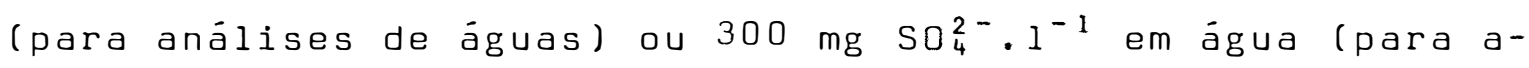
nálise de plantas) e a solução $R_{2}$ era de cloreto de bário dihidrato a $20 \% \mathrm{~m} / \mathrm{v}$ em PVA a $0,05 \% \mathrm{~m} / \mathrm{v}$, em ambos os caos.

Para cada situação, forám observadas importan tes características tais como estabilidade da linha de base, altura do sinal registrado, reprodutibilidade da medida, entre outras. 


\subsection{0 sistema proposto}

\subsubsection{Considerações preliminares}

Em função dos resultados obtidos nos experimentos conduzidos conforme 4.5. tornou-se necessário repro Jetar o sistema FIA mostrado na figura 7 , uma vez que, em re gime de operação contínua,observou-se invariavelmente uma adsorção de sulfato de bário no percurso analítico do sistema. Assim sendo, vários procedimentos foram investigados pa ra eliminar esse problema.

Inicialmente, as adições de sulfato e de bário via $R_{1}$ e $R_{2}$ (Figura 7 ) foram substituídas por adições pulsa das,utilizando-se um sistema FIA com zonas coalescentes em confluència (Figura 8 a).

Posteriormente, testou-se um sistema com adição sequencial de uma solução de EDTA alcalino injetada simultaneamente com a amostra na mesma solução carregadora (F gura $8 b)$.

o terceiro sistema testado baseou-se na utili zação de fluxos alternativos intermitentes de soluções de EDTA alcalino e de cloreto de bário, de modo a permitir uma acidez adequada durante a formação da suspensão de sulfato de bário e suficiente alcalinidade durante o processo de lavagem do percurso analitico com EDTA (Figura 9 ).

\subsubsection{Operação do sistema com fluxos alternativos}

O diagrama de fluxos mostrado na Figura 9 indica o injetor-comutador (I) na posição de amostragem. A a- 

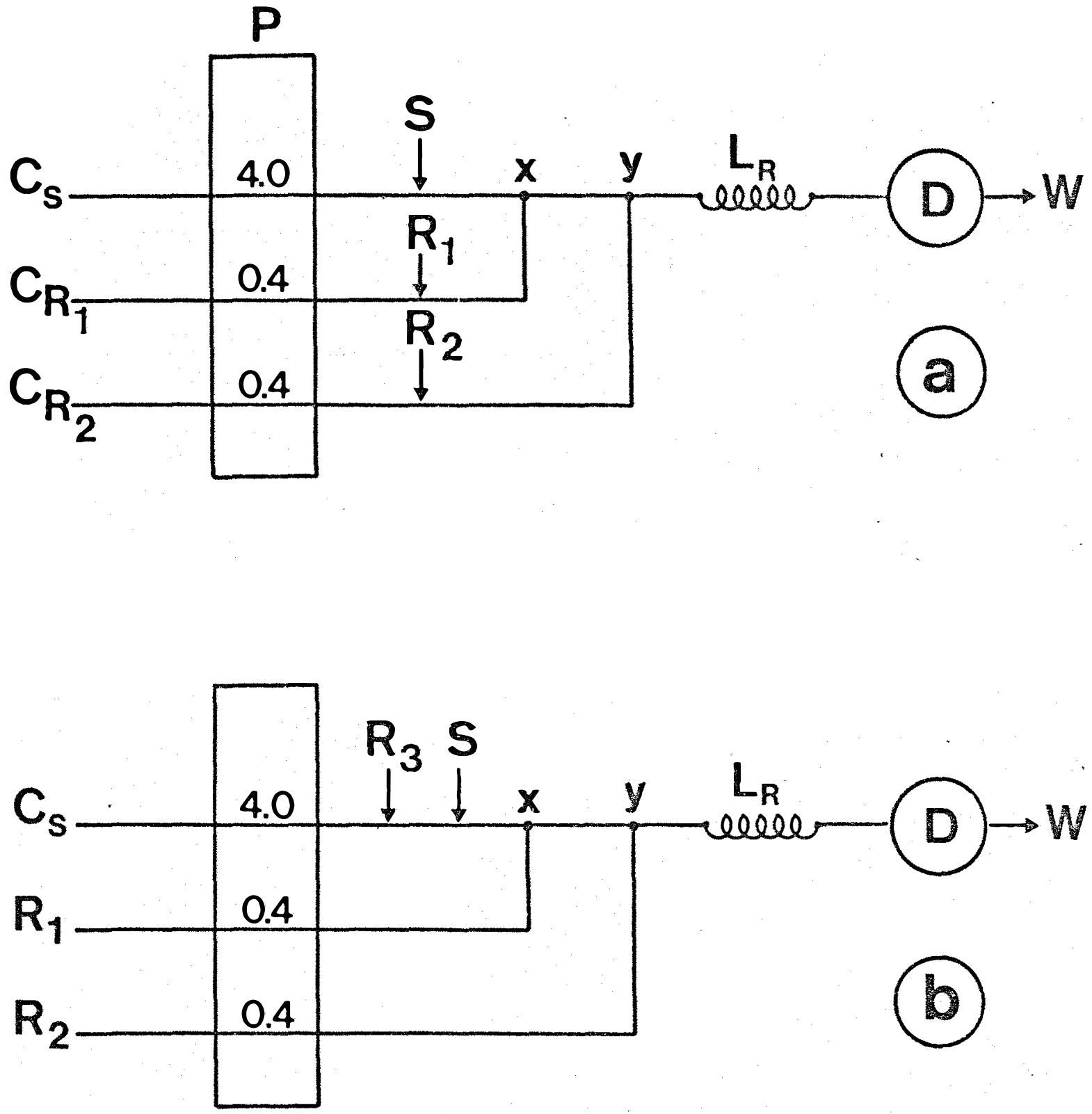

Figura 8 - Diagramas de sistemas de injeção em fluxo: (a) com zonas coalescentes em confluêncie; $C_{S}=$ água; $C_{R_{1}}=$ $\mathrm{HCl} 0,1 \mathrm{~N} ; C_{R_{2}}=$ solução de $\mathrm{PVA} \underline{0}, 05 \% \mathrm{~m} / \mathrm{V} ; \mathrm{S}=\mathrm{amos}$ $\operatorname{tra}(600 \mu \mathrm{l}) ; \mathrm{R}_{1}=100 \mathrm{mg} \mathrm{SO}{ }_{4}^{2} . \mathrm{I}^{-1}$ em HCl $0,1 \mathrm{~N}(50 \mu \bar{I})$; $\mathrm{R}_{2}=\mathrm{solução} \mathrm{de} \mathrm{BaCl}{ }_{2} \cdot{ }_{2} \mathrm{H}_{2} \mathrm{O} 5 \% \mathrm{~m} / \mathrm{v}$ em $\mathrm{PVA} 0,05 \% \mathrm{~m} / \mathrm{v}$ $(50 \mu 1) ; S x=10 \mathrm{~cm} ; R_{1} x=R_{2} x=x y=1 \mathrm{~cm} ; L_{R}=100 \mathrm{~cm}$; $D=410 \mathrm{~nm}$; $W=$ descarte. (b) com zonas sequênciais. $C_{S}, R_{1}, R_{2}, S, L_{R}, D$ e $W$ (idem (a); $R_{3}=$ solução de EDTA $5 \% \mathrm{~m} / \mathrm{v}$ em NaOH $0,05 \mathrm{~N}(25 \mu l) ; R_{3} S=10 \mathrm{~cm}$ (Iinha de transmissão entre os pontos de injeção de $R_{3}$ e $S$ ); $S x=1 \mathrm{~cm} ; x y=10 \mathrm{~cm}$. 


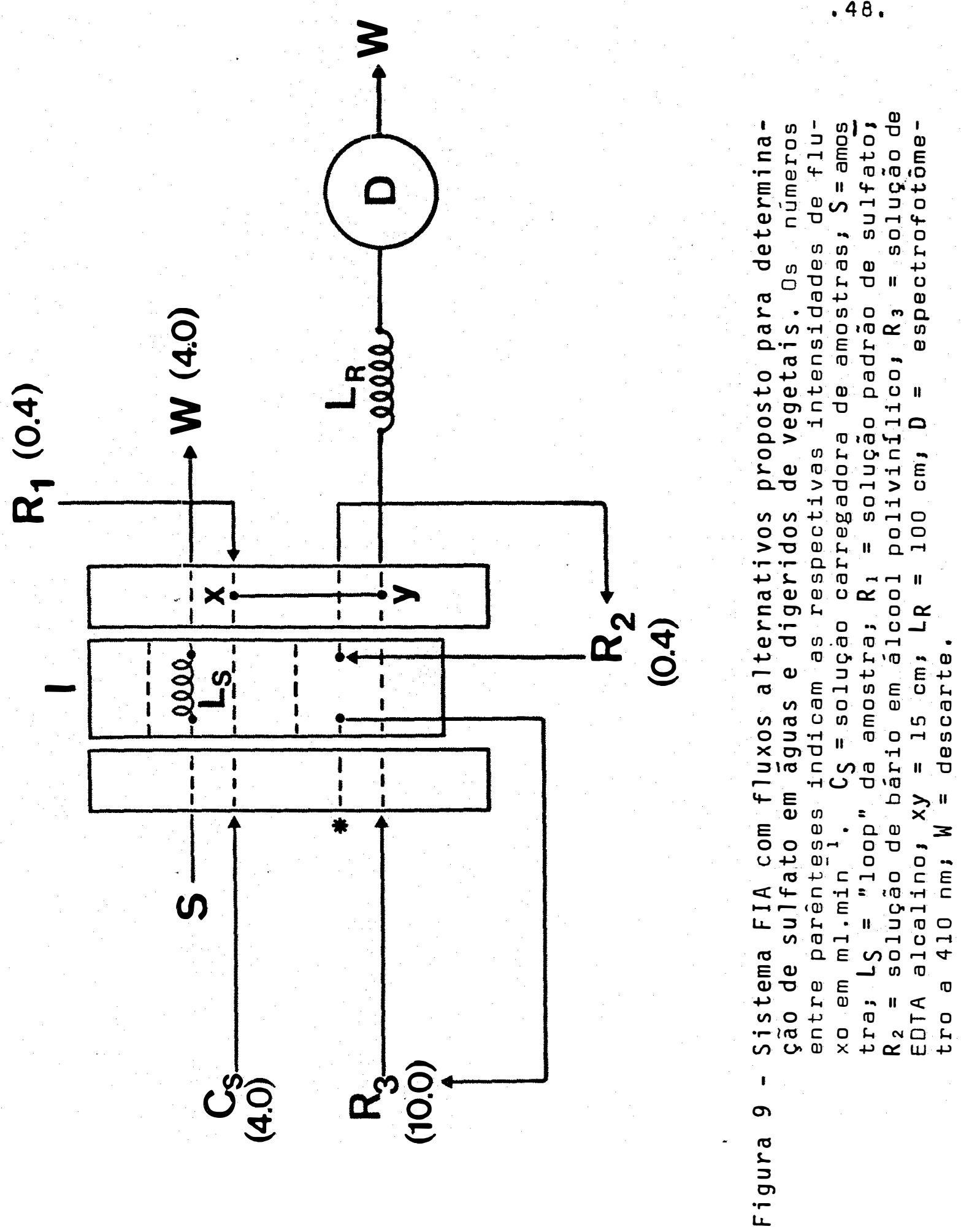




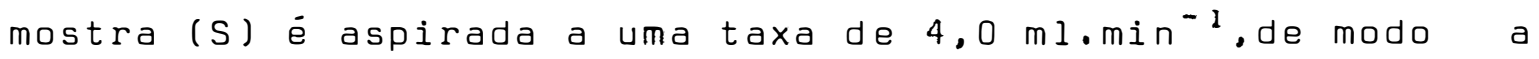
preencher o 'loop' $L_{S}(600 \mu l)$ em cerca de $10 \mathrm{~s}$, seu excesso sendo descartado $(W)$. Ao mesmo tempo, a solução de cloreto de bário $\left(R_{2}\right)$ permanece recirculando em sistema fechado, enquanto a solução de EDTA alcalino $\left(R_{3}\right)$,bombeada em alta velo cidade, lava o percurso analítico, a partir do ponto de con fluência $(y)$. Quando o injetor é comutado para a posição de injeção, o volume de amostra selecionado é introduzido na so lução carregadora de amostras $\left(C_{S}\right)$. Simultaneamente,o reagente $R_{3}$ passa a recircular, ao passo que o reagente cloreto de bärio $\left(R_{2}\right)$ é dirigido ao percurso analítico de forma a interagir com a zona da amostra, tão logo ela inicie sua pas sagem através de $y$. A perfeita interação entre a zona da amostra e a solução de cloreto de bário é garantida pela esco Iha adequada da linha de transmissão xy $(15 \mathrm{~cm})$, esta escolha sendo feita em função da razão de intensidades de fluxo $\left(\emptyset_{C}+\emptyset_{R_{1}}\right) / \emptyset_{R_{2}}$. A adição de uma solução de sulfato à zona da amostra via ponto de confluéncia $x$ é feita de modo a permitir melhores condições de nucleação de sulfato de bário, a reação de precipitação ocorrendo no reator $L_{R}(100 \mathrm{~cm})$. Quan do a zona processada de amostra passa pela unidade de detecção ( 0 ), a turbidez formada é medida a $410 \mathrm{~nm}$ e registrada. o produto da reação vai para descarte (W) e quando o má ximo sinal foi obtido, o injetor é comutado novamente para a posição indicada na figura 9 , iniciando-se um novo ciclo.

\subsubsection{Efeito do fluxo intermitente de EDTA}

O efeito da concentração de EDTA no reagente $R_{3}$ foi inicialmente investigado com vistas à determinação de sulfato em digeridos de vegetais, porque, nos sistemas mais 
simples (Figura 7), a adsorção de sulfato de bário no percurso analitico era mais pronunciada, comparativamente ao sistema para determinação em águas. Assim, soluções padrão de sulfato, na faixa de 0 a $100 \mathrm{mg} \cdot \mathrm{l}^{-1}$, foram preparadas em ácido perclórico 0,25 M e injetadas em triplicata na solução carregadora constituída pelo mesmo ácido. As soluções $R_{1}$ e $R_{2}$ foram, respectivamente, água e solução de cloreto de bário dihidrato a $5 \% \mathrm{~m} / \mathrm{V}$ em PVA $0,05 \% \mathrm{~m} / \mathrm{V}$. As soluções de EDTA, bombeadas a $10 \mathrm{ml} \cdot \mathrm{min}^{-1}$, foram preparadas em hidróxido de só dio 0,2 M, concentração esta suficiente para neutralizar o ácido perclórico e garantir um $\mathrm{pH}$ alcalino no reator $\mathrm{L}_{\mathrm{R}}$ durante o processo de lavagein. Foram testadas concentrações de EDTA na faixa de 0,03 a $3,0 \% \mathrm{~m} / \mathrm{v}$.

Em função dos resultados obtidos, estudou-se a influência da intensidade de fluxo de $R_{3}$ no processo de la vagem, utilizando-se injeções de uma solução padrão $100 \mathrm{mg} \mathrm{SO} 4^{-} \cdot 1^{-1}$. A concentração de EDTA e a alcalinidade do reagente $R_{3}$ foram mudadas para cada intensidade de fluxo investigada, de modo a manter as mesmas concentrações de EDTA e de hidróxido de sódio no reator tubular, independentemente das variações na intensidade de fluxo de $R_{3}$. Assim, quando - fluxo deste reagente foi de $10,0,5,0$ e $2,5 \mathrm{ml}^{-\mathrm{min}^{-1}}$, as con centrações de hidróxido de sódio foram de $0,2,0,4$ e 0,8 M e as concentrações de EDTA, 0,3, 0,6 e $1,2 \% \mathrm{~m} / \mathrm{v}$, respectivamente. A situação em ausência de lavagem $\left(\varpi_{R_{3}}=0 \mathrm{ml} \mathrm{min}^{-1}\right)$ foi também investigada.

Uma vez definidas as melhores condições de la vagem, a água empregada em $R_{1}$ foi substituída por uma solu ção $100 \mathrm{mg} \mathrm{SO} \mathbf{2}^{-} \cdot i^{-1}$ e o sistema reavaliado, injetando-se du rante duas horas soluções padrão de sulfato na faixa de 20 a $100 \mathrm{mg} \cdot \mathrm{I}^{-1}$. 


\subsubsection{Efeito da acidez das amostras}

Este experimento foi realizado face à varia çao na acidez de digeridos de vegetais, os quais, se preparados conforme descrito em 3.3.1., apresentam acidez ao re dor de $0,25 \mathrm{M}$, com desvios máximos de $\pm 0,10 \mathrm{M}$ (RE/s et ali $\bar{i}$, 1979).

Desta forma, soluções padrão de sulfato na faí $x a$ de 20 a $100 \mathrm{mg} \mathrm{SO} 4^{-} \cdot 1^{-1}$ foram preparadas em ácido perclórico na faixa de 0,15 a 0,35 M e injetadas em triplicata no sistema da Figura 9, fazendo-se:

$c_{S}$ - solução de ácido perclórico a $0,25 \dot{M}$; $R_{1}$ - soluções padrão 300 e $100 \mathrm{mg} \mathrm{SO} 4^{-} \cdot 1^{-1}$ quando foram empregadas em $R_{2}$ - soluções de cloreto de bário dihidrato a 5 e $20 \% \mathrm{~m} / \mathrm{V}$ em PVA $0,05 \% \mathrm{~m} / \mathrm{v}$, respecti vamente.

$R_{3}$ - solução de EDTA $0,3 \% \mathrm{~m} / \mathrm{v}$ em hidróxido de sódio 0,2 M.

\subsubsection{Efeito de Tons interferentes}

Definidas as melhores condições para a deter minação de sulfato em águas e digerilos de vegetais, o efeito de ions interferentes foi estudads empregando-se o siste ma FIA da Figura 9 , no qual soluções padrão de sulfato $20, \overline{0}$ e $100 \mathrm{mg} \cdot \mathrm{l}^{-1}$ eram injetadas em triplicata em auséncia ou pre

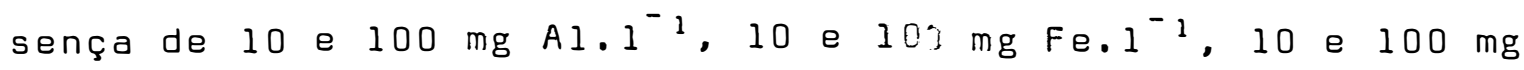

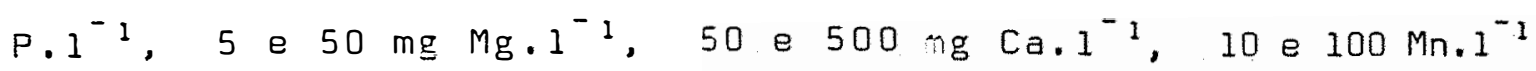

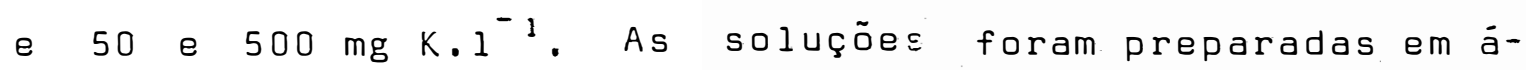
cido nitrico $0,1 \% v / v$ e em ácics perclórico 0,25 M,quan do as condições do sistema FIA foram fixadas para 
análise de águas e de digeridos de vegetais, respectivamente:

- Agua: $\quad C_{S}$ - ácido nitrico $0,1 \% v / v$ :

$$
\begin{aligned}
& \mathrm{R}_{1}-100 \mathrm{mg} \mathrm{SO} \frac{2}{4}^{-} \cdot \mathrm{1}^{-1} \text { em HCl } 0,5 \mathrm{M} \text {; } \\
& R_{2} \text { - solução de cloreto de bärio a } 5 \% \mathrm{~m} / \mathrm{V} \text { em PVA } \\
& \text { a } 0,05 \% \mathrm{~m} / \mathrm{v} \text {; } \\
& R_{3} \text { - solução de EDTA } 0,3 \% \mathrm{~m} / \mathrm{V} \text { em NaOH } 0,07 \mathrm{M} \text {. }
\end{aligned}
$$

- Plantas: $C_{S}$ - solução de ácido perclórico 0,25 M:

$R_{I}-100 \mathrm{mg} \mathrm{SO} 4^{-} \cdot 1^{-1}$ em ägua ;

$R_{2}$ - solução de cloreto de bário a $20 \% \mathrm{~m} / \mathrm{V}$; em PVA a $0,05 \% \mathrm{~m} / \mathrm{v}$ :

$R_{3}$ - solução de EDTA $0,3 \% \mathrm{~m} / \mathrm{V}$ em $\mathrm{NaOH} 0,2 \mathrm{M}$.

A interferência de carbonato/bicarbonato foi testada injetando-se solução padrão de carbonato $1000 \mathrm{mg} \cdot \mathrm{l}^{-1}$ e fazendo-se:

$$
\begin{aligned}
& C_{s} \text { - água; } \\
& R_{1} \text { - solução de ácido clorídrico na faixa de } \\
& \quad 0,1 \text { a } 1,0 \mathrm{M} \text {; } \\
& R_{2} \text { e } R_{3} \text { - conforme estabelecido para análi- }
\end{aligned}
$$
ses de äguas.

4.6.6. Anālises de āguas e de digeridos de vegetais

$$
\text { Empregando-se o sistema FIA da Figura 9,solu- }
$$
ções padrão de sulfato na faixa de 0,0 a $25,0 \mathrm{mg}^{-1}$ foram utilizadas para análises de águas, cujas amostras acham-se descritas em 3.3.2. Todas as medidas foram feitas em tripli cata. As composições de $R_{1}, R_{2}$ e $R_{3}$ são especificadas em 4.6.5. (sistema para análise de águas), água sendo empregada como fluido carregador de amostras $C_{S}$. Utilizando-se as mesmas soluções padrão, as amostras foram analisadas por tur- 
bidimetria conforme procedimento recomendado por APHA (1975) e os resultados foram comparados com aqueles obtidos no sistema FIA.

Analogamente, soluções padrão de sulfato na fäixa de 0,0 a $100 \mathrm{mg}^{-1} \mathrm{1}^{-1}$, preparadas em ácido perclórico $0.25 \mathrm{M}$, foram utilizadas para análises de digeridos de vege tais, obtidos conforme descrito em 3.3.1. 0 sistema FIA foi operado com soluções apresentando a mesma composição que aquelas descritas em 4.6.5. A exatidão do método proposto foi avaliada através da análise das mesmas amostras por gravime t.ria, segundo procedimento recomendado pela AOAC (1980).

Uma vez confirmadas as boas características de exatidão dos métodos propostos, foram realizados testes de estabilidade, analisando-se amostras reais de águas e de digeridos de vegetais durante oito horas ininterruptas. Especial atenção foi dada à possibilidade de variações nas curvas de padronização e na linhia básica. 
A ciência é feita de fatos, como a casa de pedras. Mas uma cole ção de fatos não é mais ciência do que um monte de pedras $\bar{e}$ uma casa.

POINCARE

5.1. Dimensionamento do protótipo

De acordo com os procedimentos descritos em 4.2.1. e 4.2.2. o protótipo do sistema foi dimensionado con forme especificado em 4.3. (Figura 7). Assim, com as vazões das soluções $R_{1}$ e $R_{2}$ mantidas em $0.4 \mathrm{ml} \cdot \mathrm{min}^{-1}$, e com a solu ção carregadora de amosiras $C_{S}$ escoando a $4,0 \mathrm{mI} \cdot \mathrm{min}^{-1}$, foi possível simular as condições desejadas de acidez e de super saturação na bobina de reação $L_{R}$. Como as razões $\emptyset_{R} / \emptyset_{C_{S}}$ e $\theta_{R_{2}} / \theta_{C_{S}}$ são iguais a l/l0, as concentrações das espécies ${ }$ quí mícas ${ }^{S}$ de $R_{1}$ e $R_{2}$ na bobina de reação serão aproximadamente dez vezes menores do que as suas concentrações nas respectivas soluções. 
Com uma bobina de reação $L_{R}$ de comprimento igual a $100 \mathrm{~cm}$, boa homogeneização entre as soluções foi con seguida, uma vez que, em todas as situações investigadas, a precisão das medidas não foi limitante. Ainda,flutuações pe quenas na linha de base, em geral inferiores a 0,002 unidades de absorbãncia, confirmaram as boas condições de mistura no sistema.

Nesta situação, um tempo de residéncia de $9 \mathrm{~s}$ no reator $L_{R}$ pode ser estimado. Injetando-se $600 \mu l$ de amos tra,um fator de dispersão igual a 0,78 foi determinado, o qual indica que a dispersãa do sistema é limitacia,compatível com o método a ser desenvolvido no qual a sensibilidade analítica é relevante. A baixa velocidade analitica no protóti po (cerca de 70 determinações por hora)'é devida ao excessivo tempo de limpeza no percurso analítico em ausência de uma solução específica para tal fim.

\subsection{Efeito da acidez e de diferentes àcidos}

Os resultados dos experimentos conduzidos con forme 4.4.1 são apresentados através das Figuras 10, 11 e 12, respectivamente para os ácidos perclórico, clorídrico e nítrico.

Analisando-se apenas as curvas de isoconcentração de sulfato, observa-se que ocorre uma diminuição na tur bidez à medida que a acidez aumenta, efeito este mais pronun ciado sob condições mais ácidas e de menores concentrações de sulfato. Esta diminuição na turbidez formada pode ser devida à combinação de dois efeitos:

a) aumento da solubilidade do sulfato de bá- 

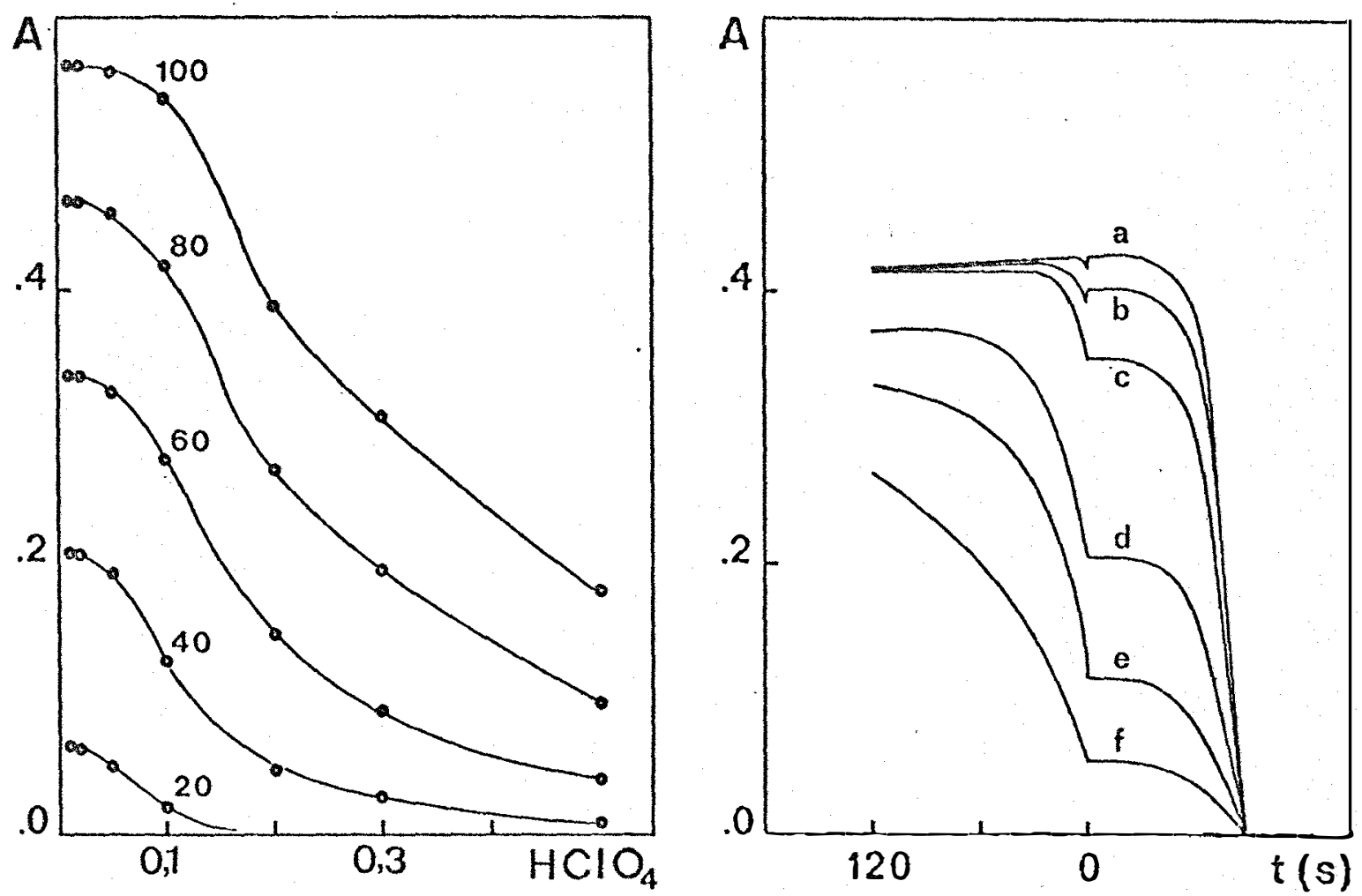

Figura 10 - Efeito do àcido perciórico.

A esquerda: número de partículas formadas, em uni dades de absorbáncia, em função dä concentração do àcido, expressa em molaridade. Os números sobre as cur vas indicam teores de sulfato ém $\mathrm{mg} \cdot \mathrm{I}^{-1}$ na amostra injetada.

A direita: curvas indicando a cinética de nucleação, relativas a $60 \mathrm{mg} \mathrm{SO}_{4}^{2-} \cdot 1^{-1}$. As letras de a a $f$ indicam valores de $0,01-0,05-0,1-0,2-0,3$ e $0,5 M$ $\mathrm{HClO}_{4}$, respectivamente.

Obs.: 0 instante em que o fluxo é nu lo é assinalado por $t=0$. 

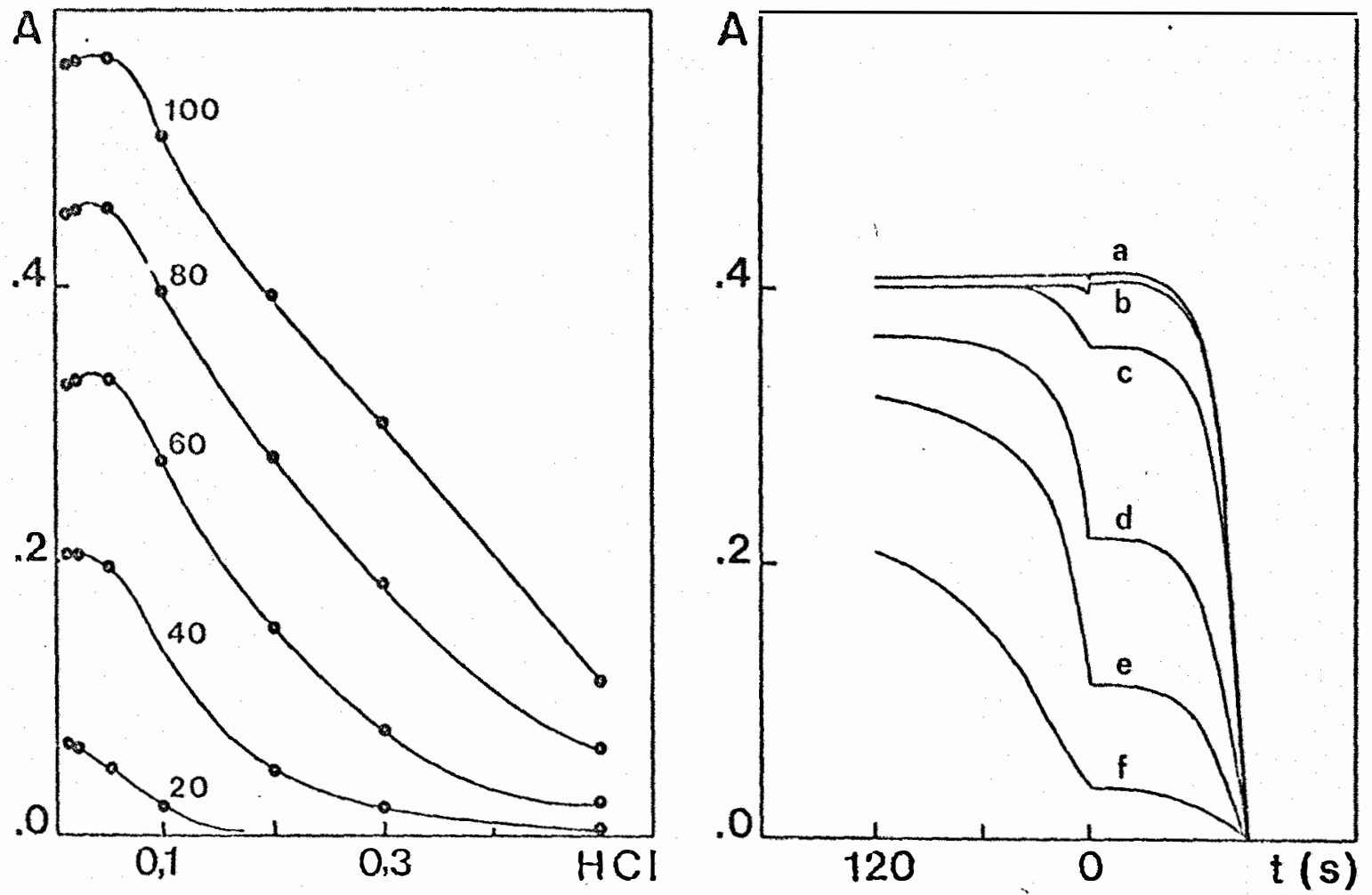

Figura 11 - Efeito do ācido clorídrico.

$\bar{A}$ esquerda: número de partículas formadas, em uni dades de absorbància, em função da concentração do ácido, expressa em molaridade. Os números sobre as cur vas indicam teores de sulfato e $\bar{m}$ $\mathrm{mg} \cdot \mathrm{I}^{-1}$ na amostra injetada.

A direita: curvas indicando a cinética de nucleação, relativas a $60 \mathrm{mg} \mathrm{SO} 4^{2-} \cdot 1^{-1}$. As letras de a a $f$ indicam valores de $0,01-0,05-0,1-0,2-0,3$ e $0,5 M$ HCl, respectivamente. 

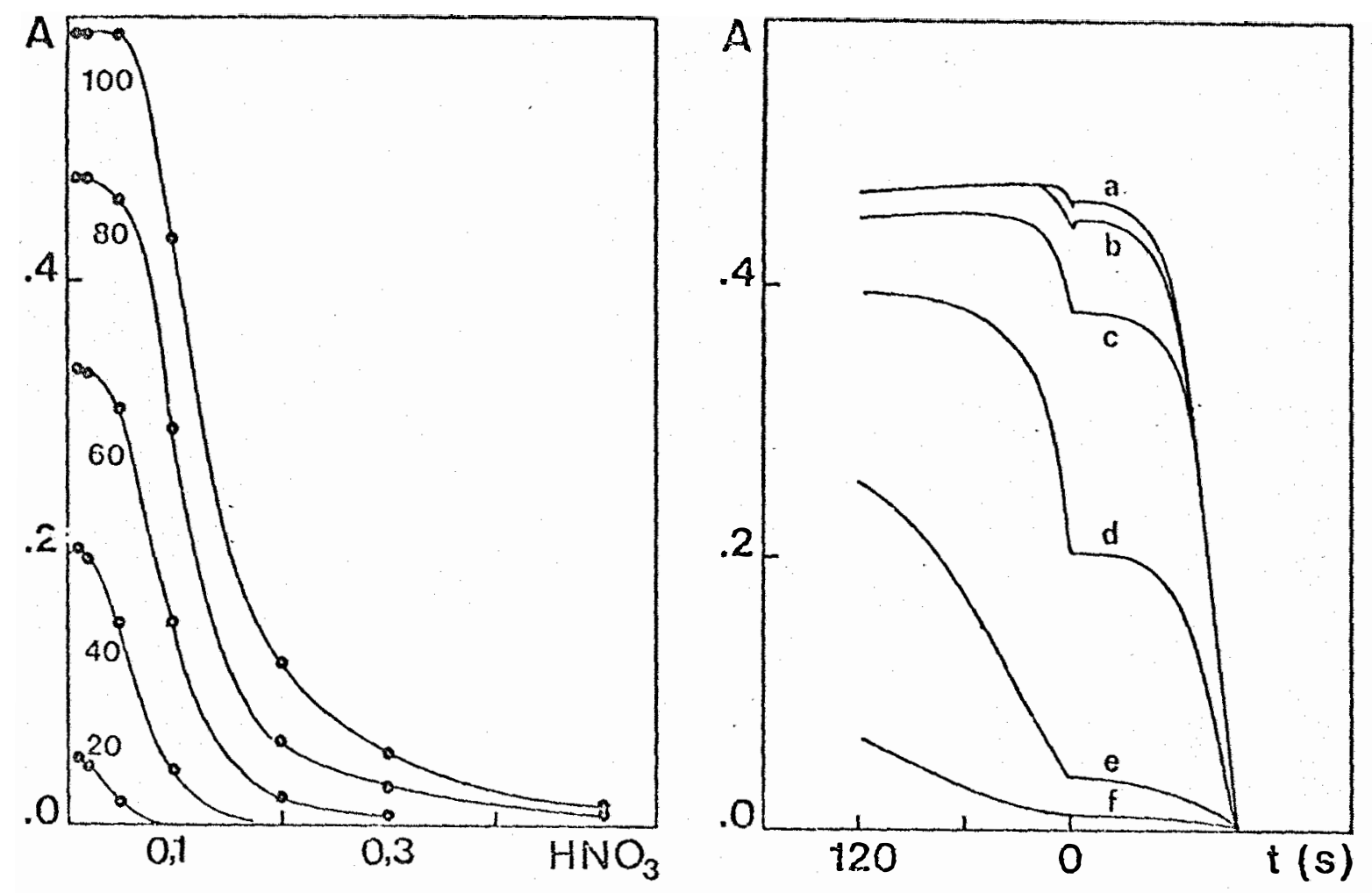

Figura 12 - Efeito do ācido nitrico.

A esquerda: número de partículas formadas, em uni dades de absorbáncia, em função da concentração do ácido, expressa em molaridade. Os números sobre as cur vas indicam teores de sulfato e $\mathrm{mg} \cdot \mathrm{l}^{-1}$ na amostra injetada.

A direita: curvas indicando a cinética de nucleaçào, relativas à $60 \mathrm{mg} \mathrm{SO}{ }^{2} \cdot 1^{-1}$. As letras de a a findicam valores de $0,01-0,02-0,05-0,1-0,2$ e $0,3 \mathrm{M}$ $\mathrm{HNO}_{3}$, respectivamente. 
rio causado pelo aumento da acidez, ou da concentração de ànions, que pode modificar as condições de supersaturação do melos

b) redução da velocidade das reações envol-; vidas causada pelo aumento da acidez do meio, a qual implica em uma diminuição do grau de completação das reações envolvidas, considerando-se os 9 segundos disponíveis para o desenvolvimento das mesmas no siste ma FIA.

O efeito a é justificado, quando se conside ra que ao se variar a acidez do meio de 0,01 a 0,5 M em áci do nitrico, a solubilidade do sulfato de bário, a $18^{\circ} \mathrm{C}$ aumen ta de 0,2 para $3,9 \mathrm{mg}^{-1} \mathrm{1}^{-1}$ (KOLTHOFF e SANDELL, 1962), valores estes concordantes com os dados das curvas de isoconcentração de sulfato da Figura 12. Ainda, as curvas que descre vem a cinética de nucleação indicam que, após o equilíbrio. há diferenças no número final de partículas formadas para di ferentes níveis de acidez. Deve-se aqui enfatizar que a tur bidez, medida em atısorbància, reflete o número de partículas formadas por unidade de volume, se for assumida a premissa de que as partículas de sulfato de bário formadas em cada situação tendem a apresentar, no equilíbrio, a mesma forma e - mesmo tamanho, em virtude da presença do álcool polivinílí co.

0 efeito b é justificado ao se analisar as cur vas que descrevem a cinética de nucleação, as quais permitem concluir que a velocidade de nucleação é muito dependente da acidez do meio. Verifica-se também que a cinética de nuclea ção depende, também. da natureza do ãnion e do teor de sulfa 
to. As diferenças encontradas parecem ser muito mais devidas às variações na barreira da energia de ativação à nucleação do que às variações na solubilidade.

No tocante à natureza dos ácidos investigados.: observa-se que o efeito causado por variações de concentração do ácido nítrico é muito mais pronunciado que aquele do ácido clorídrico, o efeito deste último sendo um pouco mais pronunciado, relativamente ao ácido perclórico. A intensidade deste efeito aumenta com a acidez do meio e coma diminui ção do teor de sulfato.

As diferenças encontradas são provavelmente devidas à adsorção preferencial de nitrato > cloreto > perclorato na rede cristalina das partículas de sulfato de bário. Este efeito pode ser explicado se for aplicada a regra de adsorção de PANETH-FAJANS-HAHN, a qual permite prever que a adsorção aumenta com a diminuição da solubilidade do composto formado com a impureza (KOLTHOFF e SANDELL, 1962). Assim, uma vez que o sulfato de bário está em contacto com excesso de íons bário,espera-se que o mesmo adsorva nitrato > cloreto > perclorato,cuja ordem acompanha a ordem de so lubilidade dos respectivos composios de bário. Resultados se melhantes para ions cloreto e nitrato são comentados por SALUTZKY (1966). O efeito destes ànions foi confirmado utili zando-se o sistema FIA da Figura 7 e substituindo-se o reagente $R_{1}$ por soluções de nitrato de sódio e de cloreto de só dio $2 \mathrm{M}$ em ácido perclórico $0,1 \mathrm{M}$. Observou-se que a inter ferência de nitrato é muito maior do que a de cloreto, especialmente quando as concentrações de sulfato na amostra inje

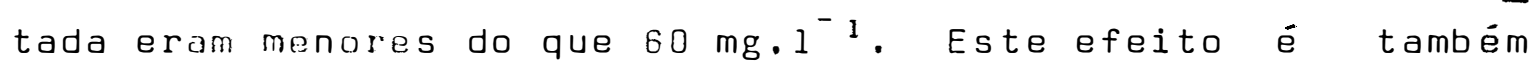
observável nas figuras ll e 12, comparando-se.os resultados das curvas de isoconcentração correspondentes a 20 e 
$100 \mathrm{mg} \mathrm{SO} 4^{-} \cdot \mathrm{I}^{-1}$ e referentes à acidez igual a $0,05 \mathrm{M}$.

Para os fins analíticos do presente trabalho, e considerando-se um tempo de reação igual a 9 segundos, pode-se concluir que o ácido perclórico é superior aos demais ácidos em condições de acidez elevada $\left[\left(\mathrm{H}^{+}\right)>0,3 \mathrm{M}\right]$. Sob condições de acidez levemente ácidas, a natureza do ácido deixa de ser relevante no projeto do sistema FIA. Evidentemente, estas conclusões são válidas quando o reagente $R_{2}$ (Figura 7) apresenta uma concentração de cloreto de bário dihidra to igual a $5 \% \mathrm{~m} / \mathrm{v}$. Face ao exposto acima,pode-se afirmar que o emprego de nitrato de bário para a determinação de sulfato em sistemas fIA não é recomendado.

5.3. Efeito das concentrações de íons bārio e sulfato

Os resultados dos experimentos desoritos em 4.4.2. são apresentados através das Figuras 13 e 14 , e aque les obtidos de acordo com o procedimento descrito em 4.4.3 são mostrados na Figura 15.

As curvas de isoconcentração de sulfato,obtidas em meio de ácidos clorídrico e nítrico 0,0l M (Figura 13), mostram que não existem grandes diferenças no número de partículas de sulfato de bário formadas para baixas concentrações de sulfato quando soluções de cloreto de bário na faixa de 5 a $40 \% \mathrm{~m} / \mathrm{V}$ são empregadas. Por outro lado, não existem diferenças significativas para todos os níveis de sulfato testados quando são utilizadas soluções de cloreto de bário de 10 a $40 \% \mathrm{~m} / \mathrm{V}$. Resultados obtidos em meio de ácido perclórico 0,0l M apresentaram a mesma tendência mostrada nas curvas referentes à mesma acidez em ácido clorídrico. 
$\mathrm{HCl} 0.01 \mathrm{M}$

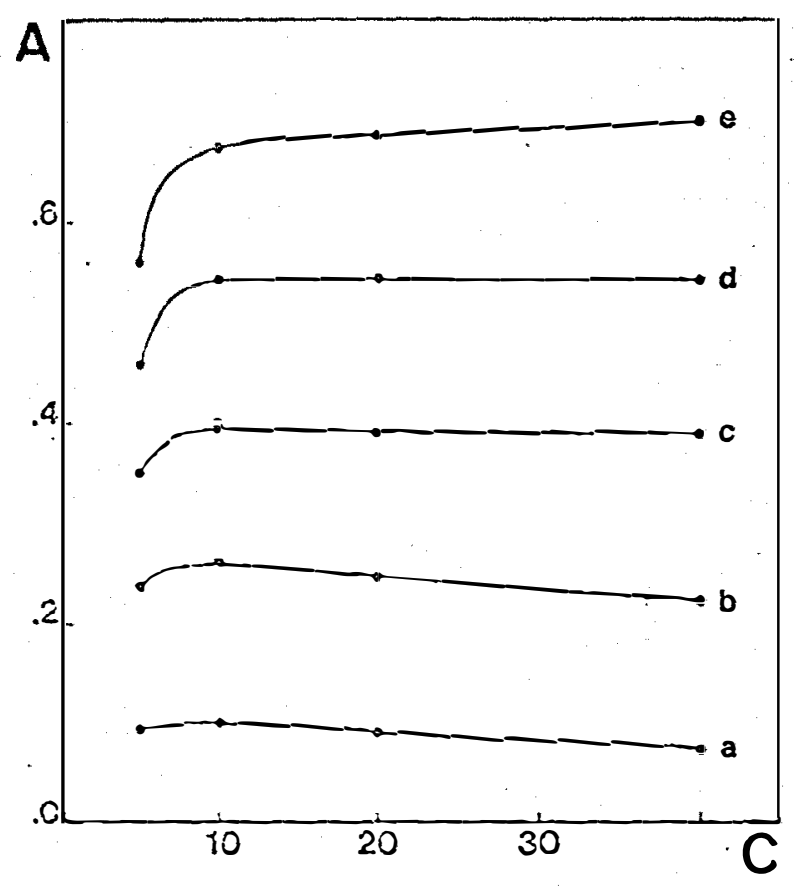

$\mathrm{HNO}_{3} 0.01 \mathrm{M}$

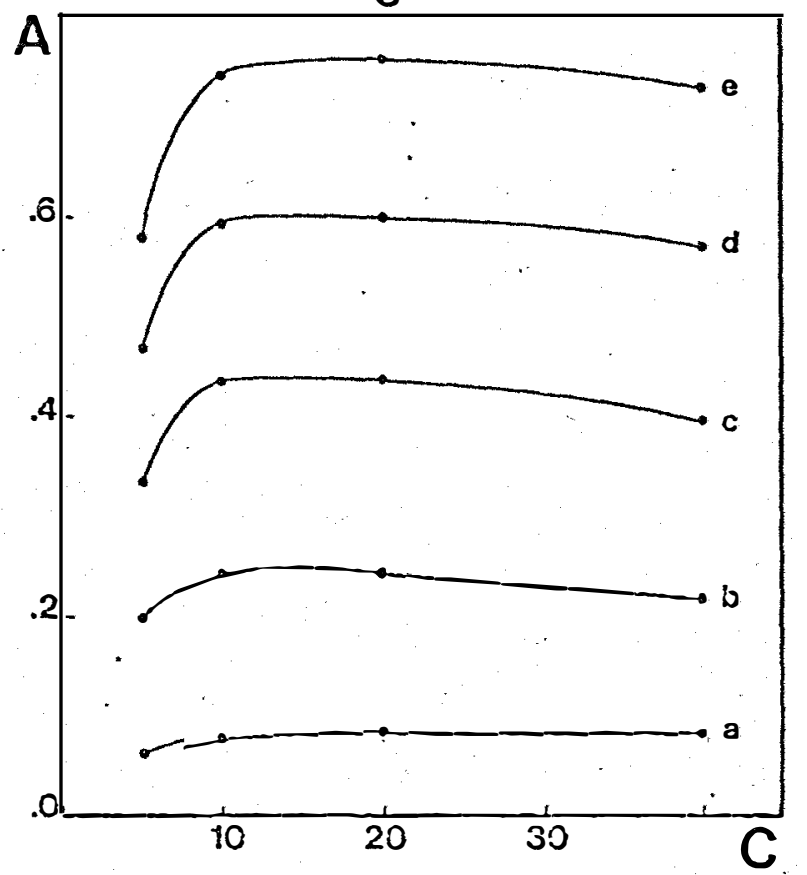

Figura $1 \hat{j}$ - Efeito da concentração de bārio em meio de àcidos cloridrico e nitrico $0,01 \mathrm{M}$. A - indica a turbidez formada, e C exprime a concentração de cloreto de bário dihidrato em \% m/v na solução $R_{2}$ (Figura 7). a, b, $c, d$ e e correspondem aos teores $20,40,60,80$ e $100 \mathrm{mg} \mathrm{S0} 4^{-} \cdot 1^{-1}$, respectivamente. 
$\mathrm{HCl} 0.25 \mathrm{M}$
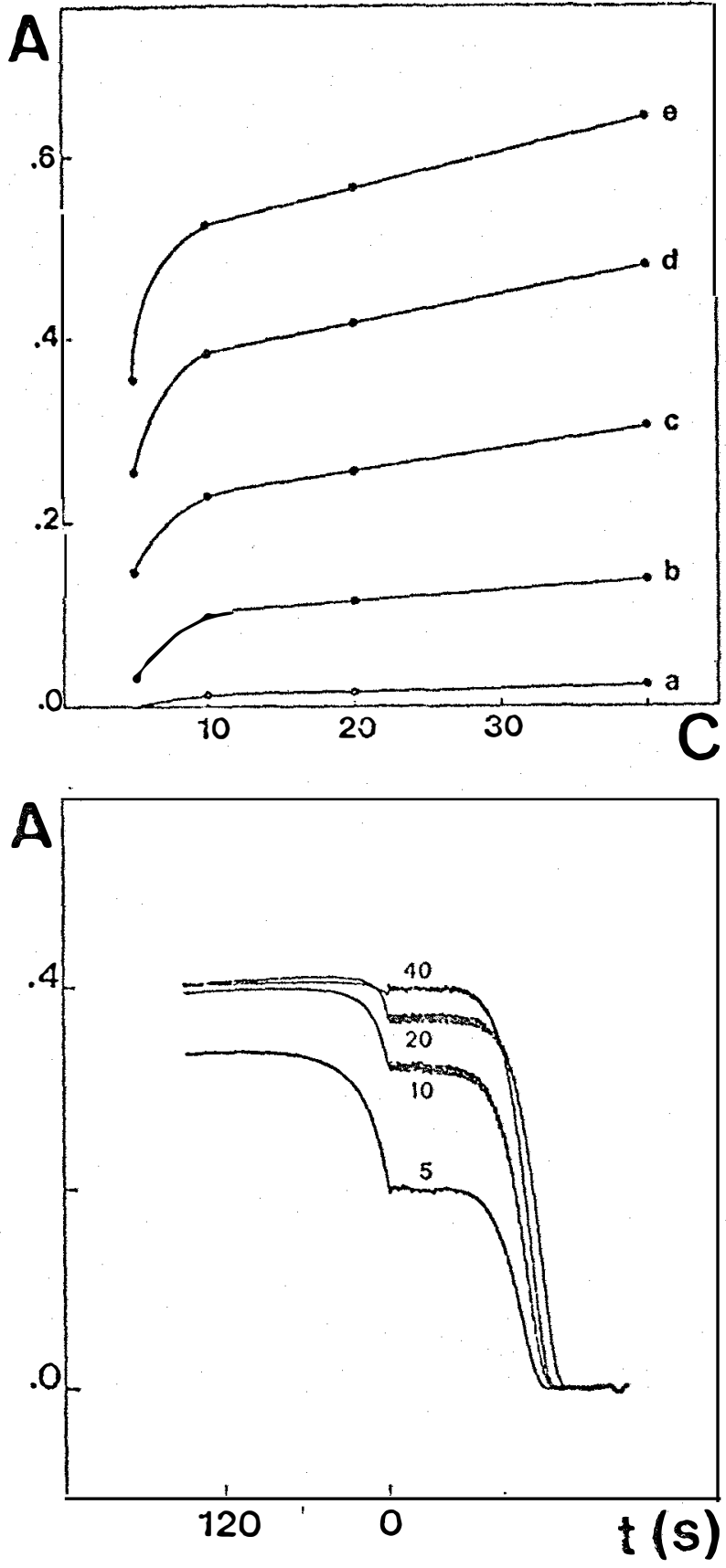

$\mathrm{HNO}_{3} \quad 0.25 \mathrm{M}$
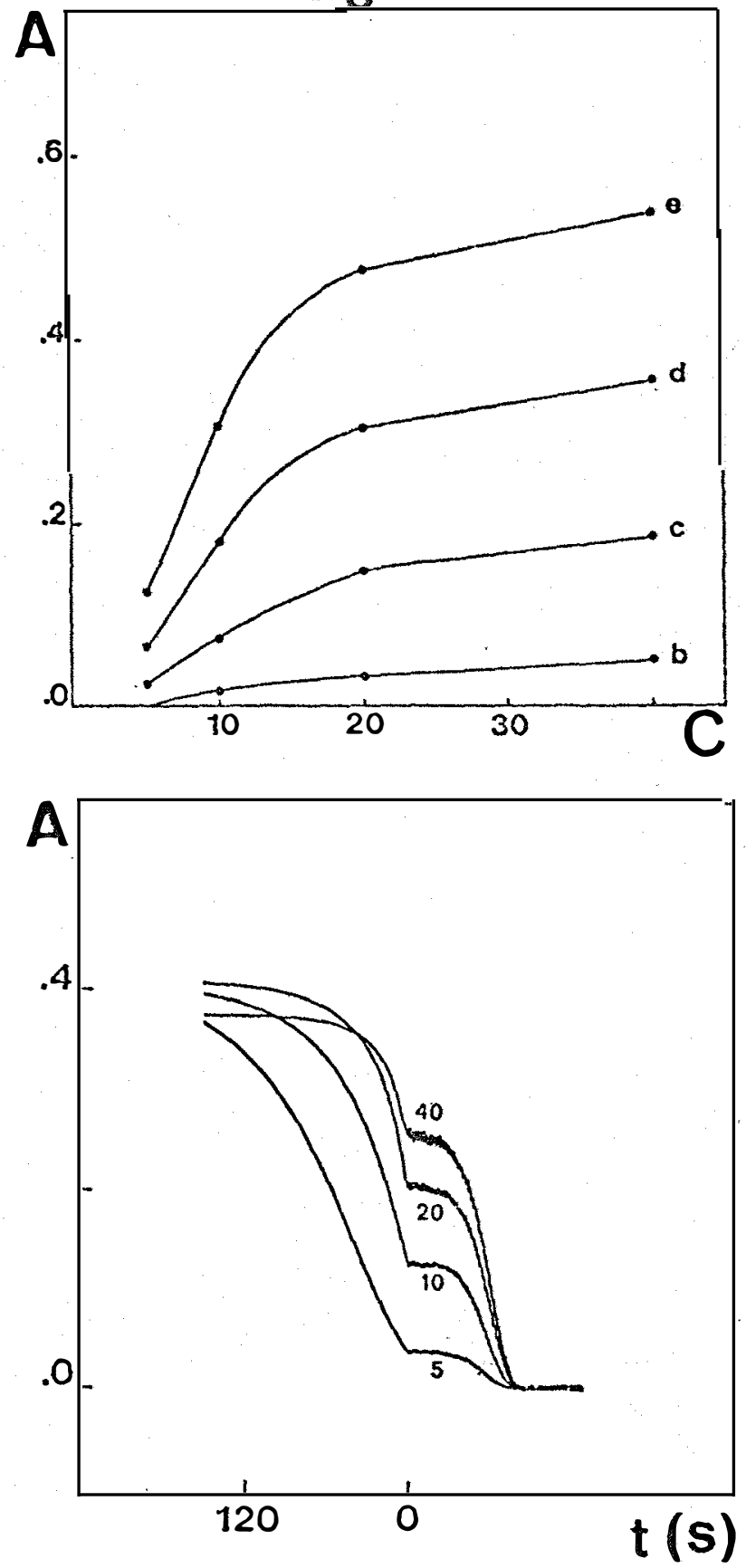

Figura 14 - Efeito da concentração de bārio em meio de ācidos clorídrico e nitrico 0,25 M.

Acima: A indica a turbidez formada, e $\mathrm{C}$ exprime a concentração de cloreto de bário dihidrato em \% $\mathrm{m} / \mathrm{v}$ na solução $R_{2}$ (Fi gura 7); $a, b, c, d$ e e correspondem aos teores 20,40 , 60,80 e $100 \mathrm{mg} \mathrm{SO} \mathbf{2}^{2-} \cdot 1^{-1}$ nas soluções injetadas.

Abaixo: curvas indicando a cinética de nucleação, relativas a $60 \mathrm{mg} \mathrm{SO} \mathrm{SO}_{4}^{2-} \cdot \mathrm{l}^{-1}$. Os números indicados nas curvas correspondem às concentrações das soluções de cloreto de bário dihidrato expressas em \% $\mathrm{m} / \mathrm{v}$. 
.64.

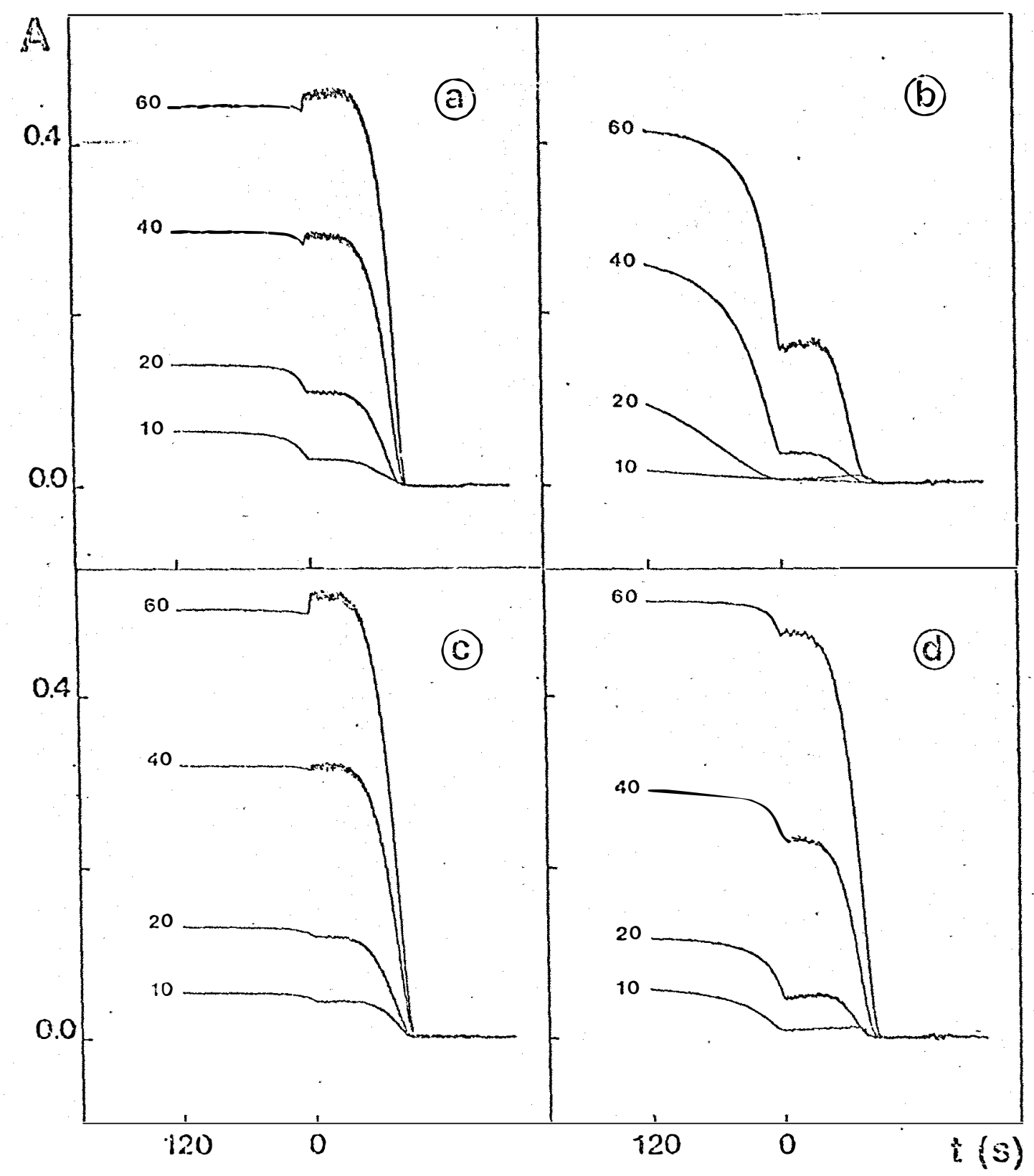

Figura 15 - Efeito da concentração de sulfato e bārio na cinētica de nucleação. Ds números 10, 20, 40 e 60 correspondem aos teores de sulfato nas respectivas soluções padrão em $\mathrm{mg} \cdot \mathrm{l}^{-1}$. Os conjuntos de curvas a, b, c e d referem-se à composição das soluções $R_{1}$ e $R_{2}$ no sistema da Figura 7.

$\mathrm{a}-\mathrm{R}_{1}=0,1 \mathrm{~N} \mathrm{HClO}_{4}, \mathrm{R}_{2}=5 \% \mathrm{BaCl}_{2} \cdot 2 \mathrm{H}_{2} \mathrm{O}$;

b $-R_{1}=2,5 \mathrm{~N} \mathrm{HClO}_{4}, \mathrm{R}_{2}=5 \% \mathrm{BaCl}_{2} \cdot 2 \mathrm{H}_{2} \mathrm{O}$;

c $-R_{1}=0,1 \mathrm{~N} \mathrm{HClO}_{4}, \mathrm{R}_{2}=20 \% \mathrm{BaCl}_{2} \cdot 2 \mathrm{H}_{2} \mathrm{O}$;

d $-R_{1}=2,5 \mathrm{~N} \mathrm{HClO}_{4}, \mathrm{R}_{2}=20 \% \mathrm{BaCl}_{2} \cdot 2 \mathrm{H}_{2} \mathrm{O}$; 
Em contraste, as curvas de isoconcentração obtidas em meio de ácidos clorídrico e nítrico 0,25 M (Figu ra 14), indicam que quanto maior a concentração maior a turbi dez formada. Isto pode ser explicado considerando-se o tempo de 9 s disponivel para a reação, conforme indicam as res pectivas curvas referentes à cinética de nucleação. E interessante observar que, afós o equilibrio ( $t>120 \mathrm{~s})$, o núme ro de partículas de sulfato de bário praticamente independe da concentração inicial de íons bário. Além disso, no equilíbrio, as diferenças entre os meios nitrico e clorídrico são desprezíveis, apesar de as velocidades de nucleação serem significativamente diturentes.

Para fins analiticos é importante notar que. comparando-se as curvas de isoconcentração de sulfato das Figuras 13 e 14, o efeito da acidez é minimizado com o aumen to da concentração de bário. A análise dos sinais correspon dentes ao tempo de reação de 9 s (patamar das curvas antes da parada dos fluxos - Figura 15 J confirma que o aumento na concentração de bário compensa,dentro de certos limites, o efeito da acidez, o qual, em concordància com o exposto em 5.2, é mais pronunciado para baixas concentraçóes de sulfato.

Existem na literatura equações correlacionando velocidade de nucleação com a razão de supersaturação (WALTON, 1967). Neste sentido,sabe-se que tanto na nucleação homogenea como na heterogenea existe uma razão de supersaturação crítica, abaixo da qual a velocidade de nucleação é muito lenta, e acima da qual a velocidade é rápida. Assim, considerando-se a proposição de LA MER e DINEGAR (1951), variando-se as atividades iónicas iniciais de bário e de sulfa to, ocorrerá uma variação na razão de supersaturação, desde que a raiz quadrada do produto iônico exceda a solubilidade 
do sulfato de bário. Os dados da Figura 15 sugerem que a ve locidade de nucleação seja função das concentrações iniciais de bário e de sulfato, e que as diferenças encontradas sejam devidas às variações no grau de supersaturação. Nos experi mentos conduzidos conforme 4.4 .2 e 4.4 .3 , quando foram utili zadas altas concentrações de sulfato e de bário, muito prova velmente a supersaturação crítica foi atingida, a nucleação sendo predominantemente homogenea.

Uma discussão dos resultados em termos de su persaturação critica poderia ser feita com base nos dados for necidos por LA MER e DINEGAR (195I), COLLINS e LEINEWEBER (1956), NIELSEN (1957, 1961) mas a mesma não é pertinente. De qualquer forma, pode-se afirmar que, se o valor de supersatu ração crítica fornecido por NIELSEN (1961) for tomado como referéncia $\left\{s^{*}=630\right\}$, nos experimentos onde a razão de super saturação foi bem menor que este valor,com toda a certeza a nucleação foi heterogenea, ou seja, são partículas de impure zas que catalizam a nucleação.

Finalmente, a presença de íns nitrato em altas concentrações (Figura 14. $\mathrm{HNO}_{3} 0,25 \mathrm{M}$ ) confirma os resultados mostrados na Figura 12. Assim, devido também ao fe nômeno de adsorção, o íon nitrato causa uma aparente diminuição na razão de supersaturação e, consequentemente, na velocidade da nucleação. Este último fato foi comentado por LA MER e DINEGAR em 1951.

Para os fins analiticos do presente trabalho, levando-se em conta o tempo de reação de 9 s previamente es tabelecido,pode-se concluir que uma solução de cloreto de bá rio dihidrato a $5 \% \mathrm{~m} / \mathrm{V}$ em PVA $0.05 \% \mathrm{~m} / \mathrm{V}$ pode ser empregada quando se pretende determinar sulfato na faixa de 0 a $40 \mathrm{mg} \cdot \mathrm{I}^{-1}$ 
(caso particular de análise de águas). Quando as amostras fo rem digeridos de vegetais lacidez equivalente a $0,25 \mathrm{~N}$ de ácido perclóricol, uma solução de cloreto de bário dihidrato $20 \% \mathrm{~m} / \mathrm{v}$ em PVA $0,05 \% \mathrm{~m} / \mathrm{v}$ deve ser utilizada.

Na discussão dos resultados reportados até o momento, o termo cinética de nucleação foi empregado ao in vés de cinética de crescimento, porque o crescimento dos cris tais pode, sob certas circunstáncias, ser considerado como uma forma especial de nucleação heterogênea (WALTON, 1967). No entanto, se for observada a conclusão de DOREMUS (1958) o termo cinética de crescimento parece mais adequado, desde que este autor considera que a nucleação ocorre rapidamente, e que o número de partículas é constante durante as medidas no período de crescimento dos cristais. Por outro lado, consi derando-se que o primeiro estágio da precipitação envolve nu cleação e crescimento e o segundo estágio somente crescimento (JOHNSON e O'ROURKE 1953, 1954) os dois termos parecem. se confundir.

5.4. Efeito da adição de sulfato

Os resultados dos experimentos descritos em 4.4.4 são apresentados através das Figuras 16 e 17 . Visando facilitar a discussão, os resultados obtidos de acordo com o procedimento descrito em 4.5, foram incluidos neste item.

As curvas de isoconcentração de sulfato (Figü ra 16) indicam que a adição de sulfato à zona da amostra melhora tanto a linearidade das curvas de padronização, como o limite de detecção do método. Ocorrendo a reação em meio ácido diluído, $\left[H^{+}\right]=0,0 I N$ (conjuntos de curvas a e c ), não são obser 
.68.
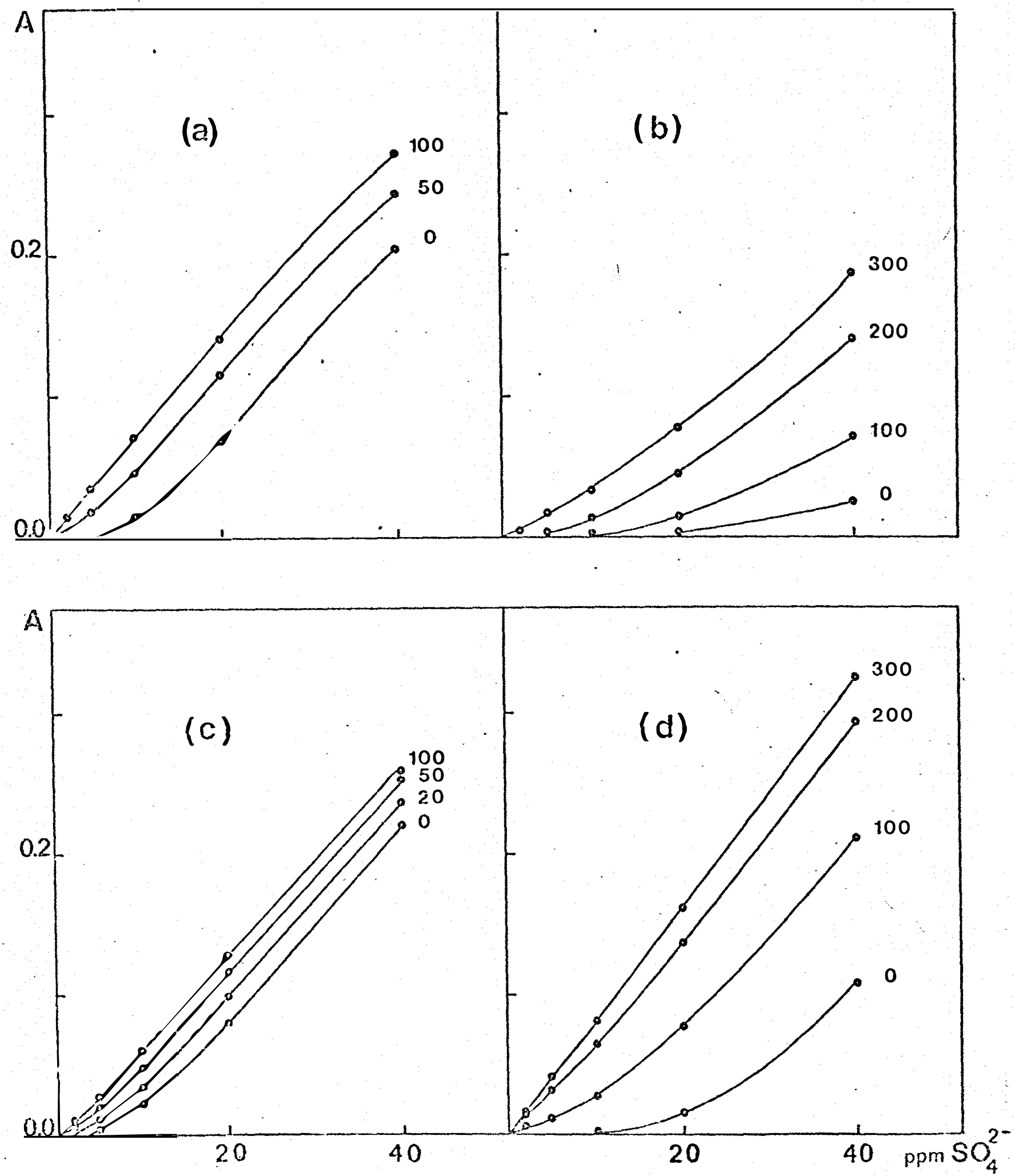

Figura 16 - Efeito da adição de sulfato nas curvas de padronização. Os números ao lado das curvas correspondem aos teores de sulfato na solução $R_{1}$ (Figura 7), em mg. ${ }^{-1}$. Os conjuntos de curvas a e c foram obti dos em meio de ácido perclórico 0,01 M utilizando-se em $R_{2}$ (Figura 7) soluçà de cloreto de bärio a 5 e $20 \% \mathrm{~m} / \mathrm{v}$, respectivamente. Os conjuntos b e d foram obtidos em meio de ácido perclórico 0,25 N, utilizando-se em $R_{2}$ soluções de cloreto de bário a 5 e $20 \% \mathrm{~m} / \mathrm{v}$, res pectivamente. 


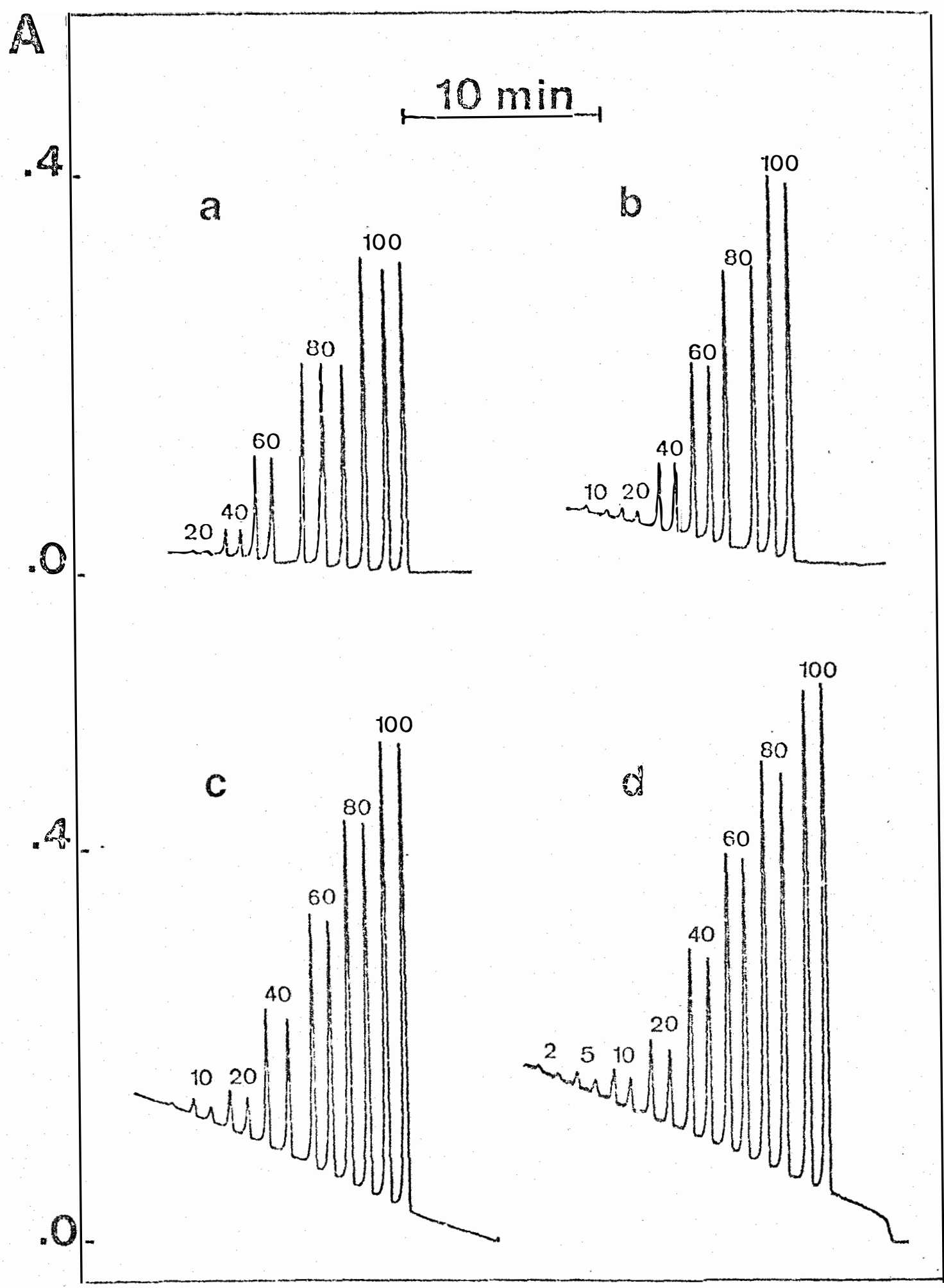

Figura 17 - Efeito da adição de sulfato na estabilidade da linha băsi ca e no limite de detecção. Os números sobre os picos iñ dicon us teares de sulfato, nas respectivas soluções padrão, expressas em $\mathrm{mg}^{-1} \mathrm{1}^{-1}$. Todas as soluções foram injetadus en duplicata. $a, b, c$ e d correspondem às adições de $0,100,200$ e $300 \mathrm{mg} \mathrm{S \textrm {SO } _ { 4 } ^ { 2 }} \cdot \mathrm{I}^{-1}$ (preparadas em ácido perclórico $2.5 \mathrm{~N}$ ) via $R_{1}$ (Figura 7$)$. Em $R_{2}$ utilizou-se soluçào de cloreto de bário dihidrato $5 \% \mathrm{~m} / \mathrm{v}$. 
vadas diferenças significativas entre as curvas de padroniza ção referentes à mesma adição de sulfato, quando são empregadas soluções de cloreto de bário a 5 e $20 \% \mathrm{~m} / \mathrm{v}$. Em contraste, em meio ácido $\left[\mathrm{H}^{+}\right] \simeq 0,25 \mathrm{~N}$ cconjuntos de curvas b e d), observa-se que as características analiticas são mais favoráveis quando solução de cloreto de bário $20 \% \mathrm{~m} / \mathrm{v}$ foi utilizada. Neste caso. a adição promóvida pela solução $300 \mathrm{mg} \mathrm{SO4^{- }} .1^{-1}$ foi suficiente para linearizar a função na faixa de concentrações indicada. Estes resultados não surpreendem, face ao disposto no item 5.3,pois a adição de sulfato e a escolha adequada da solução de bário concorrem para um ajuste das condições de supersaturação desejadas,favorecendo a determinação de baixas concentrações de sulfato na amostra.

Entretanto, a adição contínua de sulfato leva a uma instabilidade na linha de base do sistema. Empregando-se solução de cloreto bário a 5\% m/v,quanto maior a adição,acidez do meio e tempc de operação, maior a quantidade de sulfa to de bário adsorvida nas paredes internas do reator $L_{R}$ e da célula de fluxo (Figura I7). Quando se empregou solução de cloreto de bário a $20 \% \mathrm{~m} / \mathrm{v}$, mesmo em condições de acidez ele vada $\left[\mathrm{H}^{+}\right]=0.25 \mathrm{~N}$, quanto maior a adição de sulfato, menor foi a quantidade adsorvida nas paredes internas da célula de fluxo. Nestas condições,uma linha de base, sem apresentar um deslocamento crescente em função do tempo, foi observada. Es te fato contribuiu para que se testasse o protótipo em rotina de larga escala,utilizando-se condições analíticas para digeridos de vegetais, conforme descrito em 4.5. 0 resultado da análise pode ser apreciado através do registro mostrado na Figura 18. A operação do sistema durante cerca de 50 minutos apresentou uma linha de base instável, assim como uma variação noss sinais referentes aos padrões utilizados no iní cio e no final da análise. A instabilidade do sistema foi 

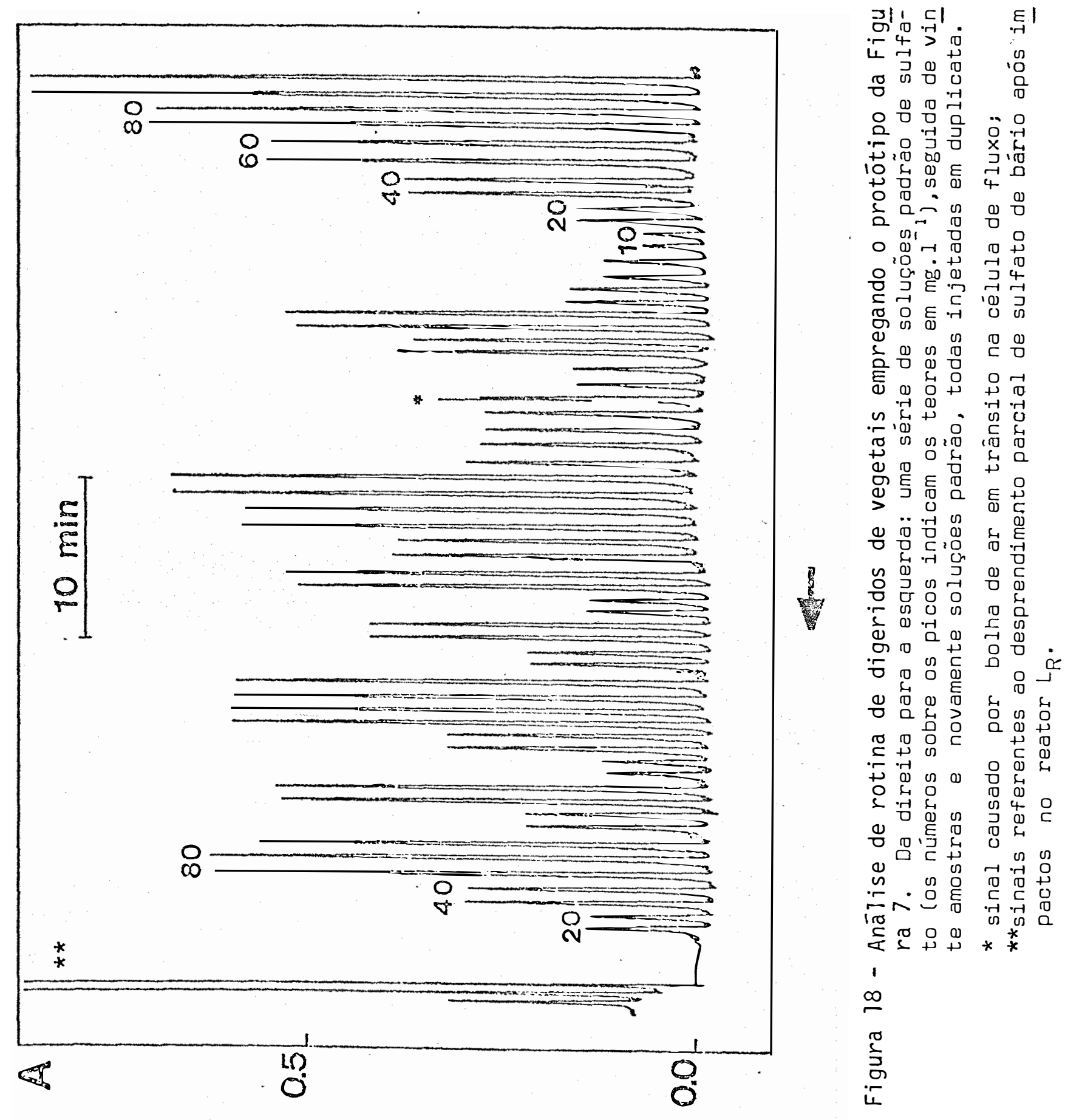
devida ao acúmulo irregular de sulfato de bário no reator $L_{R}$ ' fato este observado visualmente. Impactos sucessivos no rea tor $L_{R}$ permitiram deslocar parcialmente o sulfato de bárío adsorvido, cujos sinais transientes são mostrados na mesma , Figura. A necessidade de se reprojetar o sistema para os fins analiticos desejados foi, neste ponto, inquestionável. Os resultados dos novos projetos são apresentados a seguir.

\subsection{0 sistema proposto}

A escolha do sistema proposto foi realizada após a comparação do desempenho dos sistemas fIA das Figuras 8 e 9 (item 4.6$)$.

O emprego de zonas coalescentes em confiuència (Figura 8a) mostrou-se promissor para situações de menor acidez, apesar de a velocidade analitica permanecer em 70 amostras por hora e de ser observada uma variação crescente na linha básica de 0,005 unidades de absorbáncia por hora. Resultados semelhantes foram obtidos quando se utilizou o sis tema com adição sequencial de solução alcalina de EDTA (Figü ra 8b). Desde que, empregando-se estes sistemas, o problema da adsorção de sulfato de bário nas paredes internas do reator tubular e da célula de fluxo não foi completamente elimi nado, a necessidade de uma nova configuração tornou-se evidente.

A Figura 9 mostra o diagrama de fluxos do sís tema fIA com allernáncia de reagentes, proposto no presente trabalho, a qual pode ser considerado, até certo ponto, co mo uma combinacóo dos sistemas indicados na figura 8 . Neste sistema, a dufino de bário somente ocorre na presença da zo- 
na da amostra, o que corresponde ao principio da coalescência de zonas; a adição do EDTA ê feita em sequẽncia à passa gem da amostra processada pelo sensor, em analogia ao proces so de adição sequencial (Sistema FIA da Figura 8b). Todas as considerações apresentadas a seguir referem-se ao sistema FIA da Figura 9 .

\subsubsection{Lavagem do sistema}

Os resultados dos experimentos realizados con turme 4.6.2 mostraram que a eficiência do processo de lava gem independe da concentração de EDTA na solução $R_{3}$ (Figura 9), quando esta se situa entre $0,03 \%$ e $3,0 \% \mathrm{~m} / \mathrm{V}$. Deve-se salientar que, também quando $R_{3}$ foi somente solução 0,25 M em ácido perclórico, a lavagem do sistema foi satisfatória. Este fato permite concluir que a eficiència de lavagem é muito mais devida à brusca mudança na vazão através do reator $L_{R}$, do que à reação química do EDTA com o sulfato de bário residual, ou seja, a limpeza do sistema é principalmente devida a um efei to de transporte de massa. Entretanto, decidiu-se manter o EDTA na solução $R_{3}$ porque, na ausència deste agente complexante, um ligeiro aumento na linha básica foi observado após operação continua do sistema durante duas horas. A concentração de EDTA para a operação do sistema foi escolhida como $0,3 \% \mathrm{~m} / \mathrm{v}$, em hidróxido de sódio 0,2M. O emprego de maiores concentrações em $R_{3}$ levou sempre a um aumento pronunciado no sinal correspondente à prova em branco,o qual é causado pelas diferenças de índices de refração entre os reagentes alternantes.

$D$ efeito do fluxo intermitenté de $R_{3}$, verificado após experimentos conduzidos conforme 4.6.3, é apresen- 
tado na Figura 19. Os resultados indicam que a taxa de escoamento de $R_{3}$ tem uma influência marcante tanto na forma do pico registrado,como também na eficiéncia de lavagem e na velocidade analitica. Isto vem confirmar que o processo de, lavagem é mais dependente do transporte de massa do que da quimica envolvida. Uma intensidade de fluxo de $10 \mathrm{ml.min}{ }^{-1}$ foi selecionada para $R_{3}$ porque, nesta situação,o tempo de lim peza é de apenas alguns segundos. Valores acima de $10 \mathrm{ml.min}{ }^{-1}$ foram evitados para prevenir uma pressão hidrodinámica exce siva no sistema (RUZICKA e HANSEN, 1981).

Os testes de adição contínua de sulfato à zona da amostra, realizados também no sistema proposto, indica ram que uma concentração de $100 \mathrm{mg} \mathrm{SO}_{4}^{2-} . I^{-1}$ no reagente $\mathrm{R}_{\mathrm{I}}$ (Figura 9 ) pode ser recomendado para a determinação deste ánion em águas naturais e em digeridos de vegetais, se forem utilizadas em $R_{2}$, soluções de cloreto de bário dihidrato a 5 e $20 \% \mathrm{~m} / \mathrm{v}$, respectivamente, e se forem mantidas as condições de acidez para cada tipo de amostra especificadas na Figura 9. No caso de digeridos de vegetais podem ser alternativamente empregadas, em $R_{1}$, solução contendo $300 \mathrm{mg} \mathrm{SO} 4^{-} .1^{-1}$ e, em $R_{2}$, solução de cloreto de bário dihidrato a $5 \% \mathrm{~m} / \mathrm{v}$,com resultados semelinates.

\subsubsection{Efeito da acidez das amostras}

Os resultados dos experimentos conduzidos con forme 4.6.4, referentes ao efeito da variação da acidez dos digeridos de vegetais, são apresentados na Tabela 1.

A anāise dos dados mostra que o efeito da va riação da acidez é mais pronunciado para concentrações de sul 


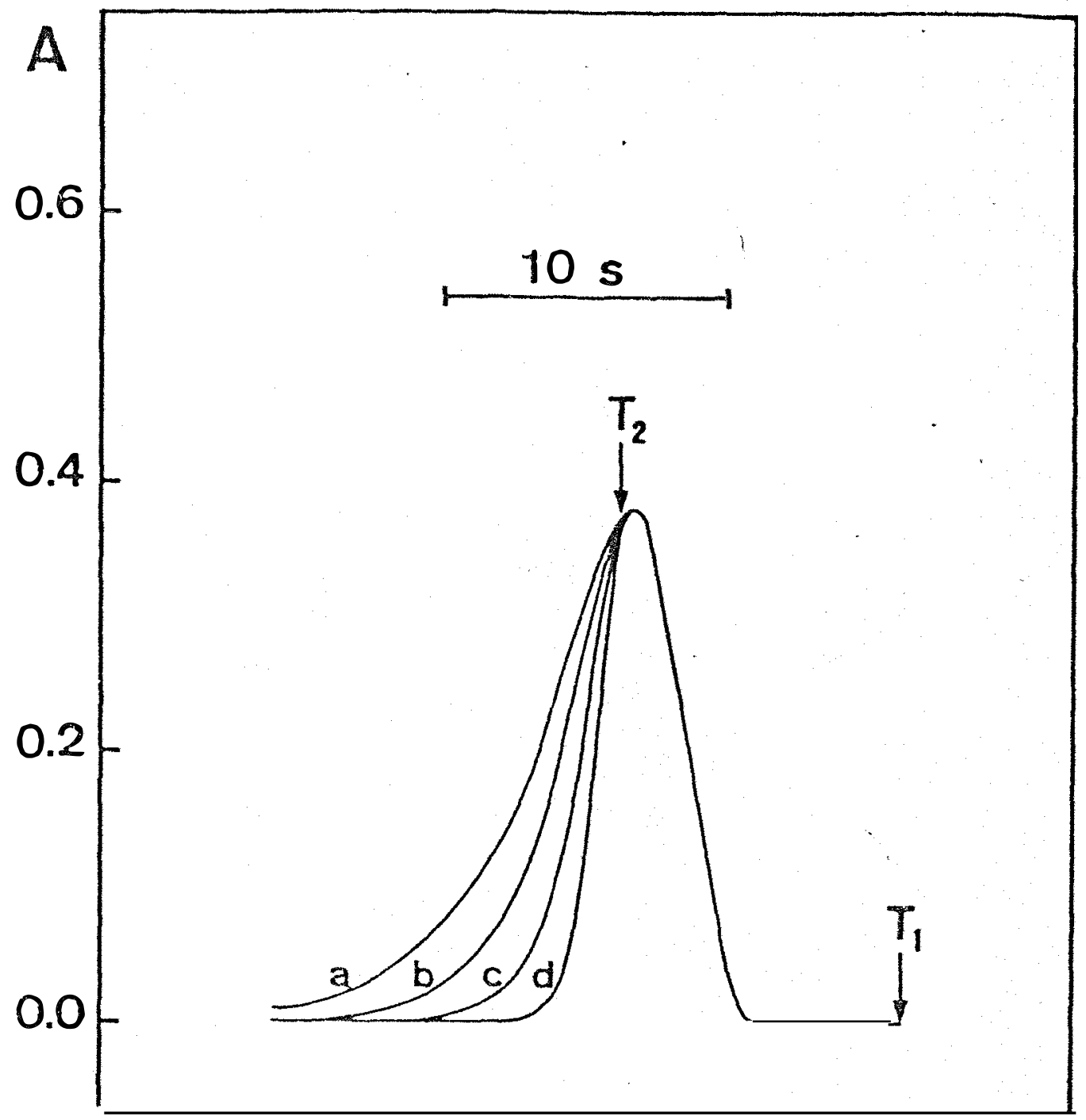

Figura 19 - Efeito da intensidade de fluxo da solução de EDTA alcalino. $T_{1}$ indica o instante da injeção da solução padrão $100 \mathrm{mg} \mathrm{SO} 4^{2-} \cdot \mathrm{I}^{-1}, \mathrm{~T}_{2}$ corresponde ao momento em que o injetor (Figura 9 ) é ccriutado para a posição de amostragem; a, b, c e d referem-se às vazões $0,0,2,5,50$ e $10,0 \mathrm{ml} \mathrm{min}^{-1}$ das soluções de EDTA alcalino, respectivamente. 


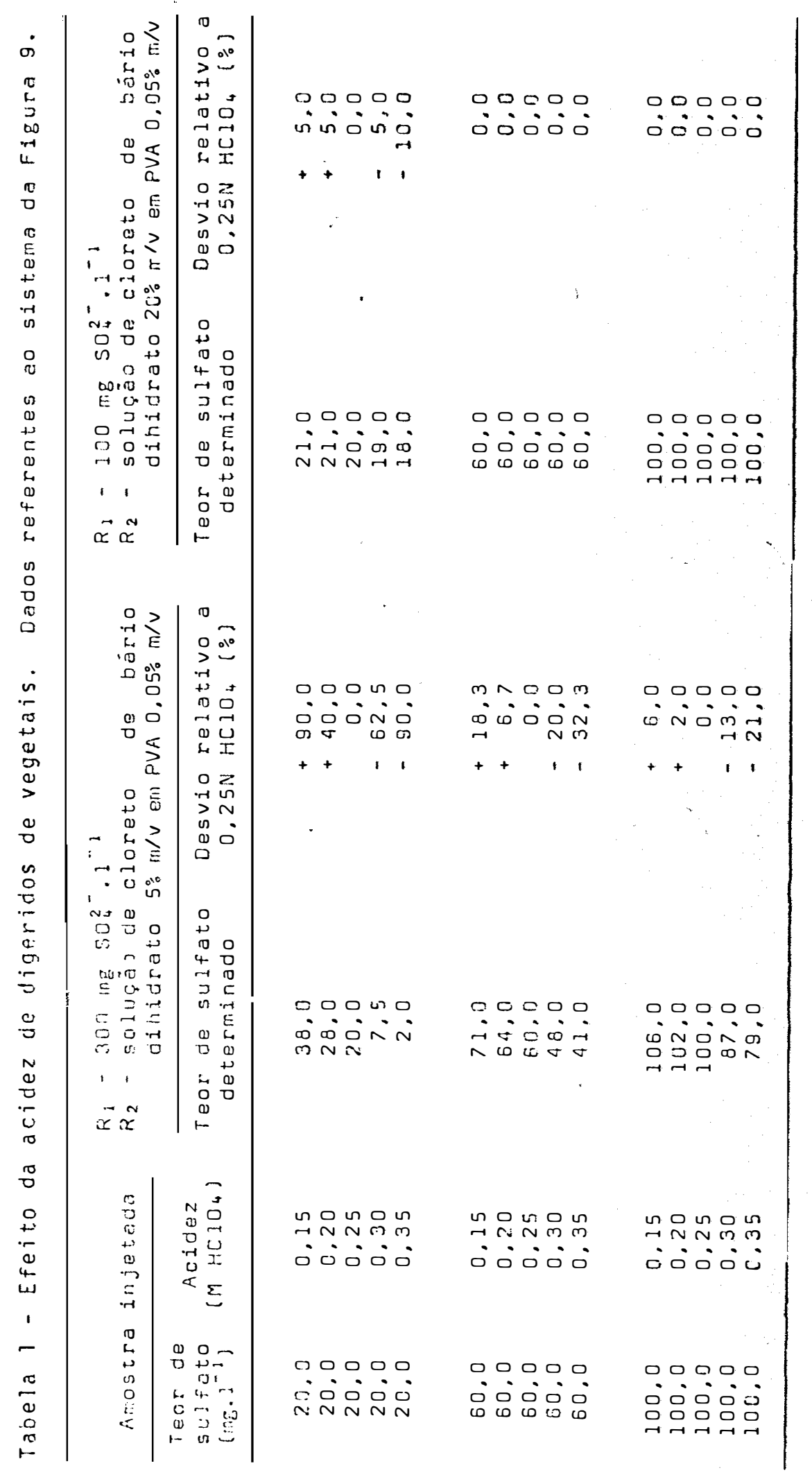


fato e de bário mais baixas, em concordància com os resultados discutidos em 5.2 e 5.3 .

Para análises de vegetais, a solução de clore, to de bário dihidrato a $20 \% \mathrm{~m} / v$ é mais recomendada. Os desvios encontrados para menores concentrações de sulfato são í relevantes, considerando-se que, quando o procedimento de decomposição das amostras é bem conduzido, a variação na acidez destas é bem pequena. Neste sentido, uma acidez de $0,25 \pm 0,02 \mathrm{M}$ em ácido perclórico foi estimada após a titula ção de 20 digeridos.

No tocante à análise de äguas naturais, varia ções de acidez das amostras não são importantes. De um modo geral, não se recomenda a acidificação da amostra após a coleta (APHA, 1975). Entretanto, é frequentemente solicitada a determinação de sulfato em amostras já acidificadas,as quais foram coletadas e preservadas visando determinações de vários elementos. Nestas amostras, a adição de 1 a $4 \mathrm{ml}$ de ácidos clorídrico ou nítrico concentrados por litro resulta em uma acidez muito baixa para comprometer significativamente a cinética de nucleação e, consequentemente, a exatidão dos resultados. Testes realizados com amostras de águas naturais revelaram que, mesmo quando a acidez das amostras variou de $100 \%$, não se observaram variações nos resultados ana liticos.

\subsubsection{Caracteristicas analiticas}

O método proposto é praticamente insensivel às variações de temperatura, tanto do ambiente como das amos tras, conforme indicaram os testes conduzidos de acordo com o procedimento descrito em 4.4.5. Isto elimina a necessi- 
dade do uso de banho à temperatura constante, assim como não é preciso aguardar que amostras com temperatura em torno de $10^{\circ} \mathrm{C}$ atinjam a temperatura ambiente. Esta característica é explicada quando se considera que nas condições da operação' do sistema (Figura 9), a cinética da nucleação é pouco pass 1 vel de ser modificada por variações de temperatura, uma vez que um grau de completação maior que $90 \%$ é atingido nos sistemas propostos.

A Tabela 2 indica que o método proposto é pou co suscetivel às interferéncias dos íns estudados lítem 4.6.5.),considerando-se que, em amostras típicas de àguas e de digeridos de vegetais, as espécies químicas potencialmente interferentes ocorrem em concentrações menores que os máximos teores testados. Assim, não é comum a presença de ferro e alumínio a níveis acima de $10 \mathrm{mg}^{-1} \mathrm{l}^{-1} \mathrm{em}$ digeridos de vegetais, cuja relação entre massa de matéria seca e o volume final da solução é igual ou maior que l/loo. Também, é in comum a ocorrência de cálcio em concentrações acima de $200 \mathrm{mg} \cdot \mathrm{I}^{-1}$ em águas.

Com respeito à interferència de íns bicarbonato, ao nível de $1000 \mathrm{mg} \cdot \mathrm{I}^{-1}$, a mesma é totalmente eliminada,quando a concentração do ácido no reagente $R_{l}$ (sistema pa ra análise de águas) foi igual ou maior que $0,5 \mathrm{~N}$. Por este motivo, concluiu-se que a solução $R_{3}$ deve ser preparada em meio de ácido clorídrico (ou perclórico) 0,5 N. Convém salientar que, caso as amostras de águas sejam preservadas com ácidos, a solução carregadora deve apresentar uma acidez semelhante à acidez das mesmas, e a concentração do ácido na solução $R_{l}$ diminuir, de tal forma que a concentração ácida no percurso xy do sistema (Figura 9 ) não exceda 0,05 N. 
Tabela 2 - Interferéncias quimicas na determinação de sulfato. Dados obtidos conforme 4.6.5, $20 \mathrm{SO}_{4}+10 \mathrm{Al}$

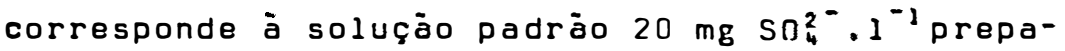

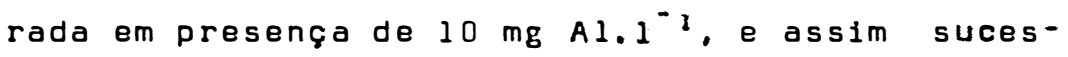
sivàmente.

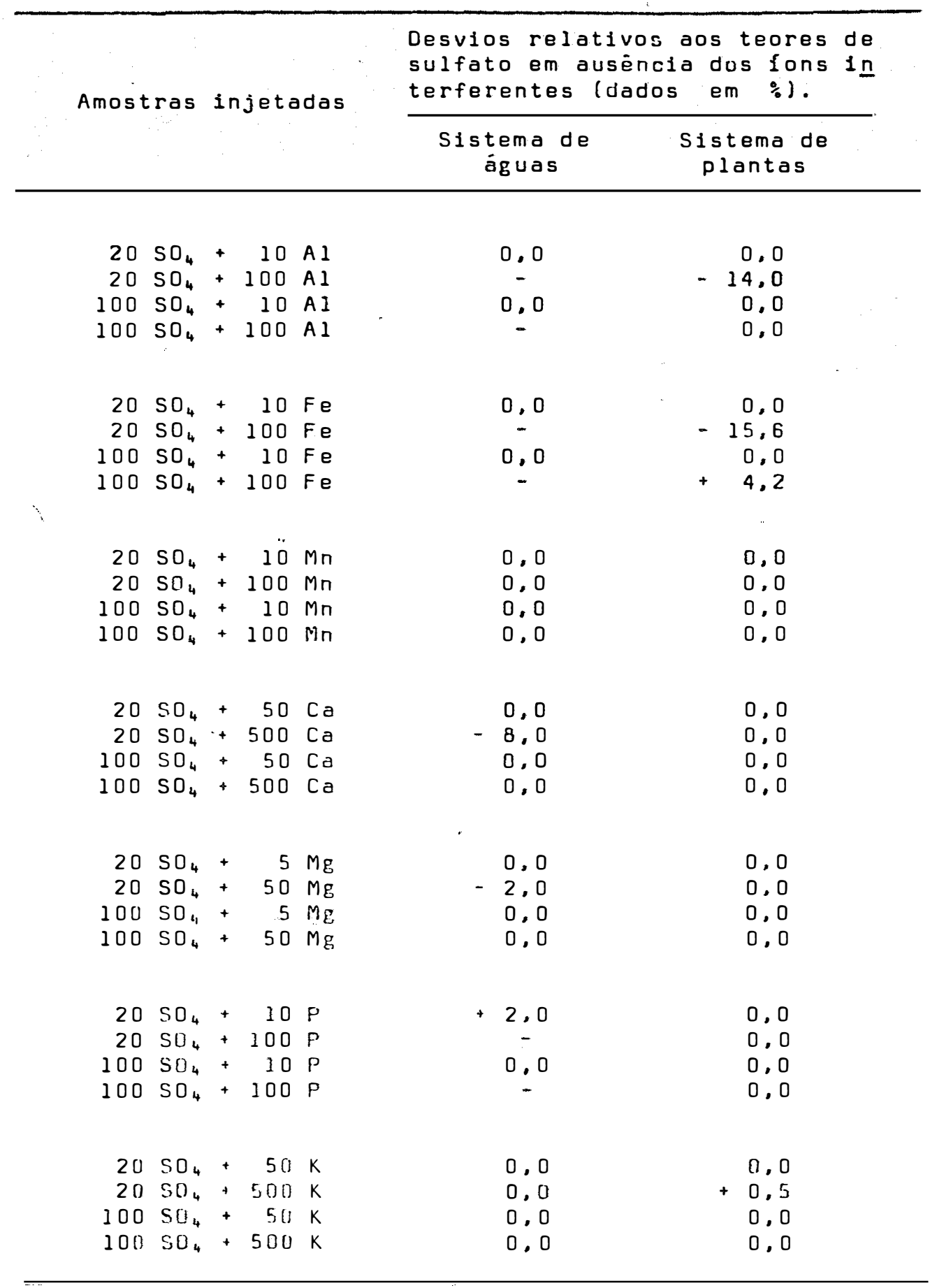


tras, particularmente de águas, são corrigidas facilmente com emprego do próprio sistema, determinando-se a prova em branco de cada amostra. Para tanto, basta substituir a solução de cloreto de bário $5 \% \mathrm{~m} / \mathrm{V}$ em PVA $0,05 \% \mathrm{~m} / \mathrm{V}$ (solução $R_{2}$ ).) por uma solução de PVA $0,05 \%$. Determinado o valor do sinal da prova em branco, a correção é feita através da subtração dos sinais correspondentes. Tanto o sistema de águas, como o de plantas, apresentam uma ótima estabilidade, não se notando nenhuma variação no comportamento da linha básica durante 8 horas de operação contínua. Após este período de tem $\mathrm{N} 3$, variações menores que $5 \%$ foram verificadas nas alturas dos picos correspondentes às soluções padrão empregadas. A Figura 20 mostra parte de um registro típico relativo à determinação de sulfato em águas naturais, o qual fornece, tam bém, uma idéia da estabilidade do sistema. Tanto o sistema de águas como o de plantas é caracterizado por uma velocidade analitica de 120 amostras por hora.

Os desvios padrão relativos de medidas sucessivas de amostras com teores entre 10 e $100 \mathrm{mg} \mathrm{s04^{- }} \cdot \mathrm{I}^{-1}(\mathrm{n}=20$ para cada amostral foram menores que $1 \%$ o que reflete a boa precisão das medidas. Os resultados mostrados na Figura 20 , fornecem também, uma boa indicação da precisão.

Finalmente, os dados contidos na Tabela 3 ,mostram que existe boa concordáncia entre o método proposto e os métodos oficiais recomendados. Testes de recuperação de sulfato, realizadas nas mesmas amostras, apresentaram valores entre 97 e $102 \%$, confirmando a boa exatidão do método proposto. 


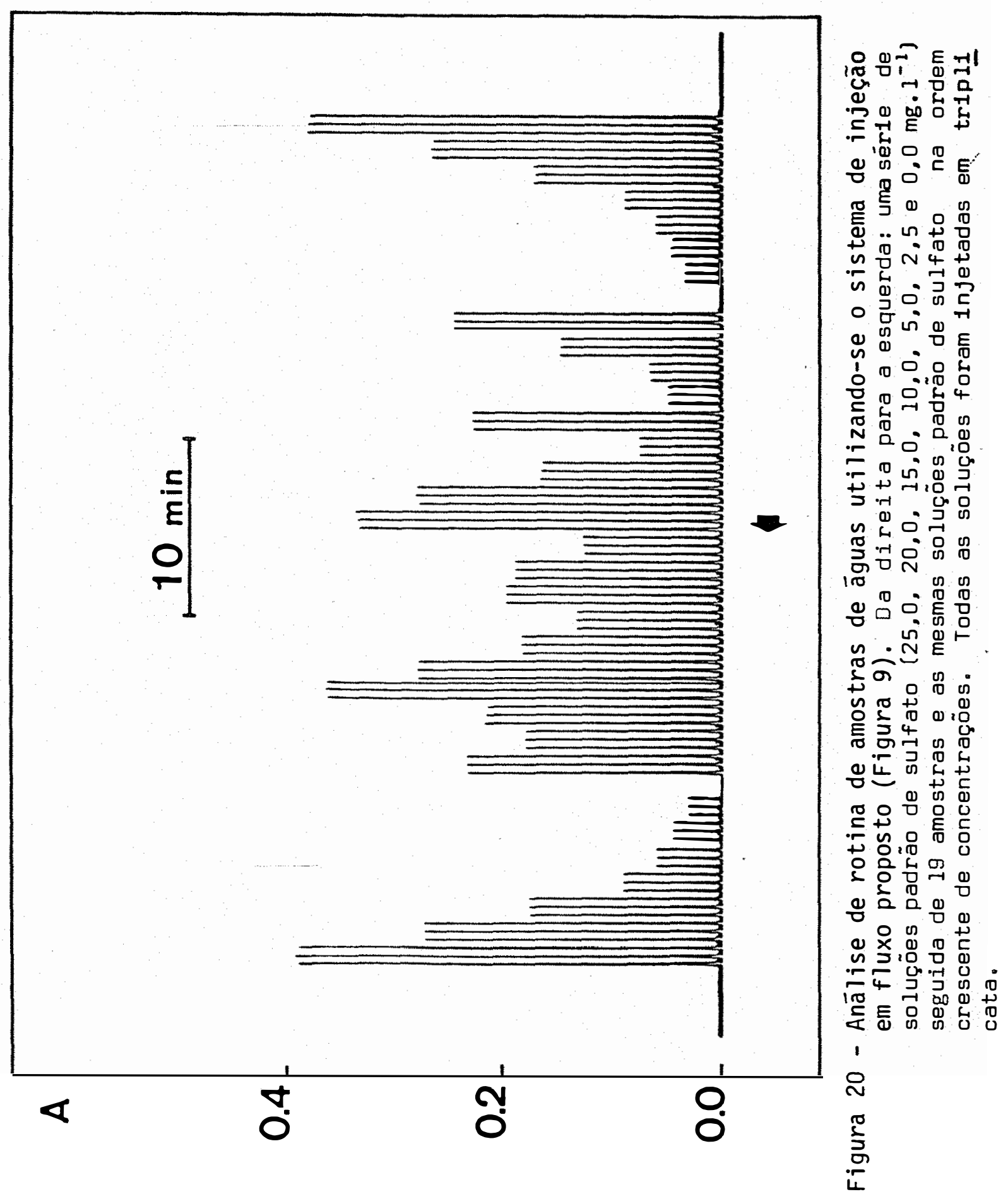


Tabela 3 - Comparação de procedimentos para a determinação de sulfato em digeridos de vegetais e águas naturais.

\begin{tabular}{|c|c|c|c|}
\hline \multirow{2}{*}{$\begin{array}{c}\text { Amostra } \\
\text { (tecido foliar) }\end{array}$} & \multicolumn{2}{|c|}{ lmatéria } & \multirow{2}{*}{$\frac{\text { seca })}{(\text { gravimé- }}$} \\
\hline & $\begin{array}{l}\text { Método } \\
\text { proposto }\end{array}$ & $\begin{array}{l}\text { Método } \\
\text { trico }\end{array}$ & \\
\hline 01 & 0.30 & & 0.25 \\
\hline 12 & 0.25 & & 0,24 \\
\hline 16 & 0.32 & & 0.29 \\
\hline 22 & 0.30 & & 0,27 \\
\hline 36 & 0.26 & & 0,26 \\
\hline 79 & 0,46 & & 0,46 \\
\hline
\end{tabular}

\begin{tabular}{|c|c|c|c|}
\hline \multirow[b]{2}{*}{$\begin{array}{c}\text { Amostra } \\
(\text { água) }\end{array}$} & \multicolumn{3}{|c|}{$\mathrm{mg} \mathrm{SO} 4^{2-} \cdot 1^{-1}$} \\
\hline & $\begin{array}{l}\text { Método } \\
\text { proposto }\end{array}$ & $\begin{array}{l}\text { Método } \\
\text { métrico } \\
\text { (APHA, }\end{array}$ & $\begin{array}{c}\text { turbidi- } \\
\text { manual } \\
1975)\end{array}$ \\
\hline 109 & 11 & & 10 \\
\hline 114 & 18 & & 18 \\
\hline 122 & 25 & & 23 \\
\hline 125 & 21 & & 23 \\
\hline 134 & 16 & & 15 \\
\hline 192 & 32 & & 29 \\
\hline
\end{tabular}




\section{CONCLUSOES}

Em principio, qualquer procedimento de qui mica analitica pode ser automatizado em sis temas de injeção em fluxo.

ZAGATTO E REIS

A incorporação da turbidimetria à técnica da

análise por injeção em fluxo confirma a potencialidade e a versatilidade dos sistemas FIA.

Nesta tese, foi possível reforçar a hipótese de que estes sistemas são indispensáveis não somente na área de Química Analítica mas também na de Físico-Química. Assim,es tudos de cinética de nucleação forneceram subsídios importan tes que possibilitaram viabilizar o método turbidimétrico pa ra a determinação de sulfato em análises de larga escala,tan to em águas naturais como em digeridos de vegetais.

o método proposto pode, com algumas modifica 
ções, ser estendido a outras matrizes e é caracterizado por apresentar precisão superior àquela dos métodos da literatú ra, exatidão comparável à dos métodos oficiais de análise. velocidade analítica de 120 amostras por hora e consumo de reagentes muito baixo $(2,5$ a $10 \mathrm{mg}$ de cloreto de bário dihí drato por determinação). Face as suas excelentes caracteristicas analiticas e, considerando-se a facilidade de implantação dos sistemas FIA aliada a seu baixo custo operacional, espera-se que os procedimentos propostos sejam,a par tir de sua divulgação, empregados intensivamente. Neste particllar, a utilização destes procedimentos para a determi nação de sulfato em análises de rotina na Seção de Radioquímica e Química Analitica do CENA tem se mostrado altamente vantajosa.

Finalmente, conclui-se que um estudo mais detalhado sobre cinética de nucleação pode esclarecer algumas dúvidas que persistem nos processos de formação e crescimento de precipitados o que, evidentemente, poderá ser conduzi do empregando-se o sistema estudado. 
7. B I BLI I GRAF IA

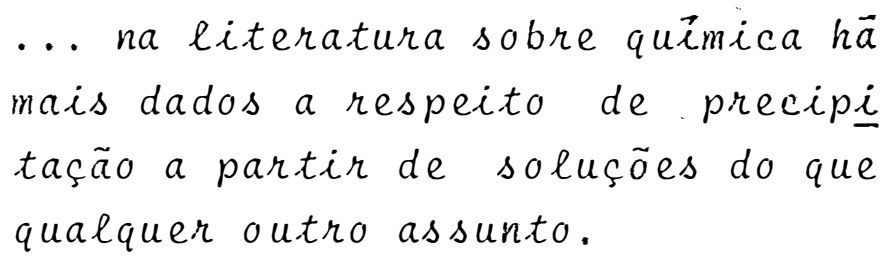

WALTON

AOAC - ASSOCIATION OF OFFICIAL ANALYTICAL CHEMISTS. 1980.

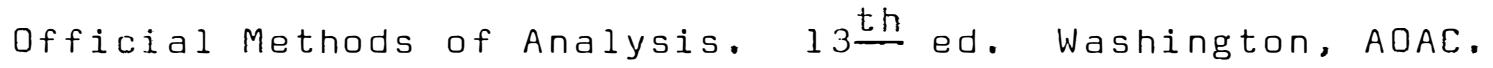
p. $38-39$.

APHA - AMERICAN PUBLIC HEALTH ASSOCIATION; AMERICAN WATER WORKS ASSOCIATION AND WATER POLLUTION CONTROL FEDERATION. 1975. Standard methods for examination of water and wastewater. 14 th ed. New York, American Public Health Association. p. 496 .

ATTIYAT, A.S.; CHRISTIAN, G.D. 1984. Nonaqueous solvents as carrier or sample solvent in flow injection analysis/atomic absorption spectrometry. Anal. Chem., Washington, $56: 439-442$. 
BABAN, S.; BEETLESTONE, D.; BETTERIDGE, D.; SWEET, P. 1980. The determination of sulphate by flow injection aralysis with exploitation of pH gradients and EOTA. Anal. Chim. Acta, Amsterdam, 114:319-323.

BASSON, N.D.; BOOHMER, R.G. 1972. An automated procedure for the determination of sulphur in plant tissue. Analyst, London, 97: 266-270.

BATAGLIA, 0.C. 1976. Determinação indireta de enxofre em plantas por espectrofotometria de absorção atômica. Ciên cia e Cultura, são Paulo, 28(6): 672-675.

BEATON, J.D.; BURNS, G.R.; PLATOU, J. 1968. Determination of sulphur in soils and plant material. London, Sulphur Institute, 56p. (Technical Bulletin) $n^{9} 14$.

BERGAMIN F?, H.; REIS, B.F.; ZAGATTO, E.A.G. 1978a. A new divice for improving sensitivity and stabilization in flow injection analysis. Anal. Chim. Acta, Amsterdan, 97: 427431.

BERGAMIN F :, H.; MEDEIROS, J.X.; REIS, B.F.; ZAGATTO, E.A.G. 1978b. Solvent extraction in flow injection analysis. Determination of molybdenum in plant material. Anal. Chim. Acta, Amsterdan, 101: 9-15.

BERGAMIN F:, H.; ZAGATTO, E.A.G.; KRUG, F.J.; REIS, B.F. 1978c. Merging zones in flow injection analysis. Part 1. Double proportional injector and reagent consumption. Anal. Chim. Acta, Amsterdan, 101: 17-23. 
BERGAMIN F:, H.; REIS, B.F.; JACINTHO, A.0.; ZAGATTO, E.A.G. 1980. Ion exchange in flow injection analysis. Determination of ammonium ions at the $\mu g \cdot \ell^{-1}$ level in natural waters with pulsed reagent. Anal. Chim. Acta, Amsterdan, 117: 81-89.

BESWICK, G.; JOHNSON, R.M. 1970. Sulphur in foodstuffs - I. Determination as sulphate. Talanta, London, 17: 709-716.

BETTERIDGE, D. 1978. Flow injection analysis. Anal. Chem., Washington, $50(9): 832 \mathrm{~A}-846 \mathrm{~A}$.

BETTERIDGE, D.; FIELDS, B. 1978. Construction of pH gradients in flow injection analysis and their potential use for multielement analysis in a single sample bulus. Anal. Chem., washington, 50:654-656.

BUTTERS, B.; CHENERY, E.M. 1959. A rapid method for the determination of total sulphur in soils and plants. Analyst, London, 84: 239-245.

COLLINS, F.C.; LEINEWEBER, J.P. 1956. The kinetics of the homogeneous precipitation of barium sulfate. J. Phys. Chem., Baltmore, 60: 389-394.

DOREMUS, R.H. 1958. Precipitation kinetics of ionic salts from solution. J. Phys. Chem., Baltmore, 62: 1068-1075.

GALES, M.E.; KAYLOR, W.H.; LONGBOTTON, J.E. 1968 . Determination of sulphate by automatic colorimetric analysis. Analyst, London, 93: 9.7-100. 
GINE, M.F.; ZAGATTO, E.A.G.; BERGAMIN F?, H. 1979. Semiautomatic determination of manganese in natural waters and plant digests by flow injection analysis. Analyst, London; 104: 371-375.

GINE, M.F.; BERGAMIN F:, H.; ZAGATTO, E.A.G.; REIS, B.F. 1980. Simultaneous determination of nitrate and nitrite by flow injection analysis. Anal. Chim. Acta, 114: 191197.

GINE, M.F.; REIS, B.F.; ZAGATTO, E.A.G.; KRUG, F.J.; JACINTHO, A.0. 1983. A simple procedure for standard additions in flow injection analysis. Spectrophotometric determination of nitrate in plant extracts. Anal. Chim. Acta, Amsterdan, 155: 131-138.

HANSEN, E.H.; RUZICKA, J. 1976. Flow injection analysis. Part VI. The determination of phosphate and chloride in blood serum by dialysis and sample dilution. Anal. Chim. Acta, Amsterdan, 87: 353-363.

HANSEN, E.H.; RUZICKA, J.; KRUG, F.J.; ZAGATTO, E.A.G. 1983. Selectivity in flow injection analysis. Anal. Chim. Acta, Amsterdan, 148: 111-125.

HOCHGESANG, F.P. 1966. Nephelometry and turbidimetry. In: KOLTHOFF, I.M.; ELVING, P.J.; SANDELL, E.B. Ed. Treatise on Allalytical Chemistry. 2. Ed. New York, Interscience. part I. 5, 3289-3328. 
JACINTHO, A.0.; ZAGATTO, E.A.G.; REIS, B.F.; PESSENDA, L.C.R.; KRUG, F.J. 1981. Merging zones in flow injection analysis. Part VI. Determination of calcium in natural waters, soil and plant materials with glyoxal bis (2hydroxyanil). Anal. Chim. Acta, Amsterdan, 130: 361-368.

JACINTHO, A.0.; ZAGATTO, E.A.G.; BERGAMIN F:, H.; KRUG, F.J.; REIS; B.F.; BRUNS, R.E.; KOWALSKI, B.R. 1981b. FlOW injection systems with inductively - coupled argon plasma atomic emission spectrometry. Part 1. Fundamental considerations. Anal. Chim. Acta, Amsterdan, 150:243255 .

JOHNSON, R.A.; O'ROURKE, J.D. 1954. The kinetics of precipitation formation: barium sulphate. J. Am. Chem. Soc., Easton, 76: 2124-2126.

KARLBERG, B.; THELANDER, S. 1978. Extraction based on the flow-injection principle. Part I. Description of the extraction system. Anal. Chim. Acta, Amsterdan, 98: 1-7.

KEILY, H.J.; ROGERS, L.B. 1955. Nephelometric determination of sulphate impurity in certain reagent grade salts. Anal. Chem., Washington, 27(5): 759-764.

KOLTHOFF, I.M.; SANDELL, E.B. 1962. Textbook of quantitative inorganic analysis. 3. ed. New York, MacMillan. Cap. 20. $759 \mathrm{p}$.

KONDO, 0.; MIYATA, H.; TOEI, K. 1982. Determination of sulphate in river water by flow injection analysis. Anal. Chim. Acta, Amsterdan, 134: 353-358. 
KRUG, F.J.; BERGAMIN F:; H.; ZAGATTO, E.A.G.; JøRGENSEN, S.S. 1977. Rapid determination of sulphate in natural waters and plant digests by continuous flow injection turbidimetry. Analyst, London, 102: 503-508.

KRUG, F.J. 1980. Determinação de baixas concentraçōes de sulfato em águas naturais por turbidimetria em sistema de injeção em fluxo. Piracicaba, CENA/USP. Relatório apresentado ao CNPq. Julho. $35 p$.

KRUG, F.J.; MORTATTI, J.; PESSENDA, L.C.R.; ZAGATTO, E.A.G.; BERGAMIN Fo, H. 1981. Flow injection spectrophotometric determination of boron in plant material with azomethine-H. Anal. Chim. Acta, Amsterdan, 125: 29-35.

KRUG, F.J.; REIS, B.F.; GINE, M.F.; FERREIRA, J.R.; JACINTHO, A.0.; ZAGATTO, E.A.G. 1983. Zone trapping in flow injection analysis. Spectrophotometric determination of low levels of ammonium ion in natural waters. Anal. Chim. Acta, Amsterdan, 151: $39-48$.

LA MER, V.K.; DINEGAR, R.H. 1951. The limiting degrees of supersaturation of the sparingly soluble sulphates. J. Am. Chem. Soc., Easton, 73: 381-385.

LAZRUS, A.L.; HILL, K.C.; LODGE, J.P. 1966. A new colorimetric microdetermination of sulfate ion. Automation in Analytical Chemistry, Technicon Symposia, 1965, White Plain, p. 291-293. 
LEA, R.; WELLS, C.G. 1980. Determination of extractable sulfate and total sulfur from plant and soil material by an autoanalyser. Comm. Soil Sci. Plant Anal., New York, $11(5): 507-516$.

MADSEN, B.C.; MURPHY, R.J. 1981. Flow injection and photometric determination of sulfate in rainwater with methylthymol blue. Anal. Chem., Washington, 53(12): 19241926 .

MARCZENKO, Z. 1976. Spectrophotometric determination of elements. Chichester, Ellis Horwood. Cap. 50. p. 505.

MCSWAIN, M.R.; WATROUS, R.J. 1974. Improved methylthymol blue procedure for automated sulfate determinations. Anal. Chem., washington, 43(9): 1329-1331.

MINDEGAARD, J. 1979. Flow multi-injection analysis. A system for the analysis of highly concentrated samples without prior dilution. Anal. Chim. Acta, Amsterdan, $104: 185-189$.

MORTATTI, J.; KRUG, F.J.; PESSENDA, L.C.R.; ZAGATTO, E.A.G.; J GRGENSEN, S.S. 1982. Determination of iron in natural waters and plant material with 1,10 -phenanthroline by flow injection analysis (FIA). Analyst, London, 107: 659-663.

NIELSEN, A.E. 1957. Nucleation in barium sulfate precipitation. Acta Chem. Scan., Copenhagen, 11: 15121515 . 
NIELSEN, A.E. 1961. Homogeneous nucleation in barium sulfate precipitation. Acta Chem. Scan., Copenhagen, 15(2): 441-442.

OLSEN, S.; PESSENDA, L.C.R.; RUZICKA, J.; HANSEN, E.H. 1983 . Combination of flow injection analysis with flame atomic absorption allows determination of heavy metals in sea water down to ppb level. Analyst, London, 108: 905-917.

O'ROURKE, J.D.; JOHNSON, R.A. 1955. Kinetics and' mechanism in formation of slightly soluble ionic precipitates. Anal. Chem., Washington, 27(11): 1699-1704.

PAINTON, C.C.; MOTTOLA, H.A. 1983. Dispersion in continuous-flow sample processing. Anal. Chim. Acta, Amsterdan, 154: 1-16.

RANGER, C. 1981. Flow injection analysis. Anal. Chem., Washington, 53(1): 20A-32A.

REIJN, J.M.; VAN DER LINDEN, W.E.; POPPE, H. 1980. Some theoretical aspects of flow injection analysis. Anal. Chim. Acta, Amsterdan, 114: 105-118.

REIJN, J.M.; VAN DER LINDEN, W.E.; POPPE, H. 1981a. Dispersion in open tubes and tubes packed with large glass beads. Anal. Chim. Acta, Amsterdan, 123: 229-237.

REIJN, J.M.; VAN DER LINDEN, W.E.; POPPE, H. 1981b. Transport phenomena in flow injection analysis without chemical reaction. Anal. Chim. Acta, Amsterdan, 126: $1-3$. 
REIJNDERS, H.F.R.; VAN STADEN, J.J.; GRIEPINK, B. 1979. Photometry in a continuous flow system. Determination of sulphate in a continuous flow system in environmental samples with dimethylsulphonazo (III). Frezenins 2 . Anal. Chem., Washington, 295: 122-124.

REIS, B.F.; BERGAMIN F:, H.; ZAGATTO, E.A.G.; KRUG, F.J. 1979. Merging: zones in flow injection analysis. Part III. Spectrophotometric determination of aluminium in plant and soil materials with sequential addition of pulsed reagents. Anal. Chim. Acta, Amsterdan, 107: 309317.

REIS, B.F.; ZAGATTO, E.A.G.; JACINTHO, A.0.; KRUG, F.J.; BERGAMIN F:, H. 1980. Merging zones in flow injection analysis. Part IV. Simultaneous spectrophotometric determination of total nitrogen and phosphorus in plant material. Anal. Chim. Acta, Amsterdan, 119: 305-311.

REIS, B.J.; JACINTHO, A.0.; MORTATTI, J.; KRUG, F.J.; ZAGATTO, E.A.G.; BERGAMIN F?, H.; PESSENDA, L.C.R. 1981. Zone sampling processes in flow injection analysis. Anal. Chim. Acta, Amsterdan, 123: 221-228.

ROCKS, B.; RILEY, C. 1982. Flow injection analysis: a new approach to quantitative measurements in clinical chemistry. Clin. Chem., New York, 28(3): 409:421.

RUZICKA, J.; HANSEN, E.H, 1975. Flow injection analysis. Part I. A new concept of fast continuous flow analysis. Anal. Chim. Acta, Amsterdan, 78: 145-157. 
RUZICKA, J.; HANSEN, E.H. 1978. Flow injection analysis. Part $x$. Theory, techniques and trends. Anal. Chim. Acta, Amsterdan, 99: 37-76.

RUZICKA, J.; HANSEN, E.H. 1979. Stopped flow and merging zones - a new approach to enzymatic assay by flow injection analysis. Anal. Chim. Acta, 106: 207-224.

RUZICKA, J.; HANSEN, E.H. 1980. Flow injection analysis. Principles, applications and trends. Anal. Chim. Acta, Amsterdan, 114: 19-44.

RUZICKA, J.; HANSEN, E.H. 1981. Flow injection analysis. New York, John Wiley, $207 p p$.

RUZICKA, J.; HANSEN, E.H.; RAMSING, A.U. 1982. FlOW injection analyser for students, teaching and research. Spectrophotometric methods. Anal. Chim. Acta, Amsterdan, $134: 55-71$.

RUZICKA, J.; HANSEN, E.H. 1983. FIA is aiready a routine tool in Brazil. Trends Anal. Chem, Cambridge (UK), 2(7): V-VII.

SALUTSKY, M.L. 1959. Precipitates: their formation, properties, and purity. In: KOLTHOFF, I.M.; ELVING, P.J.; SANDELL, E.B. Ed. Treatise on analytical chemistry. New York, Interscience. Part I. V. 1, p. 733-765.

SANDELL, E.B.; ELVING, P.J. 1959. Methods of analytical chemistry. In: KOLTHOFF, I.M.; ELVING, P.J.; SANDELL, E. B. Ed. Treatise on analytical chemistry. New York, Interscience, Part I, V. 1, 1-17. 
SANSUN, L.L.; ROBINSON, J.B.D. 1974. Wet digestion, manual and automated analysis of total sulphur in plant material. Comm. Soil Sci. Plant Anal., New York, 5(5): $365-383$.

STEWART, K.K.; BEECHER, G.R.; HARE, P.E. 1976. Rapid analysis of discrete samples: the use of nonsegmented, continuous flow. Anal. Biochem., New York, 70(1): $167-173$

STEWART, K.K. 1981. Flow injection analysis: a review of its early history. Talanta, London, 28: 789-797.

SKEGGS, L.T. 1957. Automatic method for colorimetric analysis. Am. J. Clin. Pathol., 38: 311+322. In: Chem. Abst., 1958,1694 i.

TECHNICON. 1972. Sulfate in water and wastewater. Technicon Autoanalyser II, Tarrytown. Industrial Method No. $118-71 w$.

TEIXEIRA, J.P.F.; BATAGLIA, 0.P.; ARRUDA, P. 1976. Determina Ção automatizada de enxofre em plantas, pelo sistema autoanalisador I Technicon. Bragantia, Campinas, 77, nota $n^{8}$ 16 .

TOENNIES, G.; BAKAY, B. 1953. Photonephelometric microdetermination of sulfate and organic sulfur. anal. chem., washington, 25(I): 160-165. 
VAN DEN BERG, J.H.M.; DEELDER, R.S.; EGBERINK, H.G.M. 1980. Dispersion phenomena in reactors for flow analysis. Anal. Chim. Acta, Amsterdan, 114: 91-104.

VANDERSLICE, T.J.; STEWART, K.K.; ROSENFELD, A.G.; HIGGS, D.J. 1981. Laminar dispersion in flow injection analysis. Talanta, London, 28: 11-18.

WALTON, A.G. 1967. The formation and properties of precipitates. New York, Interscience. $232 \mathrm{p}$.

ZAGATTO, E.A.G.; KRUG, F.J.; BERGAMIN F :, H.; JøRGENSEN, S.S.; REIS, B.F. 1979a. Merging zones in flow injection analysis. Part II. Determination of calcium, magnesium and potassium in plant material by continuous flow injection atomic absorption and flame emission spectrometry. Anal. Chim. Acta, Amsterdari, 104: 279-284.

ZAGATTO, E.A.G.; REIS, B.F.; BERGAMIN F?, H.; KRUG, F.J. 1979b. Isothermal distillation in flow injection analysis. Determination of total nitrogen in plant material. Anal. Chim. Acta, Amsterdan, 109: 45-54.

ZAGATTO, E.A.G.; JACINTHO, O.A.; MORTATTI, J.; BERGAMIN Fo, H. 1980. An improved flow injection determination of nitrate in waters by using intermittent flows. Anal. Chim. Acta, Amsterdan, 320: 399-403.

ZAGATTO, E.A.G.; JACINTHO, O.A.; PESSENDA, L.C.R.; KRUG, F. J.; REIS, B.F.; BERGAMIN Fi, H. 1981. Merging zones in flow injection analysis. Part $V$. Simultaneous determination of aluminium and iron in plant digests by a zone sampling approach. Anal. Chim. Acta, Amsterdan, $125: 37-43$. 
ZAGATTO, E.A.G.; JACINTHO, O.A.; KRUG, F.J.; REIS, B.F.;

BRUNS, R.E.; ARAUJO, M.C.U. 1983. Flow injection

systems with inductively coupled argon plasma atomic emission spectrometry. Part II. The generalized standard addition method. Anal. Chim. Acta, Amsterdan, $145: 169-178$.

ZAHN, V. 1937. Determination of small proportions of sulfur. Ind. Eng. Chem., Washington, 9(1) : 543-547.

ZHAOLUN, F. 1981. Flow injection analysis. Fenxi Huaxue (Anal. Chem.). Pequin, 3: 369-372. 